\title{
Avaliação da composição corporal de idosos: densitometria e impedância bioelétrica.
}

Maria de Lourdes do Nascimento

Tese de doutorado apresentada ao Programa de Pós Graduação em Saúde Pública para a obtenção do título de Doutor em Saúde Pública

Área de concentração: Nutrição

Orientadora: Profa. Dra. Maria de Fátima Nunes Marucci

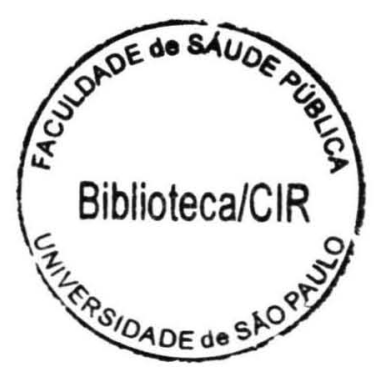

São Paulo

2005 
Autorizo, exclusivamente para fins acadêmicos e científicos, a reprodução total ou parcial desta tese, por processos fotocopiadores. Para fins curriculares da autora, é solicitado que seja comunicado por e-mail: lurdinhanascimento@ig.com.br ou telefone (11) 5034-0041 onde a tese será citada.

Assinatura:

Data: São Paulo,

$$
46234 \mid 2005 \text { dor }
$$


DEDICATÓRIA

Este trabalho é dedicado aos Mestres...

\section{MARLA DE FÁTIMA NUNES MARUCCI}

\section{NEY GERALDO RIBEIRO PERRACINI}

Para mim, eles são...

A SABEDORIA,

A FORÇA E

A BELEZA 


\title{
AGRADECIMENTO ESPECIAL
}

\author{
Aos Amigos e Professores ... pessoas incriveis
}

PROF. DR. JOSÉ MARIA PACHECO DE SOUZA

PROF. MS PAULO DE TARSO PUCCINI

PROF. DR. JOSÉ ALFREDO GOMES ARÊAS

SAMUEL PONCE DE FREITAS

PROF. MS JOSÉ RICARDO ANYAR

PRISCILA MARIA FUNCIA FERNANDES

MARIANA DUARTE UNGER

LUCILE BITNER

SILVANA INÁCIO DOS SANTOS

SAMI LIBERMAN

VANESSA VIEIRA PEREIRA

NELSON CARVAS JÚNIOR

Que ajudaram a construir esta obra tão valiosa para mim ... 


\section{AGRADECIMENTOS}

A Deus, por tudo.

À minha querida orientadora, Professora Dra. Maria de Fátima Nunes Marucci, pela grande amizade, orientação e confiança.

Ao meu querido Dr. Ney Ribeiro Perracini, pela amizade, ensinamentos e apoio.

Aos meus pais, Gibson do Nascimento e Maria Sebastiana Andrade do Nascimento, pelo estimulo constante.

Aos meus queridos Professores, Ana Maria Dianezi Gambardella, Elizabeth A.F. da Silva Torres, Sonia Buongermino de Souza e Sonia Tuncunduva Philippi, E Ana Maria Cervatto pela amizade e ensinamentos.

Ao Prof. Dr. Carlos Augusto Monteiro, responsável pelo Laboratório de Avaliação Nutricional de Populações - LAMPOP, pelo empréstimo do aparelho de impedância bioelétrica.

À Cecilia Nakagawa, Carmen Lucia de Carmargo e todos os preceptores e membros da equipe interdisciplinar do Serviço de Geriatria e Gerontologia do HSPE, pela amizade e incentivo.

A todas as nutricionistas do Serviço de Nutrição do HSPE, que lutam todos os dias para manter a excelência da profissão e da assistência aos pacientes.

Aos funcionários do Serviço de Radiologia, em particular Maria da Conceição A.F.M. Silva, Maria da Guia Feitosa Maia e Valéria Jorge de Oliveira, pelo auxilio no levantamento dos dados.

A toda a minha familia, em particular às minhas tias Maria Aparecida da Silva e Zenith do Nascimento pela colaboração constante.

Aos primos, Antônio Marcos da Silva e Dulcinéa Aparecida Carvalho da Silva, pela confiança e constante apoio.

Aos funcionários do Departamento de Nutrição: Alessandra Blaya Frutuoso, Elisabete Araujo Cheffir Pires, Eslizabeth Deobaldo dos Santos e Roseli Novaes Santiago Prates, pela colaboração e apoio.

Aos funcionários da Biblioteca da Faculdade de Saúde Pública - USP pela amizade e pela disposição em colaborar na localização das referências bibliográficas.

A todos os idosos. 


\section{RESUMO}

Nascimento ML. Avaliação da composição corporal de idosos: densitometria e impedância bioelétrica. São Paulo; 2005 [Tese de doutorado- Faculdade de Saúde Pública da USP].

OBJETIVO: Avaliar a concordância da impedância bioelétrica em idosos, comparando com a densitometria. MÉTODOS: A amostra foi constituida por 40 indivíduos idosos ( $\geq 60$ anos),de ambos os sexos, atendidos em ambulatório de geriatria. Os indivíduos foram submetidos ao exame de impedância bioelétrica (BIA) e de densitometria (DEXA), para a estimativa da quantidade de massa magra (MM$\mathrm{kg}$ ) e de gordura (GO- $\mathrm{kg}$ ). A caracterização da amostra foi analisada de forma descritiva. As variáveis, BIA e DEXA, foram analisadas em relação às medidas de tendência central e dispersão. A correlação foi verificada pelo coeficiente de Pearson e pelo gráfico de dispersão. A concordância foi analisada pelo coeficiente de concordância/correlação de Lin - CCC e pelo procedimento de Bland-Altman. Com base nesses resultados desenvolveu-se também um modelo de regressão linear. RESULTADOS: As médias de MM (kg) estimadas pela BIA $(\mathrm{m}=47,57 \pm 8,11)$ foram maiores do que pela DEXA $(\mathrm{m}=43,94 \pm 8,53)$. As médias de $\mathrm{GO}(\mathrm{kg})$ estimadas pela DEXA ( $m=22,95 \pm 8,70)$ foram maiores do que pela BIA $(m=20,10$ $\pm 8,53)$. Em relação ao sexo, as médias de MM estimadas pela BIA $(m=55,47$ $\pm 6,85)$ e pela DEXA ( $m=52,62 \pm 5,94)$ foram maiores para o sexo masculino do que para o feminino [BIA $(m=43,32 \pm 4,95)$ e DEXA $(m=39,27 \pm 5,51)]$. Ao contrário, as médias de GO no sexo feminino, estimadas pela BIA $(m=21,31 \pm 8,75)$ e pela 
DEXA $(m=24,48 \pm 8,57)$ foram maiores do que para o sexo masculino [BIA $(\mathrm{m}=$ $17,86 \pm 8,00)$ e DEXA $(m=20,12 \pm 8,52)]$. Estas diferenças foram estatisticamente significativas. A análise das variáveis em relação à idade, não foi estatisticamente significativa. Observou-se alta correlação entre os valores de MM mensurados pela BIA e DEXA ( $r=0,91 p=0,001)$ e entre os valores de GO mensurados pela BIA e DEXA $(r=0,92 ; p=0,001)$. Em relação à MM, observou-se concordância entre BIA e DEXA $(C C C=0,83 ; p=0,001)$ e em relação à $G O(C C C=0,88 ; p=0,001)$ entre as duas medidas analisadas. A demonstração gráfica da análise de concordância mostrou que a BIA superestima os valores de $\mathrm{MM}$ em relação à $\mathrm{DEXA}(\mathrm{m}=3,63$; L.C. $=-3,30 ; 10,56)$ e subestima os valores de GO em relação à DEXA (m= - 2,85; L.C. $=-9,46 ; 3,76)$. CONCLUSÃO: O presente estudo permitiu verificar que há concordância entre as estimativas de MM e de GO pela BIA em relação à DEXA.

Descritores: Composição corporal. Densitometria. Impedância bioelétrica. Idosos. 


\begin{abstract}
Nascimento ML. Evaluation of the body composition of the elderly: dual energy X-ray absorptiometry and bioeletrical impedance analysis. Sao Paulo; 2005 [Tese de Doutorado - Faculdade de Saúde Pública - Universidade de São Paulo].
\end{abstract}

Objective: To evaluate the Agreement between results of bioelectrical impedance and densitometry as means of analysis of body composition among the elderly. Methods: The sample consisted of 40 elderly individuals ( $\geq 60$ years of age), of both sexes, attended in an outpatient geriatric clinic. Individuals were submitted to bioelectrical impedance analysis (BIA) and dual energy $x$-ray absorptiometry (DEXA), in order to estimate the quantity of lean mass (MM-kg) and of body fat (GO - kg). The characterization of the sample was analyzed descriptively. BIA and DEXA variables were analyzed in relation to the central tendency and to dispersion. Correlation was verified by means of the Pearson coefficient and the dispersion graph. Agreement was analyzed by means of the coefficient of agreement/ Lin-CCC correlation and by the Bland-Altman procedure. On the basis of these results, a model of linear regression was also developed. Results: The mean MM (kg) estimates by BIA, $(m=47.57 \pm 8.11)$, were greater than by DEXA, $(m=43.94 \pm$ 8.53). The mean $\mathrm{GO}(\mathrm{kg})$ as estimated by DEXA, $(\mathrm{m}=22.95 \pm 8.70)$ were greater than those estimated by BIA $(m=20.10 \pm 8.53)$. In relation to sex, the mean MM as estimated by BIA was $(m=55.47 \pm 6.85)$ and by DEXA $m=52.62( \pm 5.94)$ were larger for males than for females [BIA $(m=43.32 \pm 4.95)$ and DEXA $(m=39.27 \pm$ 5.51). The mean body fat for females, on the contrary, as estimated by both BIA $(\mathrm{m}=$ 
$21.31 \pm 8.75)$ and by DEXA $(m=24.48 \pm 8.57)$ were greater than for males by both [BIA $(m=17.86 \pm 8.00)$ and DEXA $(m=20.12 \pm 8.52)]$. These differences were statistically significant. Analyses of variables in relation to age were not statistically significant. A high correlation between the variables of MM, as measured by BIA and DEXA, was observed $(r=0.91 ; p=0.001)$ and between the values of $G 0$, as measured by BIA and DEXA as well $(r=0.92 ; p=0.001)$. Agreement between BIA and DEXA was observed both with respect to $\mathrm{MM}(\mathrm{CCC}=0.83 ; \mathrm{p}=0.001)$ and to GO $(\mathrm{CCC}=0.88 ; \mathrm{p}=0.001)$. The graphic demonstration of agreement indicated that BIA super estimated the values of $\mathrm{MM}$ in relation to DEXA $\quad(m=3.63$; L.C. $=-$ $3.30 ; 10.56)$ and underestimated the values of $\mathrm{GO}$ in relation to DEXA $(\mathrm{m}=-2.85$; L.C. $=-9.46 ; 3.76)$. CONCLUSION: This study made it possible to verify the agreement between estimates of MM and GO by means of BIA and DEXA.

Key words: Body Composition. Dual Energy X-ray Absorptiometry. Bioeletrical Impedance. Elderly. 
SUMÁRIO

1. INTRODUÇÃO …................................................................. 1

1.1 A saúde e o envelhecimento populacional ..................................... 1

1.2 envelhecimento e as alterações na composição corporal ..................... 4

1.3 Métodos de avaliação da composição corporal: A densitometria (DEXA) e a impedância bioelétrica (BIA) ….................................. 9

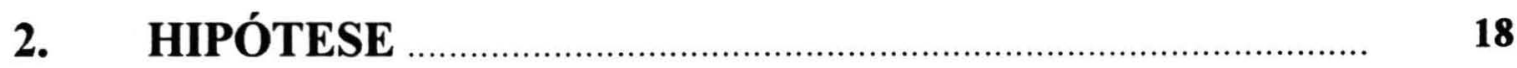

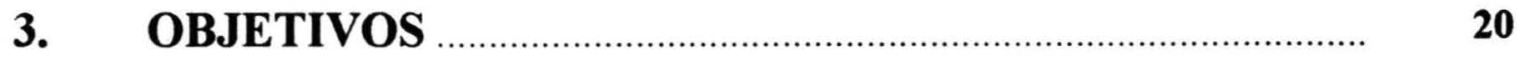

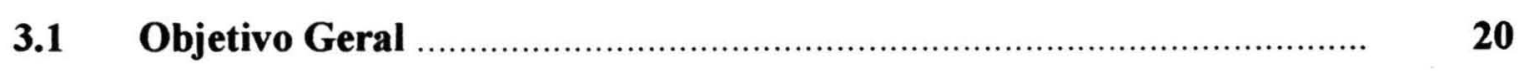

3.2 Objetivo Específico …................................................................ 20

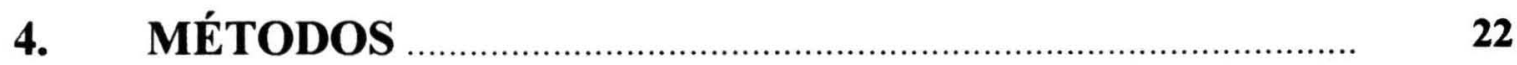

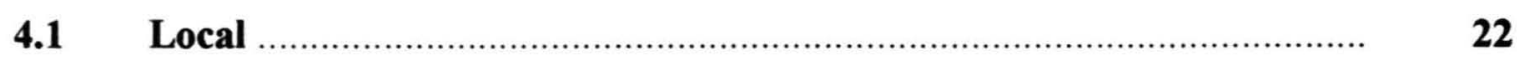

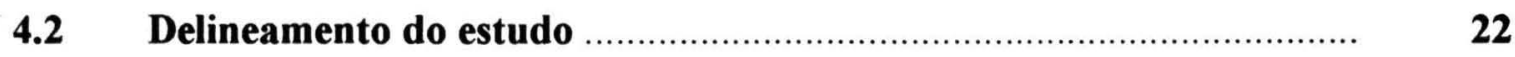

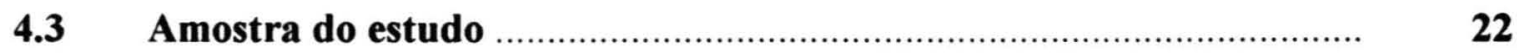

4.3.1 Critérios de exclusão …...................................................................... 23

4.4 Desenvolvimento do trabalho ...................................................... 24

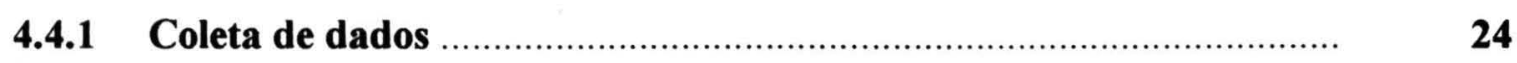

4.4.2 Caracterização da amostra estudada …............................................ 25

4.4.3 Descrição das Variáveis de estudo ...................................................... 26

4.4.3.1 Impedância bioelétrica …...............................................................

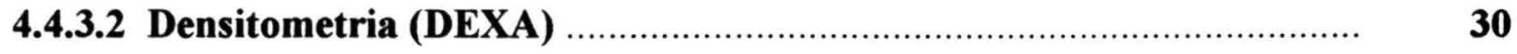

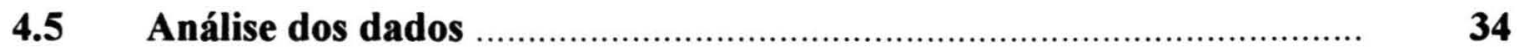

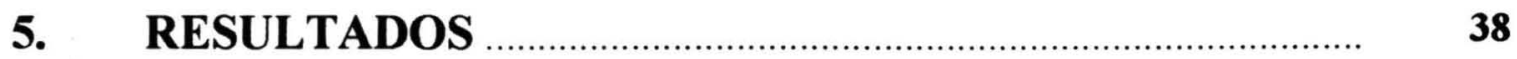

5.1 Caracterização da amostra estudada …......................................... 38

5.1.1 Quanto às características sócio demográficas .................................. 39

5.1.2 Quanto ao estilo de vida ................................................................ 40

5.1.3 Quanto aos diagnósticos clínicos …................................................... 41

5.1.4 Quanto à utilização de medicamentos ............................................... 42

5.2 Descrição das variáveis ................................................................... 43 
5.2.1 Análise descritiva das variáveis ....................................................... 43

5.2.2 Análise descritiva das variáveis em relação ao sexo .......................... 44

5.2.3 Análise descritiva das variáveis em relação à idade …....................... 45

$5.3 \quad$ Teste de distribuição normal ............................................................ 47

5.4 Descrição conjunta das variáveis estudadas ....................................... 49

5.5 Análise de concordância entre os métodos de BIA e DEXA ............... 51

5.5.1 Coeficiente de Concordância/Correlação - CCC ….......................... 51

5.5.2 Gráficos de Bland-Altman ................................................................. 55

$5.6 \quad$ Teste de diferença entre as médias ....................................................... 58

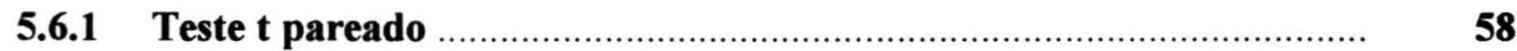

5.6.2 Teste t pareado em relação ao sexo …................................................ 58

5.6.3 Teste t pareado em relação à idade ................................................... 58

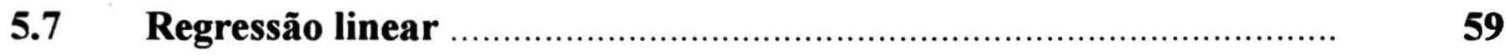

6. DISCUSSÃO

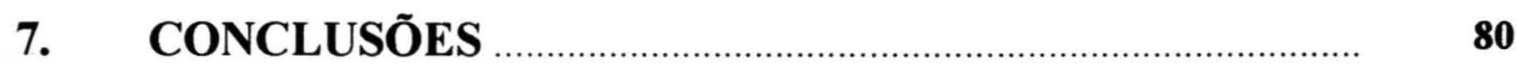

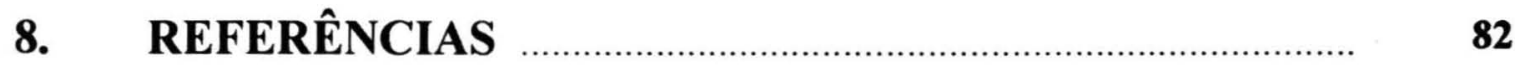

9. ANEXOS

ANEXO 1 Aprovação do Comitê de Ética da FSP-USP ……............... 96

ANEXO 2 Aprovação do Comitê de Ética do HSPE-FMO ................. 97

ANEXO 3 Termo de Consentimento Livre e Esclarecido..................... 98

ANEXO 4 Formulário da Pesquisa ...................................................... 99

ANEXO 5 Laudo da BIA .................................................................. 101

ANEXO 6 Questionário da DEXA ................................................... 102

ANEXO 7 Laudo da DEXA ....................................................... 103

ANEXO 8 Laudo da DEXA computadorizado .............................. 104 
Tabela 1. Distribuição dos idosos estudados nas duas amostras, segundo características sócio-demográficas, SP -2004.

Tabela 2. Distribuição dos idosos estudados nas duas amostras, segundo variáveis de estilo de vida, SP -2004.

Tabela 3. Distribuição dos idosos estudados nas duas amostras, segundo diagnósticos clínicos, SP -2004.

Tabela 4. Distribuição dos idosos estudados nas duas amostras, segundo a utilização de medicamentos, SP - 2004. 


\section{LISTA DE QUADROS}

Quadro 1. Percentagens recomendadas para cada compartimento corporal

Quadro 2. Características avaliadas nas duas amostras (analisada e complementar), e respectivos $\chi^{2}$ e valores de $p$.

Quadro 3. Número de indivíduos (N), médias, medianas, valores mínimos (V.Min) e máximos (V.Max), desvios-padrão (D.P.) e intervalo de confiança (I.C.) de MM (kg) e GO (kg), estimados pela DEXA idosos estudados, SP - 2004.

Quadro 4. Número de indivíduos (N), médias (m), desvios- padrão (D.P) e intervalo de confiança (I.C.) de MM (kg) e GO (kg) estimados pela BIA e pela DEXA, segundo o sexo, SP - 2004.

Quadro 5. Número de indivíduos, médias (m), desvios- padrão (D.P) e intervalo de confiança (I.C.) de MM (kg) e GO (kg) estimados pela BIA e pela DEXA, segundo o grupo etário, SP - 2004.

Quadro 6. Coeficiente de Concordância/Correlação da MM (kg) entre a BIA e a DEXA.

Quadro 7. Coeficiente de Concordância/Correlação da GO (kg) entre a BIA e a DEXA.

Quadro 8. MM (kg) e GO (kg) estimadas pela BIA e DEXA em relação ao sexo $\mathbf{e}$ à idade.

Quadro 9. Análise univariada de regressão linear da BIA (quilos de MM) com DEXA (quilos de MM).

Quadro 10. Análise univariada de regressão linear da BIA (quilos de GO) com DEXA (quilos de GO). 


\section{LISTA DE FIGURAS}

Figura 1. Esquema representativo da colocação dos eletrodos distais e proximais, para realização da impedância.

Figura 2. Aparelho de densitometria

Figura 3. Esquema de posicionamento do paciente para realização da DEXA 33

Figura 4. Histograma da MM (kg), estimada pela BIA

Figura 5. Histograma da MM (kg) estimada pela DEXA

Figura 6. Histograma da GO (kg) estimada pela BIA

Figura 7. Histograma da GO (kg) estimada pela DEXA.

Figura 8. Gráfico de dispersão de MM estimada pela BIA e pela DEXA. ....... 50

Figura 9. Gráfico de dispersão entre GO estimada pela BIA e pela DEXA. ...

Figura 10. Coeficiente de Concordância/Correlação MM em quilos estimada pela BIA e pela DEXA

Figura 11. Coeficiente de Concordância/Correlação da GO em quilos estimada pela BIA e pela DEXA.

Figura 12. Concordância entre as estimativas de MM pela BIA e pela DEXA. $O$ eixo horizontal (x) mostra a média de MM, obtida pelos dois métodos, o eixo vertical (y) as diferenças entre os dois métodos. ..

Figura 13. Concordância entre as estimativas de GO pela BIA e pela DEXA.

O eixo horizontal (x) mostra a média de GO obtidas pelos dois métodos, o eixo vertical (y) as diferenças entre os dois métodos. .

Figura 14. Gráfico de Regressão DEXA em BIA (MM)

Figura 15. Predição de valor individual para quilos de MM. O eixo horizontal (x) mostra quilos de MM, estimada pela BIA e o eixo vertical (y) mostra quilos de MM, estimada pela DEXA

Figura 16. Gráfico de Regressão DEXA em BIA (GO)

Figura 17. Predição de valor individual para quilos de GO. O eixo horizontal (x) mostra quilos de GO, estimada pela BIA e o eixo vertical (y) mostra quilos de GO, estimada pela DEXA. 
Introdução 


\section{INTRODUÇÃO}

\subsection{A saúde e o envelhecimento populacional}

O mundo está passando por um envelhecimento populacional importante. Tal processo repercute em todos os setores da sociedade.

O envelhecimento populacional não se refere nem a indivíduos, nem a cada geração, mas sim, a mudanças na estrutura etária da população, o que produz um aumento do peso relativo das pessoas acima de determinada idade, considerando como definidora do início da velhice. Este limite inferior varia de sociedade para sociedade e depende não somente de fatores biológicos, mas, também, econômicos, ambientais, cientificos e culturais (CARVALHO E GARCIA, 2003). Neste trabalho adotou-se a idade de 60 anos como o divisor entre idosos e não idosos.

O processo de envelhecimento populacional foi um fenômeno inicialmente observado em países desenvolvidos, mas recentemente, é nos países em desenvolvimento que a população idosa tem aumentado de forma mais rápida. Projeções recém publicadas pela Organização Mundial de Saúde estimam que entre 1990 e 2025 , a população idosa aumentará cerca de sete a oito vezes em países como Colômbia, Malásia, Quênia, Tailândia e Gana. As mesmas projeções indicam que entre os dez países com maior população idosa em 2025 , cinco serão países em desenvolvimento, incluindo o Brasil com um número estimado de 27 milhões de pessoas com 60 anos e mais de idade (COSTA et. al. 2000).

Este fenômeno vem sendo acompanhado por um crescente interesse em relação às alterações fisiológicas normais que incidem no declínio da capacidade funcional à medida que o indivíduo envelhece. 
Neste panorama, além da preocupação com a longevidade, há uma preocupação justa e crescente com a qualidade de vida dos indivíduos que estão envelhecendo.

A qualidade de vida pode ser definida como sendo: "a percepção de cada indivíduo acerca de sua posição na vida, de acordo com o contexto cultural e sistema de valores nos quais vivem em relação aos seus objetivos, expectativas, normas e interesses" (WHO, 1999).

Muitos estudos já demostraram as conseqüências de uma população idosa e doente, desenvolvendo as mais diferentes doenças crônicas não transmissíveis que trazem limites na independência e autonomia das pessoas.

Segundo a Organização Mundial de Saúde (1989), define-se saúde como: "completo bem estar físico, psiquico e social" e não meramente ausência de doença ou enfermidade. Define autonomia como sendo a capacidade de decisão, e independência como sendo a capacidade de realizar algo com seus próprios meios (PASCHOAL, 1997 b).

Como o envelhecimento da população brasileira torna-se cada vez mais importante conhecer a prevalência das doenças crônicas (ALMEIDA et. al., 2002). 0 grupo das doenças crônicas não transmissiveis, em sua maioria, doenças cardiovasculares, diabetes, câncer e doenças respiratórias crônicas, apresentam fatores de risco comuns, e demandam por assistência continuada de serviços e ônus progressivos, na razão direta do envelhecimento dos individuos e da população (ACHUTTI e AZAMBUJA, 2004).

.A propósito deste fato, tem sido feita a distinção entre o envelhecimento comum, no qual muitos fatores de risco intensificam os efeitos deste processo, e o 
envelhecimento bem sucedido, no qual eles não estariam presentes. Analisando esta realidade, torna-se fundamental o desenvolvimento de programas de promoção de saúde para esses indivíduos e que possam contribuir para um envelhecimento bem sucedido (PASCHOAL, 1997 a).

A avaliação do estado nutricional é de fundamental importância para os indivíduos, porque influencia significativamente na sua qualidade de vida (WHO, 1995).

A avaliação do estado nutricional é uma atividade na qual determinadas medidas são obtidos, e possibilitam detectar os possíveis distúrbios presentes e proceder a uma intervenção, prevenindo a presença futura de alguma doença ou amenizando sintomas já existentes. Estes dados podem incluir anamnese alimentar, exames bioquímicos, avaliação antropométrica, assim como métodos de avaliação da composição corporal (CHUMLEA, 1989).

Fazem-se necessárias ações que possam ser responsáveis por um incremento nas condições de saúde daqueles que envelhecem, sem que isso dependa exclusiva ou prioritariamente do incentivo às medidas terapêuticas das doenças já manifestas. "Em síntese, a solução dessa equação depende muito mais de modelos de Promoção de Saúde do Idoso, em um contexto genérico tanto do indivíduo como da sociedade, do que da evolução em um ramo isolado do conhecimento científico" (JACOB FILHO, 1998). 


\subsection{O envelhecimento e as alterações na composição corporal}

A senescência, apesar de ser um fenômeno universal e comum a quase todos os seres animais, teve o seu estudo negligenciado durante muito tempo e os mecanismos envolvidos na sua gênese ainda permanecem obscuros, existindo um longo caminho a ser percorrido até que novos estudos sejam mais esclarecidos (PAPALÉO NETTO e PONTE, 1997).

O organismo humano, desde sua concepção até a morte passa por diversas fases: crescimento, puberdade, maturidade ou estabilização e envelhecimento. $\mathbf{O}$ envelhecimento manifesta-se por declínio das funçð̃es dos diversos órgãos que caracteristicamente, tende a ser linear em função do tempo, não se conseguindo definir um ponto exato de transição, como nas demais fases. Tem início precoce, ao final da segunda década de vida até que surjam, no final da terceira década, as primeiras alterações funcionais e/ou estruturais atribuidas ao envelhecimento (PAPALÉO NETTO e PONTE, 1997).

A distinção entre processos decorrentes de manifestações biológicas que surgem com o avançar dos anos e os estados realmente mórbidos mais comuns em gerontes, ou seja, o que é considerado senescência ou senectude e senilidade muitas vezes é tarefa dificil. Os limites entre estes estados são, não raramente, imprecisos e com zonas de transição freqüentes, colocando em dificuldades a exata caracterização dos mesmos (PAPALÉO NETTO e PONTE, 1997).

Estudos realizados por MARUCCI (1992), em idosos ambulatoriais (60 anos e mais, e média de idade de 74 anos) mostrou que o grupo em questão apresentava, em média, 2,3 diagnósticos clínicos por pessoa e que as doenças mais prevalentes eram: 
hipertensão arterial sistêmica (49\%), osteoartite (32\%), doenças endócrinas e metabólicas $(26,9 \%)$, destacando-se entre estas o diabete melito $(15,6)$. Ainda devem ser consideradas as doenças do aparelho digestivo (19,5\%), as cardiovasculares (16\%), além de sinais, sintomas e afecções mal-definidos $(10,4 \%)$.

As mudanças que ocorrem ao longo dos anos têm uma grande influência no estado e necessidades nutricionais. Estas mudanças são atribuídas a vários fatores: diminuição na habilidade de preparar os alimentos, redução do apetite ou falta de motivação para comprar o alimento e se alimentar, associada à depressão e a redução da atividade física, problemas físicos ou psicológicos e outras condições degenerativas. Estes aspectos devem ser precocemente detectados para evitar o aparecimento de problemas nutricionais (KUCZMARSKI et al., 2000).

A presença de grande número de doenças em idosos, exigindo a utilização de quantidade considerável de medicamentos, é um fato que interfere na sua saúde e, consequentemente, na sua qualidade de vida (CURIATI e ALENCAR, 1994).

Existem ainda muitas dúvidas sobre este fato e, principalmente, se o processo intrínseco que ocorre com o avançar da idade, como por exemplo a alteração na composição corporal, é responsável por este fator ou se fatores extrínsecos intensificam os efeitos do processo do envelhecimento normal, como dieta, meio ambiente, causas psicossociais e econômicas (PASCHOAL,1998a).

A composição corporal altera-se com o passar dos anos. A água, principal componente, corresponde a $70 \%$ do organismo na criança, a $60 \%$ no adulto jovem e a $52 \%$ no idoso. A redução verificada no idoso em relação ao adulto jovem refere-se principalmente ao conteúdo intracelular. Enquanto no adulto jovem a relação água intracelular/ extracelular é de 2:1, no idoso é de 1,5:1. Essa redução não parece ser 
devido à diminuição da água de cada célula, mas conseqüência da menor massa celular no idoso. Devido à redução do componente aquoso do organismo, o idoso pode ser considerado um "desidratado crônico" e, frente às perdas moderadas de líquido, já apresenta desidratação evidente. Por outro lado a reposição líquida nesses individuos deve ser lenta e cuidadosa para evitar sobrecarga cardiocirculatória, pois o compartimento extracelular também é reduzido (CARVALHO FILHO, 1997).

Quanto ao componente adiposo, tende aumentar e a apresentar distribuição centrípeta no envelhecimento, depositando-se a gordura principalmente nos subcutâneos do tronco, nos epíploons e ao redor de vísceras como rins e coração. Como o tecido adiposo é anidro e apresenta menor densidade que a água, observa-se que a densidade corporal do idoso, que é de 1,03 , é menor que aquela do adulto, que é de 1,07. Nas mulheres, como o depósito de gordura é maior, a densidade corporal é menor que a do homem da mesma faixa etária (CARVALHO FILHO, 1997).

A massa celular do organismo, que é de aproximadamente $19 \%$ no adulto normal não obeso, cai para $12 \%$ no idoso, nas mesmas condições, ocasionando redução do potássio total, que na maior parte é intracelular; menor consumo de oxigênio, quando este é expresso por unidade de peso corpóreo, e diminuição do peso e volume da maioria dos órgãos. $\mathbf{O}$ conteúdo mineral ósseo também apresentase reduzido no idoso (5 \%) em relação ao adulto jovem (6\%) (CARVALHO FILHO, 1997).

Em estudo sobre alterações fisiológicas na composição corporal ocorrida durante o processo de envelhecimento, os dados indicaram que, durante um periodo de 50 anos (dos 20 aos 70 anos), ocorre diminuição significativa da massa muscular 
seguida de um gradativo no percentual de gordura corporal. Os homens perdem 11 $\mathrm{kg}$ de massa muscular e as mulheres aproximadamente, $4 \mathrm{~kg}$ (PROTHRO, 1989).

O peso corporal representa a soma da massa de tecidos (gordura, proteína e ossos) e de água. Estes componentes podem sofrer alterações de um modo imprevisivel. Medidas freqüentes do peso podem detectar estas mudanças sem especificar qual componente foi alterado. Por outro lado existem situações em que a medida do peso corporal não detecta qualquer alteração nestes componentes, apesar de as mesmas estarem ocorrendo. Um exemplo desta situação é o caso de indivíduos em processo de desnutrição com edema e ascite. $\mathbf{O}$ aumento da retenção de água pode resultar em manutenção do peso corporal, mascarando a perda de proteínas e de gorduras. De modo similar, as medidas de peso em pacientes estressados pelo trauma, queimaduras infecções ou sepse não são úteis para a avaliação do estado nutricional (FRISANCHO, 1993).

Existe uma diminuição da diminuição da estatura, com o passar dos anos, por causa da compressão vertebral, o estreitamento dos discos interverterias e a cifose. Esse processo parece ser mais rápido nas mulheres do que nos homens, devido especialmente, a maior prevalência de osteoporose após a menopausa(MATSUDO et al., 2000).

DEY et al. (1999) em estudo longitudinal sobre as alterações na estatura e no peso de indivíduos com idade entre 60 e 95 anos, verificaram que as mulheres apresentaram redução de $4,9 \mathrm{~cm}$ em sua estatura e os homens $4 \mathrm{~cm}$ durante o periodo de 25 anos. 
Outras alterações fisiológicas do envelhecimento ainda podem interferir na determinação das medidas antropométricas, como a elasticidade da pele e o relaxamento da musculatura abdominal e alterações hormonais (CABREIRA, 1998).

Uma possível causa da alteração da composição corporal durante o processo de envelhecimento também pode estar relacionada com a queda dos níveis circulantes de alguns hormônios. A redução da densidade mineral óssea que acompanha o envelhecimento ocorre tanto nas mulheres como nos homens. Nas mulheres, este processo é antecipado e agravado pela rápida perda hormonal na menopausa (MARCUS, 1996). A redução dos níveis de testosterona com o avançar da idade pode ser co-responsável pela alteração corporal, levando à diminuição da massa muscular e aumento da massa gordurosa (SNYDER et al., 1999). A secreção do hormônio de crescimento diminui com o envelhecimento e existem evidências de que o eixo GH-IGH -I exerce papel importante na manutenção da composição corporal e na massa óssea em adultos (CAPAS et al., 1993).

Em estudo longitudinal de composição corporal, em idosos de 70 a 81 anos, evidenciou-se a perda progressiva do peso corporal, e apenas discretas alterações das medidas antropométricas indiretas de gordura corporal em relação ao peso total (STEEN, 1988).

A avaliação da composição corporal do indivíduo é de suma importância e principalmente no estabelecimento da conduta a ser seguida por toda equipe multiprofissional que trata de um cliente.

Em uma revisão sobre o declínio do estado funcional nos idosos, confirmou a presença de vários fatores que reduzem o estado funcional. Verificou a associação 
entre os fatores biológicos, psicológicos e sociais no desenvolvimento de limitações funcionais nos indivíduos que envelhecem (STUCK, 1999).

O indivíduo deve ser avaliado criteriosamente antes da prescrição do fármaco, pois o mesmo pode ter sua biodisponibilidade alterada pelas modificações nos compartimentos corporais, levando à redução ou potencialização da droga (DIAZ, 1997).

As principais funções que o profissional de Nutrição desempenha nesse contexto são a identificação de indivíduos em risco para desenvolver doenças crônicas não transmissíveis e a intervenção alimentar para a prevenção e controle de enfermidades ( SAMPAIO, 2004).

Portanto, torna-se imperativa a adoção de métodos que permitam diagnosticar, de forma eficaz, as alterações na composição corporal que ocorrem no processo de envelhecimento.

\subsection{Métodos de avaliação da composição corporal: densitometria (DEXA) e impedância bioelétrica (BIA)}

O estudo e o conhecimento do processo de envelhecimento ganhou interesse considerável. Hoje, existe interesse crescente em identificar os fatores que levam a um envelhecimento sadio. Além disso, existe também interesse dos estudiosos em nutrição em associar as práticas alimentares com a redução ou retardo das mudanças fisiológicas e enfermidades que surgem com o envelhecimento, já que alimentação 
adequada é um fator primordial na manutenção das condições orgânicas e funcionais de cada indivíduo.

Por muitos anos, resultados dos métodos, hidrostáticos, da diluição de radioisótopos e dados de dissecação de cadáveres humanos e de animais, foram responsáveis por estudos sobre a avaliação da composição corporal. Vários estudos foram realizados com o uso da ultra-sonografia, infravermelho, tomografia computadorizada, ressonância magnética, técnicas de medicina nuclear e outros métodos sofisticados como a densitometria, para abordagem mais precisa e praticamente direta da mensuração da composição corporal no ser vivo (LARSSON e PRADO S/d; RIELLA, 1993). Esses métodos são de dificil execução dispendiosos, requerendo tempo, equipamentos sofisticados e pessoas bem treinadas para colher os dados. Além disso, são necessários cuidados quanto à exposição radioativa de alguns métodos (RIELLA, 1993).

A composição corporal "in vivo" pode ser deduzida por métodos indiretos, estabelecendo-se que o organismo é basicamente integrado por dois compartimentos bem diferenciados (lipídico e hídrico), constituindo um modelo de dois compartimentos.

Os modelos teóricos são usados para obter medidas referenciais da composição corporal para o desenvolvimento de métodos e equações antropométricas, de dobras cutâneas, análise de impedância e densitometria. Para estudar a composição corporal, o peso corporal é subdividido em 2 ou mais compartimentos. $\mathrm{O}$ modelo clássico de dois componentes divide a massa corporal em compartimento de gordura (GO) e massa livre de gordura (MM). A gordura consiste 
de todos os lipídios que podem ser extraídos, e a massa livre de gordura inclui água, proteinas e componentes minerais (HEYWARD e STOLARAZYK, 2000).

Para uso clínico e epidemiológico, utilizam-se métodos que podem estimar os compartimentos corporais de forma prática e econômica, baseados em medidas antropométricas. A antropometria deu início no século passado, ao desenvolvimento de uma série de métodos para avaliação do estado nutricional, ainda muito utilizados, mas com sua validade e precisão discutíveis (CHUMLEA et al., 1996 e LARSSON e PRADO, s/d)

A escolha da melhor técnica de avaliação da composição corporal é uma questão com a qual os profissionais de Nutrição e Educação Física se deparam quando necessitam realizar uma conduta com segurança (KATCH e McARDLE, 1996).

A importância de se adotar um bom método de avaliação da composição corporal deve-se ao fato de que o peso corporal, isoladamente, não pode ser considerado um bom parâmetro para a identificação do excesso ou redução dos componentes corporais (massa gorda, massa muscular, massa óssea e massa residual) ou alterações nas quantidades proporcionais dos mesmos em decorrência da dieta alimentar e/ou um processo de envelhecimento (COSTA, 1999b).

Atualmente, os nutricionistas e outros profissionais da saúde utilizam os métodos mais acessíveis para a avaliação principalmente antropometria (com maior freqüência) e muito raramente os métodos mais dispendiosos como a densitometria.

Após esta revisão sobre os métodos de avaliação da composição corporal, percebe-se que a escolha da técnica não é tão fácil quanto parece e, qualquer que seja a técnica pela qual o profissional opte, é necessário um bom conhecimento da mesma 
no que diz respeito à padronização das medidas e sua validade para o grupo ou individuo a ser avaliado. Além do fato de que as técnicas mais acessíveis são justamente as que podem produzir mais erro, é importante a verificação das vantagens e limitações da técnica escolhida para que haja menos erros e diagnósticos mais precisos (COSTA, 1996a).

Portanto, se torna importante para a avaliação da composição corporal, o estabelecimento de metodologia que possa representar de forma prática e precisa as condições orgânicas de adultos e idosos.

A densitometria (Dual-Energy X Ray Absorptimetry - DEXA) foi um método originalmente utilizado para mensurar o compartimento mineral contido no corpo humano; atualmente, também é utilizada como um método para estimar a composição corporal total e a sua distribuição no corpo humano. É um método independente de fatores de confusão observados em outras técnicas, sendo aceito como referência -gold standard (ROUBENOFF et al., 1993).

A avaliação da composição corporal, pela DEXA, permite conhecer a quantidade de massa gordurosa, óssea e magra, pois se baseia na capacidade que os tecidos têm de absorver energia. A quantidade de fótons que emerge dos tecidos para o outro lado da aplicação da energia mede a capacidade de captação e indiretamente fornece informações sobre o osso e os tecidos moles (LUKASKI, 1993 b).

A DEXA não é utilizada com freqüência para o estabelecimento da composição corporal pois, o equipamento é caro, necessita de técnicos altamente treinados para a sua operacionalização, apresenta custo operacional elevado e requer um tempo maior para sua realização em relação a antropometria (LEAN et al., 1997). 
SVENDESEN (1993) estudou, em mulheres adultas, os três principais componentes quimicos do corpo (massa gordurosa, massa magra e óssea). Concluiu que a DEXA é um método acurado e preciso para mensurar a massa magra do corpo em estudos transversais ou longitudinais.

Em estudo com doze adultos jovens com o objetivo de avaliar a densidade mineral óssea e mensurar a massa magra e gordurosa, foi observado que a DEXA proporcionou uma precisa análise da composição corporal. Contudo, sugere que são importantes outros estudos para avaliar a influência do estado de hidratação e da redução do peso nos resultados dessa metodologia (MAZES et al., 1990).

A DEXA tem sido uma alternativa para a hidrodensitometria. Alem de ser segura, rápida, requer de 10 a 20 minutos para ser executada, envolvendo uma dose mínima de radiação e exigindo a mínima cooperação do indivíduo (MAZES et al., 2000).

A DEXA é altamente confiável e tem uma grande concordância com a porcentagem de gordura obtida pela hidrodensitometria (HEYWARD e STOLARCZYK, 1996).

A impedância biológica elétrica (bioimpedância elétrica) é um método que tem sido usado mais recentemente para a avaliação da composição corporal. Quando se aplica uma corrente elétrica a um substrato há sempre uma oposição ao fluxo, Resistência (R), inversamente proporcional à condutividade ou condutância. A lei de Ohm aplicada à eletricidade integra as variáveis: $R=E$ / I onde:

$$
\begin{aligned}
& R=\text { Resistência (ohms/cm) } \\
& E=\text { Voltagem ou queda de voltagem aplicada (volts) } \\
& I=\text { Intensidade da corrente elétrica (amperes) }
\end{aligned}
$$


Se o substrato for homogêneo esta oposição será somente de $\mathbf{R}$, mas se nele houver capacitadores (condensadores), haverá uma outra frente de oposição denominada Reactância (Xc) sendo que para cada corrente aplicada a um tecido a freqüência dita crítica é aquela que induz a máxima Xc. Capacitadores ou condensadores são estruturas formadas por duas placas condutoras que limitam um meio não condutor, figuradamente um "sanduíche", sendo as duas metades do pão representativos das placas condutoras e o recheio o meio não condutor. Sendo o corpo humano não homogêneo, seus capacitadores podem ser representados pela estrutura típica das membranas celulares: duas capas (uma interna para o citoplasma e outra externa para o extracelular), ambas com intensa atividade biológica e condutora, limitando estrutura não condutora dos fosfolipidios (MÁTTAR, 1995).

Todas as substâncias, com exceção dos supercondutores, oferecem uma resistência ao fluxo da corrente elétrica. As leis de Ohm estabelecem que a resistência de uma substância é proporcional à variação da voltagem de uma corrente elétrica a ela aplicada. No corpo humano, os tecidos magros (sem gordura) são altamente condutores, por conterem grande quantidade de água e eletrólitos e representam um meio de baixa resistência elétrica. Gordura e ossos são maus condutores ou meios de alta resistência elétrica, com pouca quantidade de água ou eletrólitos condutores (COSTA, 1996 a).

A impedância bioelétrica de tecidos do corpo provê uma estimativa da água corporal, a qual é de interesse em adultos e idosos sendo que nesta última faixa etária citada está aumentado o risco para desidratação (SCHLENKER, 1993). Usando valores da água corporal total, derivada da análise da impedância bioelétrica, pode-se estimar a massa livre de gordura e gordura corporal (NIH, 1994). 
A variação do estado de hidratação modifica os resultados por afetar a condutividade, tornando-se um importante fator do erro (MONTEIRO,1998).

A impedância bioelétrica (BIA) é uma técnica que pode ser usada em indivíduos deambulantes ou não, em ambulatório ou em enfermaria para a avaliação da composição corporal de indivíduos. Apresenta relativa simplicidade, baixo custo operacional e um custo acessivel do equipamento para os profissionais. A velocidade e a relativa simplicidade de execução representam uma grande vantagem para sua utilização (COSTA, 1996 b).

LULASKI (1985a) correlacionou resultados de impedância bioelétrica com massa livre de gordura, avaliada através de hidrodensitometria, água corporal total determinada pela diluição D2O e potássio corporal total. Esse estudo indicou que a técnica de impedância bioelétrica é válida e segura para estimar a composição corporal de indivíduos.

DEURENBERG et al. (1989) encontrou valores de gordura corporal em pessoas com idade entre 60 e 83 anos através da impedância bioelétrica, altamente correlacionados com estimativas obtidas com outros métodos (indice de massa corporal, pregas cutâneas, circunferência e densidade corporal), contudo a determinação da composição corporal a partir de fórmulas que foram baseadas em populações jovens superestimam a massa magra e subestimam a gordura, portanto não podem ser aplicadas em população idosa.

Segundo SCHKENKER (1993), a impedância tem potencial para avaliar a composição corporal de pessoas idosas, apesar de ainda ser necessário desenvolver padrões que sejam consistentes com as mudanças corporais relacionadas com a idade. 
TAGLIABUE et al.(2001), em estudo sobre identificação da massa magra pela impedância: influência da adiposidade, em 68 indivíduos de ambos os sexos e com idade entre 18 e 69 anos, verificou que os valores de massa magra, encontrados pela densitometria (DEXA), se correlacionaram significativamente com os valores encontrados pela impedância.

Em estudo com 37 individuos do sexo masculino, com idade entre 28 e 70 anos, demonstrou que a impedância bioelétrica é um método válido para análise da composição corporal e pode avaliar a evolução do estado nutricional e sugere que são imprescindíveis estudos com população enferma onde normalmente ocorrem alterações na distribuição de água e eletrólitos (edemas) e na desnutrição, condições estas presentes em muitas doenças que acometem os indivíduos idosos (LUKASKI, $1985 a)$.

A impedância bioelétrica poderá representar um importante método para identificar os níveis de adiposidade da população, considerando a relação existente entre excesso de gordura corporal e doenças crônicas não transmissíveis. A realização da estimativa dos tecidos magros também oferece subsídios para o estabelecimento do diagnóstico nutricional e reavaliação da conduta adotada.

O Objetivo do presente trabalho é verificar a impedância bioelétrica como método eficiente, simples, de fácil utilização para determinar e monitorar as alterações na composição corporal que ocorrem em pessoas idosas. 
Hipótese 


\section{HIPÓTESE}

Em individuos com 60 anos e mais, os valores de massa magra e de gordura, obtidos por impedância bioelétrica, apresentam nível de concordância aceitável com os valores obtidos por densitometria. 
Objetivos 


\section{OBJETIVOS}

\subsection{Objetivo Geral}

Verificar a concordância dos valores de massa magra e de gordura obtidos por impedância bioelétrica, em relação aos valores obtidos por densitometria.

\subsection{Objetivo Específico}

Propor equação de regressão para estimar valores de massa magra e de gordura de indivíduos idosos, segundo densitometria em função dos valores obtidos por impedância bioelétrica. 
Métodos 


\section{METODOS}

\subsection{Local}

Este trabalho foi realizado no ambulatório do Serviço de Geriatria e Gerontologia de um hospital escola que atende funcionários públicos estaduais e seus dependentes. De acordo com critérios estabelecidos pelo Serviço de Geriatria, são considerados indivíduos idosos aqueles com idade igual ou superior a 60 anos.

O estudo contou com a colaboração do Serviço de Radiologia, no qual foram realizados os exames de densitometria, e da Equipe Interdisciplinar do Serviço de Geriatria que encaminhou os usuários para o estudo.

\subsection{Delineamento do Estudo}

Estudo transversal com base em dados primários.

\subsection{Amostra do estudo}

Foram investigados indivíduos idosos de ambos os sexos, atendidos em ambulatório no período de dezembro de 2003 a outubro de 2004 e que voluntariamente se dispuseram a participar da pesquisa. Inicialmente a amostra foi composta por 160 indivíduos. Durante a coleta dos dados, um dos aparelhos fundamentais para a determinação de uma das variáveis, o aparelho de Densitometria Óssea, permaneceu inoperante (problemas técnicos) durante vários períodos do 
desenvolvimento deste trabalho. Por este motivo as análises foram realizadas em uma amostra de 40 indivíduos.

O presente estudo foi aprovado pelos Comitês de Ética em Pesquisa da Faculdade de Saúde Pública de Universidade de São Paulo e do Hospital do Servidor Público Estadual "Francisco Morato de Oliveira", local no qual foi desenvolvido o estudo (Anexo 1 e 2).

Os indivíduos que participaram do estudo assinaram o Termo de Consentimento Livre e Esclarecido (Anexo 3).

\subsubsection{Critérios de Exclusão}

Não participaram da pesquisa:

indivíduos que apresentavam impossibilidade de deambulação para para mensuração de peso e estatura;

indivíduos com impossibilidade de realizar o exame de BIA ou de DEXA (desidratados, edemaciados, com ascite, com próteses metálicas);

indivíduos que utilizavam marca-passo; 


\subsection{Desenvolvimento do trabalho}

\subsubsection{Coleta de Dados}

Para a admissão no ambulatório, os indivíduos, inicialmente, foram atendidos pelo médico, o qual realizou a conduta e encaminhou o cliente para o Atendimento Nutricional. Foram convidados para participar do estudo todos os indivíduos com mais de 60 anos de idade atendidos pelo Ambulatório de Atendimento Nutricional Geriátrico onde a nutricionista estava desenvolvendo o presente trabalho. Nesta ocasião, os indivíduos que autorizaram a sua participação e não se apresentavam nas condições pré-estabelecidas pelos critérios de exclusão, foram convidados a fazer parte da pesquisa.

Durante $o$ atendimento nutricional, foram realizadas as medidas de avaliação antropométricas (peso e estatura) para a determinação da composição corporal pela BIA nos indivíduos que fizeram parte da pesquisa. Posteriormente, no prazo máximo de duas semanas, os clientes foram encaminhados para o Serviço de Radiologia do Hospital para realizarem o exame de DEXA, de acordo com o agendamento prévio e condicionado ao número de vagas existentes.

A entrevista (para coleta dos dados de caracterização da população) bem como a avaliação da composição corporal foram realizados pela nutricionista, autora deste estudo, e registrados em formulário padronizado (Anexo 4). 


\subsubsection{Caracterização da amostra estudada}

A amostra inicial foi constituída por 160 indivíduos dos quais 40 constituíram a amostra analisada e 120 a amostra complementar. Para a análise, foram comparados os 40 indivíduos que realizaram a DEXA com os 120 indivíduos que não realizaram este exame. Os resultados foram apresentados sob a forma de tabelas. Para verificar se a amostra analisada era semelhante à amostra complementar, foi realizado o teste de qui-quadrado $\left(\chi^{2}\right)$.

Os indivíduos foram caracterizados quanto:

às características socio-demográficas:

- ao sexo: masculino e feminino;

- ao grupo etário: grupo 1 com idade entre 60 e 72 anos e grupo 2 com idade igual ou superior a 73 anos (estabelecido a partir do valor da mediana da amostra);

- à cor da pele: branca, negra, amarela, parda;

- à atividade ocupacional: com ou sem atividade ocupacional atual; ao estilo de vida:

- à atividade física: com ou sem pratica de atividade física;

- ao hábito de fumar atual: com ou sem o hábito de fumar;

- ao habito de consumir bebidas alcoólicas atual: com ou sem o consumo de bebidas alcoólicas;

aos diagnósticos clínicos: quanto ao tipo de diagnóstico

a utilização de medicamentos: quanto ao tipo de medicamento; 
Os dados sobre cor, atividade ocupacional, variáveis de estilo de vida, diagnósticos clínicos e utilização de medicamentos foram referidos pelos indivíduos.

\subsubsection{Descrição das variáveis de estudo}

\subsubsection{Impedância bioelétrica}

Para o cálculo da BIA foram realizadas as medidas de resistência e reactância, com a utilização de um impedanciômetro modelo BIA $101 \mathrm{Q}$ - portátil, fabricado pela RJL Systems Inc., o qual foi testado a cada dia de coleta de dados, anteriormente à série de medidas, conforme orientação fornecida pelo Manual do Usuário CompCorp (LARSSON e PRADO, s/d):

Os indivíduos que realizaram o exame foram orientados a:

- Fazerem ingestão de pelo menos dois litros de líquidos (3\% do seu peso em litros) no dia anterior ao teste (aproximadamente 8 copos de água mais água da alimentação); uma boa hidratação é fundamental para um teste adequado;

- Não fazerem exercícios físicos ou saunas nas 8 horas antes do exame;

Foi realizado diariamente um pré-teste com o aparelho. Para testar o impedanciômetro, utilizou-se a resistência padrão $(500 \mathrm{ohm})$ que acompanha o sistema para testar o circuito eletrônico de leitura da impedância, a integridade dos cabos, as pinças de conexão dos eletrodos e a bateria. Os procedimentos adotados foram: 
- Verificar a vida útil da bateria - a carga baixa é indicada por pontos decimais no visor de leitura da impedância, neste caso é necessário trocar as baterias por novas alcalinas de $9 \mathrm{~V}$;

- Colocar as pinças de conexão dos eletrodos. Os cabos pretos do lado direito da resistência e os vermelhos do lado esquerdo, as pinças de cor vermelha devem ser conectadas próximas à resistência e as de cor preta nas pontas;

- Ligar o impedanciômetro. A leitura da resistência deve estar entre 490 e 510 ohm. Se a resistência estiver nesta faixa significa que o circuito eletrônico, os cabos e a bateria encontram-se em bom funcionamento. Se a resistência não estiver na faixa ideal anotar o valor e prosseguir com as etapas abaixo;

- Para avaliar o conector dos cabos no impedanciômetro, exercer pequena pressão na base dos cabos ou pequenos movimentos dos mesmos. Se houver uma oscilação da resistência de mais de 10 ou 15 ohm pode haver um dano no conector;

- Para avaliar a condição dos cabos fazer movimentos com os mesmos em diferentes posições e observar a flutuação da resistência. Se houver uma flutuação maior de $5 \mathrm{ohm}$ pode haver uma avaria nos cabos devendo ser substituídos.

- Se durante a realização dos testes for observado resultados não esperados, rever as etapas e recomendações de colocação.

A técnica utilizada para medir a resistência e reactância foi do Manual do Usuário CompCorp (LARSSON E PRADO, s/d).

Os procedimentos do exame foram totalmente explicados ao indivíduo examinado. A medida foi realizada com o indivíduo deitado em decúbito dorsal, 
uma da outra, evitando contato dos tornozelos e joelhos. Mãos e braços não deveriam tocar no corpo. A pele onde foram colocados os eletrodos foi limpa com algodão embebido com álcool. Os eletrodos foram fixados em uma linha imaginária que divide a cabeça da ulna e que se inicia na protuberância óssea do punho. Um outro eletrodo foi colocado em cima do nó do dedo médio da mão. No pé, o eletrodo foi colocado com a borda de corte em uma linha imaginária que divide os maléolos medial e lateral. Um outro foi fixado acima do nó do dedo médio do pé. Os cabos pretos do impedanciômetro foram colocados nos eletrodos do pé, e os cabos vermelhos nos eletrodos da mão. As pinças de conexão (jacarés) de cor preta foram conectadas nos eletrodos distais (próximos aos dedos), e as pinças de conexão (jacarés) de cor vermelha foram conectadas nos eletrodos proximais (punho e tornozelo). Em seguida o aparelho foi ligado para a realização da leitura da resistência e reactância.

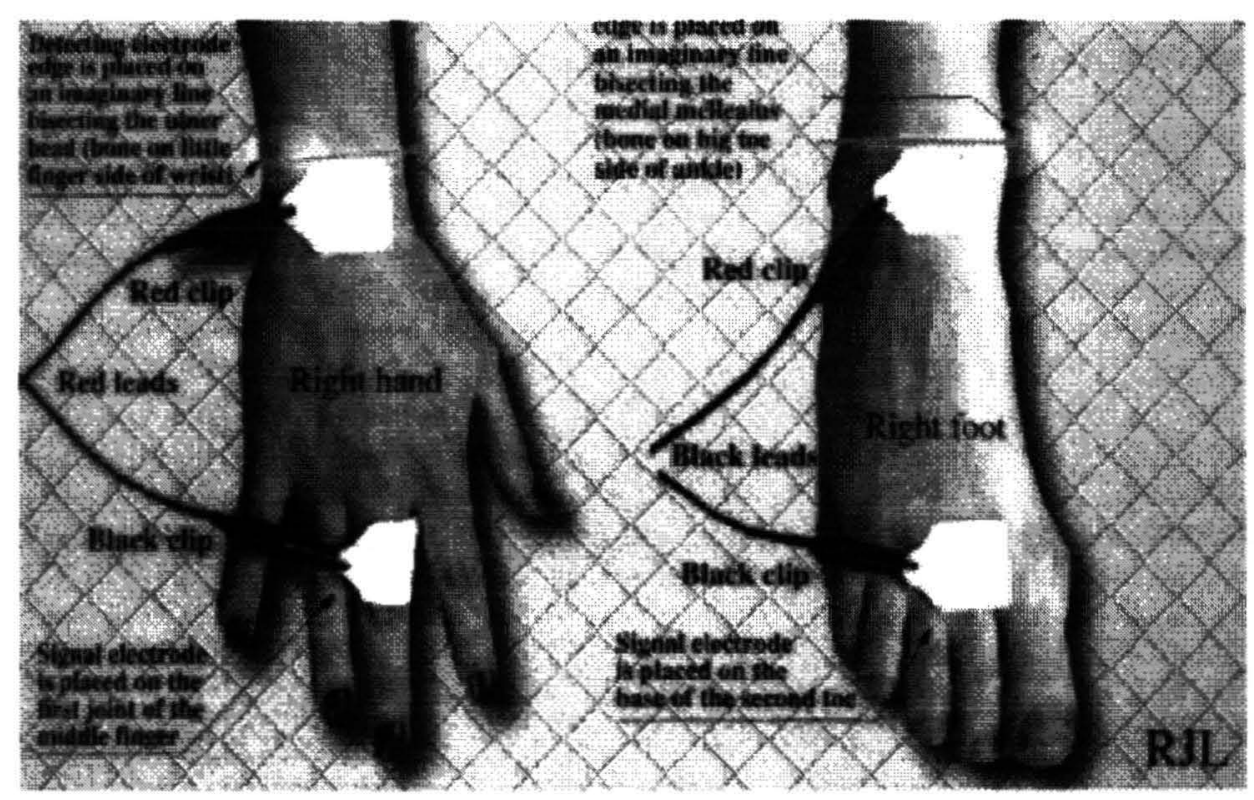

Figura 1 Esquema representativo da colocação dos eletrodos distais e proximais, para realização da impedância. 
Os valores de resistência e reactância foram registrados em formulário padronizado (Anexo 4).

Para a análise da composição corporal através deste programa, também foram necessários os valores do peso e da estatura dos indivíduos avaliados:

- o valor do peso foi obtido com os indivíduo usando vestes leves (sem casacos ou paletós) e sem sapatos. $O$ indivíduo ficou com os pés no centro da balança e o peso foi registrado quando o indivíduo permaneceu imóvel. Para a realização desta medida, foi usada a balança Soehnle, tipo digital S, com capacidade de 130 quilogramas e escala com divisões de 100 gramas. A balança foi aferida antes do inicio da pesagem de cada indivíduo (CHUMLEA 1989). O peso foi registrado em quilos (kg);

- o valor da estatura foi obtido com o indivíduo em pé, olhando para frente, sem fletir ou estender a cabeça. $O$ indivíduo encostou o corpo no antropômetro (calcanhares, panturrilhas, região glútea, ombro e cabeça). $\mathrm{O}$ indivíduo estavam descalços, ou de meias, os pés estavam alinhados. A leitura foi feita o mais próximo de 0,5 cm. A estatura foi registrada em centímetros (cm) (CARVALHO, 1992).

O “software" utilizado foi o Programa de Avaliação Corporal por Impedância, versão 2.4, criado pelo CompCorp Imp. Exp. Com. Serv. Ltda. que acompanha o equipamento que foi utilizado (LARSSON e PRADO s/d). Este programa foi elaborado para cadastrar os indivíduos e realizar o cálculo em quilos e percentagem das quantidades de água, corporal, massa magra e gordura de cada indivíduo. A partir dessa digitação o programa gerou relatórios individuais (Anexo 5). Neste 
impresso é possível comparar os valores obtidos em percentagem de cada compartimento analisado, com as percentagens recomendadas de acordo com o quadro abaixo:

\section{Quadro 1. Percentagens recomendadas para cada compartimento} corporal.

\begin{tabular}{|l|c|c|}
\hline \multicolumn{1}{|c|}{ Compartimento } & Homens & mulheres \\
\hline Água Corporal & de $55 \%$ a $65 \%$ & De $50 \%$ a $60 \%$ \\
\hline Massa Magra & de $79 \%$ a $83 \%$ & De $69 \%$ a $78 \%$ \\
(água, músculo e osso) & & De 22 \% a 31\% \\
\hline Gordura Corporal & de $17 \%$ a $21 \%$ & \\
\hline
\end{tabular}

Comp Corp. Versão 2.3 (Larsson e Prado s/d)

\subsubsection{Densitometria (DEXA)}

Para determinar a composição corporal por meio da densitometria, os indivíduos foram convidados a comparecer ao Setor de Radiologia (Diagnóstico por Imagem) em dias e horários pré-estabelecidos por este setor.

A DEXA foi realizada em uma amostra de 40 indivíduos da pesquisa. $O$ aparelho utilizado foi o densitômetro de dupla emissão de Raios-X (Lunar® DPX® X-Ray Bone Densitometer) e os dados colhidos foram analisados pelo "software" Lunar versão 3.165 copyright $1988-1987$. 


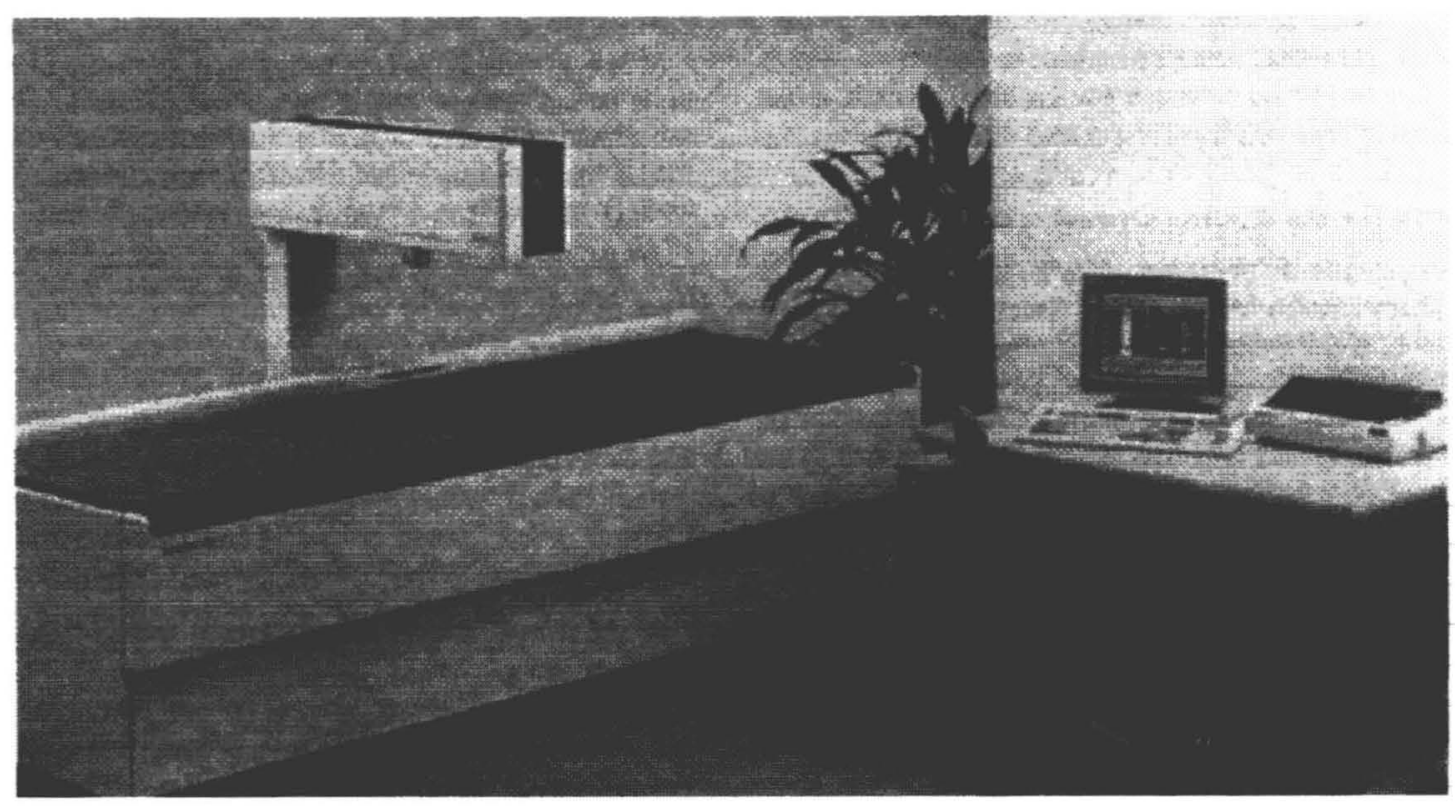

Figura 2. Aparelho de densitometria

Os indivíduos foram orientados para comparecer, de preferência sem ornamentos de metal (anéis, relógios, correntes, brincos, etc), inclusive vestimentas com botões, colchetes e zíperes.

Antes de cada sessão, foi realizado o controle de qualidade do aparelho, calibrado com um "standard phantom". Este aparelho usa um canal de Raios-X de $80 \mathrm{KV}$ com um filtro $\mathrm{K}$ edg. $\left(350 \mathrm{mg}\right.$ cerum $\left./ \mathrm{cm}^{2}\right)$ para gerar Raios-X feixe de energia de 40 a $70 \mathrm{Kev}$, total body scnans para analisar a composição corporal. (CHUMLEA, 1996).

Os pacientes que foram agendados para o exame compareceram ao guichê de recepção e receberam um questionário para ser preenchido. Este questionário apresentou perguntas sobre identificação do usuário, presença de enfermidades, uso de medicamentos, e sobre estilo de vida. (Anexo 6).

Em seguida, os indivíduos foram encaminhados ao setor de DEXA onde foram recebidos pelo técnico de densitometria e pela nutricionista autora deste trabalho. Nesta ocasião foram estabelecidos o peso e a estatura. Estes profissionais 
preencheram um formulário para a realização posterior do Laudo da DEXA. (Anexo 7).

Através do cartão do usuário e dos dados preenchidos no questionário os profissionais localizaram ou incluíram as informações dos indivíduos no banco de dados do "software". Os laudos dos exames foram impressos, para cada indivíduo, (Anexo 8).

Para realização do exame, os profissionais posicionaram o indivíduo com o corpo estendido em cima da mesa "Scan Table Mattress", tendo o cuidado de colocá-lo bem ao centro, verificando se o mesmo ficou posicionado dento dos limites da borda delimitada na mesa. $O$ espaço da linha para o mapeamento do corpo total foi de $1,303 \mathrm{~cm}$ e os pontos de resolução de $0,204 \mathrm{~cm}$ Assim o indivíduo permaneceu deitado sem fazer uso de travesseiro. Os braços ficaram ao lado do corpo, com a palma das mãos votadas para baixo e os membros inferiores ligeiramente afastados (em uma posição confortável e relaxados).

O mapeamento foi realizado sobre toda a extensão do corpo do individuo, começando pela cabeça e indo até os pés, parando automaticamente, nos componentes que detectam o fim das linhas estabelecidas para a leitura. 


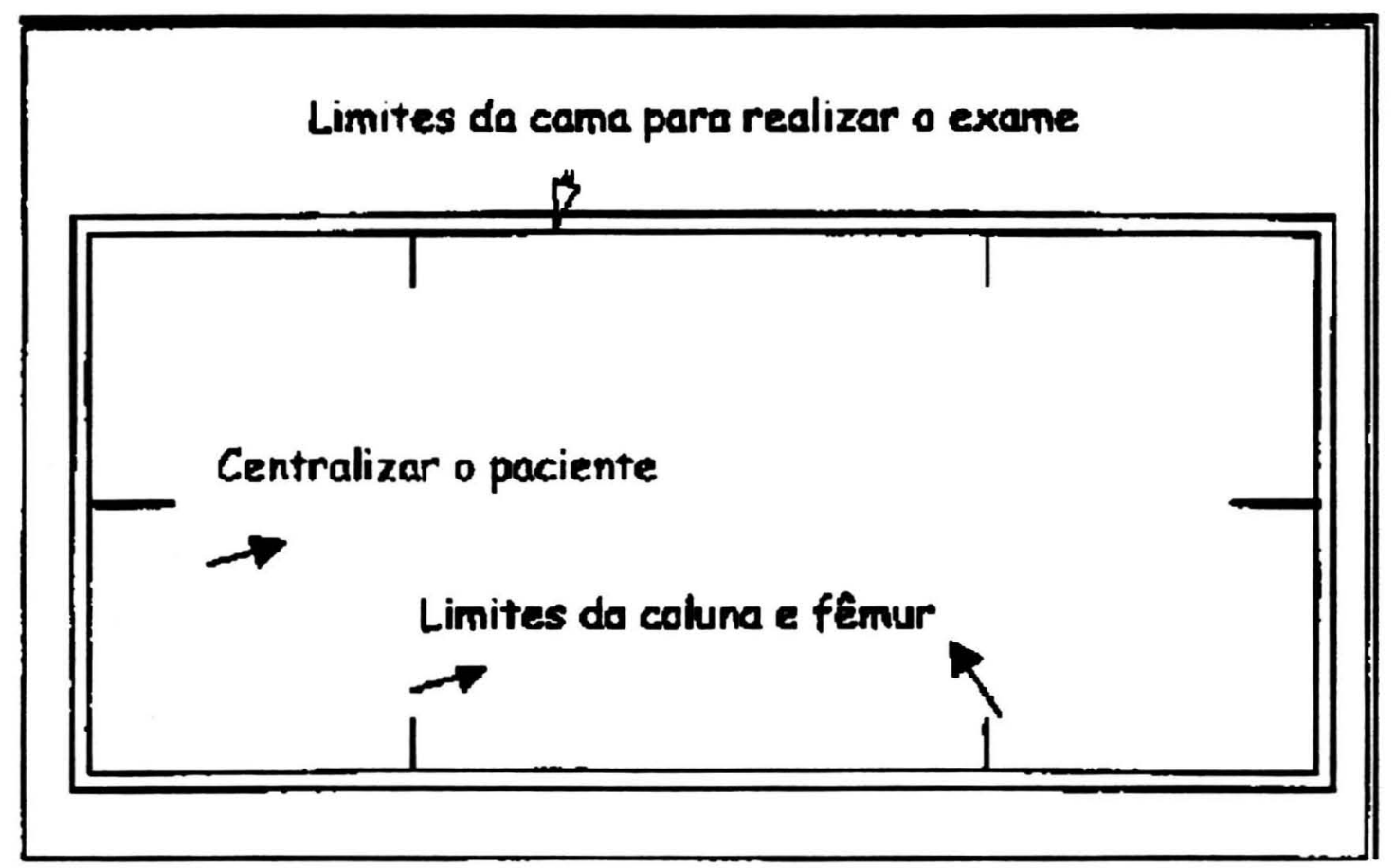

Figura 3. Esquema de posicionamento do paciente para realização da DEXA

A análise do exame foi realizada pelo médico especializado e responsável pelo setor, com separação dos diferentes segmentos corporais, seguindo parâmetros previamente estabelecidos, dividindo o corpo em: cabeça, tronco, membros superiores e inferiores (lado direito e esquerdo) fornecendo como resultado as seguintes informaçõoes:

- $\quad$ massa de gordura em gramas = Fat (grams);

- $\quad$ massa magra em gramas (músculo e água) = Lean (grams);

- conteúdo mineral ósseo em gramas = BMC (grams);

- massa magra + conteúdo mineral ósseo em gramas $=$ Lean + BMC (grams)

- massa de gordura em gramas + massa magra em gramas $=$ Tecido

(Fat + Lean em gramas $=$ Tissue $($ grams $))$

\section{BIBLLOTECA/CIR}




\subsection{Análise dos dados}

Foi criado um banco de dados no programa EXCEL versão 7,0 para Windows.

\section{1- Descrição da amostra}

Primeiramente, os dados de caracterização da amostra estudada foram analisados de forma descritiva, foram processados os cálculos para se estabelecer os números e as respectivas percentagens. Para verificar se a amostra analisada era semelhante à amostra complementar, foi realizado o teste de qui-quadrado $\left(\chi^{2}\right)$. A análise comparou os 40 indivíduos que realizaram a DEXA com os 120 indivíduos que não realizaram este exame. Os resultados foram apresentados na forma de tabelas.

As variáveis analisadas neste estudo, que são os métodos de impedância bioelétrica (BIA) e densitometria (DEXA) foram utilizados para estimar as medidas de massa magra MM (kg) e gordura GO (kg), Estes valores foram analisados em relação às medidas de tendência central (média e mediana), medidas de dispersão (desvio-padrão) e intervalo de confiança.

A realização da análise estatística foi possível por meio dos seguintes testes:

\section{2- Teste de distribuição normal}

- Foi realizado o Teste de Shapiro-Wilk, para avaliar a aderência dos valores das variáveis quantitativas contínuas (MM e GO pela BIA e DEXA) à 
distribuição normal. Adotou-se o limite $p<5 \%$ para aceitação da normalidade. Foi também realizada uma apresentação gráfica da normalidade das variáveis estudadas.

\section{3- Descrição conjunta das variáveis estudadas}

- Foi utilizada a Correlação de Pearson e o gráfico de dispersão, para verificar o comportamento dos valores de MM e GO obtidos pela BIA e pela DEXA (VIEIRA, 1991).

\section{4- Concordância entre os dois métodos}

- LIN (1989) propôs um indicador de reprodutibilidade, denominado coeficiente de concordância/ correlação (CCC), que avalia a concordância entre duas leituras (da mesma amostra), medindo a variação a partir da linha de $45^{\circ}$ através da origem ( a linha de concordância). São propriedades importantes do coeficiente variar de -1 a 1 , ter o valor 0 quando não existe correlação e o valor 1 só ocorre no caso de concordância perfeita. $\mathrm{O}$ gráfico proposto pelo autor é bastante útil para interpretação dos dados.

- BLAND E ALTMAN (1986) sugerem um método gráfico para estudar concordância, alocando pontos correspondentes às diferenças de duas observações contra as respectivas médias, em um gráfico de coordenadas cartesianas.

\section{5- Teste t pareado}

- Foi utilizado o teste $\mathrm{t}$ pareado para verificar estatisticamente as diferenças entre as médias dos valores de GO e MM estimadas pela BIA e pela DEXA. 


\section{6- Regressão Linear}

- Foi realizada para obter os coeficientes da variável DEXA como função da variável BIA.

Para todos os testes estatísticos, o nível de significância adotado foi $\alpha<0,05$.

O processamento dos dados foi feito utilizando-se os programas: "Statistical Package for Social Sciences", (SPSS INC., Chicago, IL, USA). e o Stata Statistical "Sofware", Release 8.0 College Station, TX: STATA (2003). 
Resultados 


\section{RESULTADOS}

\subsection{Caracterização da Amostra Estudada}

Em relação às características analisadas neste estudo, mão houve diferença estatisticamente significativa entre a amostra analisada (40 indivíduos) e a amostra Complementar (120 individuos). Portanto, as duas amostras foram semelhantes, o que possibilitou a utilização da amostra composta por 40 indivíduos para realização das demais análises estatísticas, em particular o estudo de concordância. Esses resultados também possibilitaram a utilização da amostra complementar de 120 indivíduos para estimar os valores de DEXA a partir da equação de regressão que foi proposta. 0 Quadro 2 apresenta esses resultados.

Quadro 2. Características avaliadas nas duas amostras (analisada e complementar), respectivos $\chi^{2}$ e valores de $\mathbf{p}$.

\begin{tabular}{|l|c|c|}
\hline \multicolumn{1}{|c|}{ Características Analisadas } & $\chi^{2}$ & Valor de $\mathbf{p}$ \\
\hline sexo & 0,36 & 0,85 \\
\hline grupo etário & 3,66 & 0,56 \\
\hline cor da pele & 2,07 & 0,56 \\
\hline atividade ocupacional atual & 2,22 & 0,33 \\
\hline prática de atividade fisica & 0,01 & 0,93 \\
\hline hábito de fumar & 1,28 & 0,26 \\
\hline hábito de beber & 0,77 & 0,38 \\
\hline presença de hipertensão arterial & 0,16 & 0,69 \\
\hline presença obesidade & 2,83 & 0,65 \\
\hline presença diabete melito & 2,01 & 0,67 \\
\hline uso de anti-hipertensivos & 0,95 & 1,00 \\
\hline uso de hipolipemiante & 0,01 & 0,33 \\
\hline uso de hipoglicemiantes orais & 2,08 & 0,15 \\
\hline
\end{tabular}




\subsubsection{Quanto às características sócio-demográficas}

A amostra analisada foi constituída por 40 idosos, sendo 26 do sexo (65 \%) feminino e 14 (35\%) do sexo masculino. A amostra complementar foi constituída por 120 idosos, sendo $76(63,30 \%)$ do sexo feminino e $44(36,70 \%)$ do sexo masculino.

Em relação ao grupo etário, na amostra analisada, 21 indivíduos $(52,50 \%)$ se encontravam no grupo etário de 73 anos e mais e 19 (47,50 \%) no grupo etário de 60 a 72 anos. $\mathrm{Na}$ amostra complementar, $83(65 \%)$ indivíduos se encontravam no grupo etário acima de 73 anos e 56 (35\%) no grupo etário de 60 a 72 anos.

Verificou-se maior proporção de individuos da cor branca nas duas amostras: $30(75 \%)$ na amostra analisada e $77(64,2 \%)$ na amostra complementar.

$\mathrm{Na}$ amostra analisada, observou-se que $21(52,50 \%)$ dos indivíduos relataram estar aposentados e na amostra complementar $61(50,80 \%)$ também relataram estar aposentados.

A tabela 1 ilustra essas informações. 
Tabela 1. Distribuição dos idosos estudados nas duas amostras, segundo características sócio-demográficas, SP - 2004.

\begin{tabular}{|c|c|c|c|c|c|c|}
\hline \multirow[t]{2}{*}{$\begin{array}{c}\text { Características } \\
\text { sócio } \\
\text { demográficas }\end{array}$} & \multicolumn{2}{|c|}{ Amostra Analisada } & \multicolumn{2}{|c|}{$\begin{array}{c}\text { Amostra } \\
\text { Complementar }\end{array}$} & \multicolumn{2}{|c|}{ Amostra Inicial } \\
\hline & $\mathbf{n}$ & $\%$ & $\mathbf{n}$ & $\%$ & $\mathbf{n}$ & $\%$ \\
\hline \multicolumn{7}{|l|}{ sexo } \\
\hline masculino & 14 & 35,00 & 44 & 36,70 & 58 & 36,30 \\
\hline feminino & 26 & 65,00 & 76 & 63,30 & 102 & 63,80 \\
\hline \multicolumn{7}{|l|}{ grupo etário } \\
\hline $60-72$ anos & 19 & 47,50 & 37 & 30,80 & 56 & 35,00 \\
\hline$\geq 73$ anos & 21 & 52,50 & 83 & 69,20 & 83 & 65,00 \\
\hline \multicolumn{7}{|l|}{ cor } \\
\hline branca & 30 & 75,00 & 77 & 64,20 & 107 & 66,90 \\
\hline negra & 3 & 7,50 & 17 & 14,20 & 20 & 12,50 \\
\hline amarela & 1 & 2,50 & 6 & 5,00 & 7 & 4,40 \\
\hline parda & 6 & 15,00 & 20 & 16,70 & 26 & 16,30 \\
\hline \multicolumn{7}{|l|}{ ativ. atual } \\
\hline Com Ativ. ${ }^{*}$ & 9 & 22,50 & 17 & 14,20 & 26 & 16,30 \\
\hline Com Aposent.** & 21 & 52,50 & 61 & 50,80 & 82 & 51,30 \\
\hline Sem Aposent.*** & 10 & 25,00 & 42 & 35,00 & 52 & 32,50 \\
\hline
\end{tabular}

\subsubsection{Quanto ao Estilo de Vida}

Observou-se que na amostra analisada $23(57,50 \%)$ dos indivíduos estudados realizavam algum tipo de atividade fisica e na amostra complementar $68(56,70 \%)$ praticavam atividade fisica.

Foi possível constatar que na amostra analisada $32 \quad(80 \%)$ indivíduos não utilizavam nenhum tipo de bebida alcoólica, sendo que na amostra complementar $103(84,62 \%)$ também não faziam uso desta bebida . 
Em relação ao hábito de fumar 36 (90 \%) indivíduos não apresentavam o hábito de fumar na amostra analisada e 114 (95\%) não apresentavam o hábito de fumar na amostra complementar.

Tabela 2. Distribuição dos idosos estudados nas duas amostras, segundo variáveis do estilo de vida, SP - 2004.

\begin{tabular}{|c|c|c|c|c|c|c|}
\hline \multirow{3}{*}{$\begin{array}{l}\text { Variáveis do } \\
\text { Estilo de vida }\end{array}$} & \multicolumn{6}{|c|}{ Amostra } \\
\hline & \multicolumn{2}{|c|}{ Amostra analisada } & \multicolumn{2}{|c|}{ Complementar } & \multicolumn{2}{|c|}{ Amostra Inicial } \\
\hline & n & $\%$ & n & $\%$ & $\mathbf{n}$ & $\%$ \\
\hline \multicolumn{7}{|l|}{$\begin{array}{l}\text { prática de } \\
\text { atividade física }\end{array}$} \\
\hline Com atividade & 23 & 57,50 & 68 & 56,70 & 91 & 56,90 \\
\hline Sem atividade & 17 & 42,50 & 52 & 43,30 & 69 & 43,10 \\
\hline \multicolumn{7}{|c|}{$\begin{array}{l}\text { utilizaçâo de } \\
\text { bebida alcoólica }\end{array}$} \\
\hline Sim & 8 & 20,00 & 17 & 15,38 & 25 & 15,60 \\
\hline Não & 32 & 80,00 & 103 & 84,62 & 135 & 84,40 \\
\hline \multicolumn{7}{|c|}{ hábito de fumar } \\
\hline Sim & 4 & 10,00 & 6 & 5,00 & 10 & 6,30 \\
\hline Não & 36 & 90,00 & 114 & 95,00 & 150 & 93,80 \\
\hline
\end{tabular}

\subsubsection{Diagnósticos clínicos}

A população estudada apresentou múltiplos diagnósticos. Observou-se que a hipertensão arterial (HAS) foi a doença mais informada em relação a o total de diagnósticos levantados. Dos indivíduos estudados na amostra analisada 27 (67,50 \%) afirmaram apresentar HAS e na amostra complementar 85 (70,80 \%) afirmaram apresentar esta enfermidade. 
A segundo doença mais informada foi obesidade, relatada por $18(45,00 \%)$ indivíduos na amostra analisada e por 59 (49,20\%) indivíduos da amostra complementar.

A terceira doença mais informada foi a diabete melito, relatada na amostra analisada por $11(27,50 \%)$ indivíduos e na amostra complementar por $48(40,00 \%)$ indivíduos.

Tabela 3. Distribuição dos idosos estudados nas duas amostras, segundo diagnósticos clínicos, SP 2004.

\begin{tabular}{lcccccc}
\hline $\begin{array}{l}\text { Diagnósticos } \\
\text { clínicos }\end{array}$ & $\begin{array}{c}\text { Amostra Analisada } \\
\mathbf{n}\end{array}$ & $\begin{array}{c}\text { Complementar } \\
\mathbf{n}\end{array}$ & $\begin{array}{c}\text { Amostra } \\
\mathbf{n}\end{array}$ & $\begin{array}{c}\text { Amostra Inicial } \\
\mathbf{n}\end{array}$ & $\mathbf{\%}$ \\
\hline HAS & & & & & & \\
\hline sim & 27 & 67,50 & 85 & 70,80 & 112 & 70,00 \\
não & 13 & 32,50 & 35 & 29,20 & 48 & 30,00 \\
\hline Obesidade & & & & & & \\
\hline sim & 18 & 45,00 & 59 & 49,20 & 77 & 48,10 \\
\hline não & 22 & 55,00 & 61 & 50,80 & 83 & 51,90 \\
\hline Diabetes & & & & & & \\
\hline sim & 11 & 27,50 & 48 & 40,00 & 59 & 36,90 \\
não & 29 & 72,50 & 72 & 60,00 & 101 & 63,10 \\
\hline
\end{tabular}

\subsubsection{Quanto à utilização de medicamentos}

Os medicamentos anti-hipertensivos foram utilizados por $29(72,50 \%)$ indivíduos na amostra analisada e por $87(72,50 \%)$ na amostra complementar.

Foi possível verificar que $7(15,50 \%)$ indivíduos da amostra analisada faziam uso de hipolipemiantes e $30(25 \%)$ na amostra complementar. 
Foi observado também que $4(10 \%)$ faziam uso de hipoglicemiantes orais na amostra analisada e $24(20 \%)$ na amostra complementar.

Tabela 4. Distribuição dos idosos estudados nas duas amostras, segundo a utilização de medicamentos, SP 2004.

\begin{tabular}{|c|c|c|c|c|c|c|}
\hline \multirow{2}{*}{$\begin{array}{l}\text { Utilização de } \\
\text { medieamentos }\end{array}$} & \multicolumn{2}{|c|}{ Amostra Analisada } & \multicolumn{2}{|c|}{$\begin{array}{c}\text { Amostra } \\
\text { Complementar }\end{array}$} & \multicolumn{2}{|c|}{$\begin{array}{l}\text { Amostra } \\
\text { Inicial }\end{array}$} \\
\hline & En & $\%$ & $\mathrm{n}$ & $\%$ & $\mathrm{n}$ & $\%$ \\
\hline \multicolumn{7}{|c|}{ anti-hipertensivos } \\
\hline $\operatorname{sim}$ & 29 & 72,50 & 87 & 72,50 & 116 & 72,50 \\
\hline não & 11 & 27,50 & 33 & 27,50 & 44 & 27,50 \\
\hline \multicolumn{7}{|l|}{ hipolipemiantes } \\
\hline $\operatorname{sim}$ & 07 & 17,50 & 30 & 25,00 & 37 & 23,10 \\
\hline não & 33 & 82,50 & 90 & 75,00 & 123 & 76,90 \\
\hline \multicolumn{7}{|c|}{$\begin{array}{l}\text { hipoglicemiantes } \\
\text { orais }\end{array}$} \\
\hline $\operatorname{sim}$ & 04 & 10,00 & 24 & 20,00 & 28 & 17,50 \\
\hline não & 36 & 90,00 & 96 & 80,00 & 132 & 82,50 \\
\hline
\end{tabular}

\subsection{Descrição das variáveis}

\subsubsection{Análise descritiva das variáveis}

A amostra analisada foi constituida por 40 individuos, sendo 14 (35\%) do sexo masculino e $26(65 \%)$ do sexo feminino. Foi verificado que a idade mínima da amostra estudada foi de 66 anos e a idade máxima foi de 89 anos. A média de idade da amostra estudada foi de 74,55 anos (d.p =6,11) e a mediana foi de 73 anos.

Em relação aos dados apresentados no quadro 3, sobre a análise das variáveis em relação as medidas de tendência central e dispersão, foi observado que as médias de quilos de massa magra $(\mathrm{MM})$ estimadas pela $\mathrm{BIA}(\mathrm{m}=47,57 \pm 8,11)$ foram 
maiores do que pela DEXA $(m=43,94 \pm 8,53)$. Analisando os valores de massa gorda (GO), foi possível verificar que as médias foram maiores pela DEXA $(\mathrm{m}=$ $22,95 \pm 8,7)$ do que pela BIA $(\mathrm{m}=20,10 \pm 8,53)$. (Quadro 3$)$.

Quadro 3. Número de indivíduos (N), médias, medianas, valores mínimos (V.Min) e máximos (V. Max), desvio-padrão (D.P) e intervalo de confiança (I.C.)da MM (kg) e GO (kg) estimados pela BIA e pela DEXA dos idosos estudados, SP - 2004.

\begin{tabular}{|lccccccccc|}
\hline Variáveis & N & Médias & Mediana & D.P. & V.Min & V.Max & \multicolumn{2}{c|}{$\begin{array}{c}\text { I.C. 95\% } \\
\text { Limite } \\
\text { inferior }\end{array}$} & $\begin{array}{c}\text { Limite } \\
\text { superior }\end{array}$ \\
\hline BIA MM & 40 & 47,57 & 46,20 & 8,11 & 32,50 & 67,80 & 44,98 & 50,16 \\
\hline DEXAMM & 40 & 43,94 & 42,53 & 8,53 & 27,38 & 64,98 & 41,21 & 46,67 \\
\hline BIA GO & 40 & 20,10 & 18,75 & 8,53 & 6,70 & 39,50 & 17,37 & 22,84 \\
\hline DEXA GO & 40 & 22,95 & 23,12 & 8,70 & 6,10 & 43,00 & 20,17 & 25,74 \\
\hline
\end{tabular}

BIA MM: quilos de massa magra estimados pela impedância bioelétrica

DEXA MM: quilos de massa magra estimados pela densitometria BIA GO: quilos de gordura estimados pela impedância bioelétrica DEXA GO: quilos de gordura estimados pela densitometria

\subsubsection{Análise descritiva das variáveis em relação ao sexo}

Analisando a descrição das variáveis em relação ao sexo, foi verificado que as médias de quilos de $\mathrm{MM}$ estimadas pela $\mathrm{BIA}(\mathrm{m}=55,47 \pm 6,85)$ e pela DEXA $(\mathrm{m}=52,62 \pm 5,94)$ foram maiores para o sexo masculino do que para o sexo 
feminino: [BIA $(m=43,32 \pm 4,95)$ e DEXA $(m=39,27 \pm 5,51)]$. Estas diferenças são estatisticamente significativas (quadro 4).

Observou-se que as médias de quilos de GO estimadas pela BIA $(\mathrm{m}=21,31$ $\pm 8,75)$ e pela DEXA $(m=24,48 \pm 8,57)$ foram maiores para sexo feminino do que para o sexo masculino[ BIA $(m=17,86 \pm 8,00)$ e DEXA $(m=20,12 \pm 8,52)]$. Estas diferenças não foram estatisticamente significativas (quadro 4).

Quadro 4. Número de indivíduos (N), médias, desvio padrão (D.P) e intervalo de confiança (I.C.) da MM (kg) e GO (kg) estimados pela BIA e pela DEXA dos idosos estudados, segundo o sexo, SP - 2004.

\begin{tabular}{|lccccccc|}
\hline \multirow{2}{*}{ Variáveis } & Sexo & N & Médias & D.P & lim. inferior & lim. superior & Valor de p \\
\hline BIA MM & M & 14 & 55,47 & 6,85 & 51,51 & 59,42 & 0,00 \\
& F & 26 & 43,32 & 4,95 & 41,32 & 45,32 & \\
DEXA MM & M & 14 & 52,62 & 5,94 & 49,19 & 56,05 & 0,00 \\
& F & 26 & 39,27 & 5,51 & 37,05 & 41,50 & \\
BIA GO & M & 14 & 17,86 & 8,00 & 13,24 & 22,48 & 0,23 \\
& F & 26 & 21,31 & 8,75 & 17,78 & 24,84 & \\
DEXA GO & M & 14 & 20,12 & 8,52 & 15,21 & 25,04 & 0,13 \\
& F & 26 & 24,48 & 8,57 & 21,01 & 27,94 & \\
\hline
\end{tabular}

M: sexo masculino

F: sexo feminino

BIA MM: quilos de massa magra estimados pela impedância bioelétrica

DEXA MM: quilos de massa magra estimados pela densitometria

BIA GO: quilos de gordura estimados pela impedância bioelétrica

DEXA GO: quilos de gordura estimados pela densitometria

\subsubsection{Análise descritiva das variáveis em relação à idade}

Também foi realizada uma análise das variáveis estudadas em relação aos grupos etários estudados. Foram estabelecidos 2 grupos etários a partir do valor da 
mediana da idade (73 anos): grupo 1 com idade entre 60 e 72 anos e grupo 2 com idade igual ou superior a 73 anos. O Quadro 5 apresenta estes valores.

Os indivíduos do grupo 1 apresentaram médias de quilos de MM estimados pela BIA $(m=48,52 \pm 7,67)$ e pela DEXA $(m=44,75 \pm 8,95)$ maiores do que o grupo 2 [BIA $(m=46,71 \pm 8,58)$ e DEXA $(m=43,22 \pm 8,29)]$. Estas diferenças não foram estatisticamente significativas (Quadro 5).

Os indivíduos do grupo 2 apresentaram médias de quilos de GO estimados pela BIA $(m=20,46 \pm 6,54)$ e pela DEXA $(m=23,27 \pm 5,97)$ maiores do que o grupo 1 [BIA $(m=19,71 \pm 10,51)$ e DEXA $(m=22,60 \pm 11,15)]$. Estas diferenças não foram estatisticamente significativas (Quadro 5).

Quadro 5. Número de indivíduos (N), médias, desvios-padrão (D.P) e intervalo de confiança (I.C.) da MM (kg) e GO (kg) estimados pela BIA e pela DEXA dos idosos estudados, segundo o sexo e grupo etário, SP - 2004.

\begin{tabular}{|lccccccc|}
\hline Variáveis & Grupo & N & Médias & D.P & lim. inferior & lim. superior & Valor de p \\
\hline BIO MM & 1 & 19 & 48,52 & 7,67 & 37,10 & 67,80 & 0,49 \\
& 2 & 21 & 46,71 & 8,58 & 32,50 & 64,80 & \\
DEXAMM & 1 & 19 & 44,75 & 8,95 & 34,25 & 64,98 & 0,57 \\
& 2 & 21 & 43,22 & 8,29 & 27,38 & 61,30 & \\
BIA GO & 1 & 19 & 19,71 & 10,52 & 6,70 & 39,50 & 0,78 \\
& 2 & 21 & 20,46 & 6,54 & 8,50 & 32,00 & \\
DEXA GO & 1 & 19 & 22,60 & 11,15 & 6,10 & 43,00 & 0,81 \\
& 2 & 21 & 23,27 & 5,97 & 13,2 & 31,1 & \\
\hline
\end{tabular}


Foi também realizada uma análise das variáveis estudadas em relação ao sexo e aos grupos etários estudados (análise conjunta). Não foram encontradas diferenças estatisticamente significativas.

\subsection{Teste de distribuição normal}

A partir da utilização do teste de Shapiro-Wilk (sw), foi possível verificar que as variáveis estudadas apresentavam distribuição aproximadamente normal $(p<5 \%)$.

As figuras 4 e 5 apresentam os histogramas dos valores de MM em quilos estimadas pela BIA e pela DEXA.

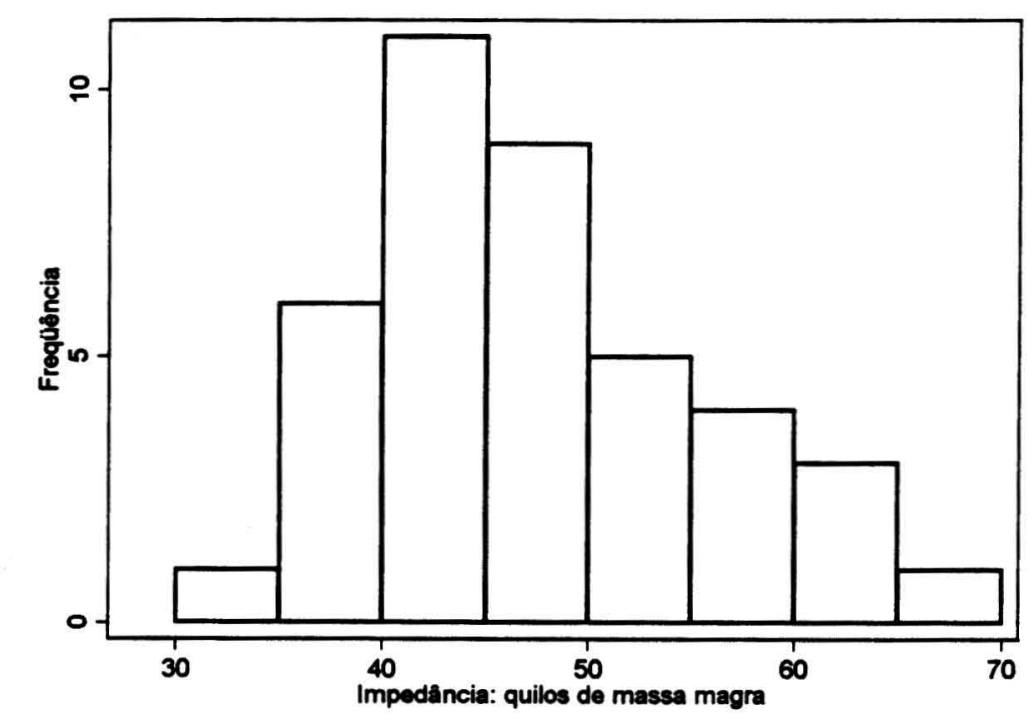

$(s w=0,96 ; p=0,02)$

Figura 4. Histograma da MM em quilos, estimada pela BIA 


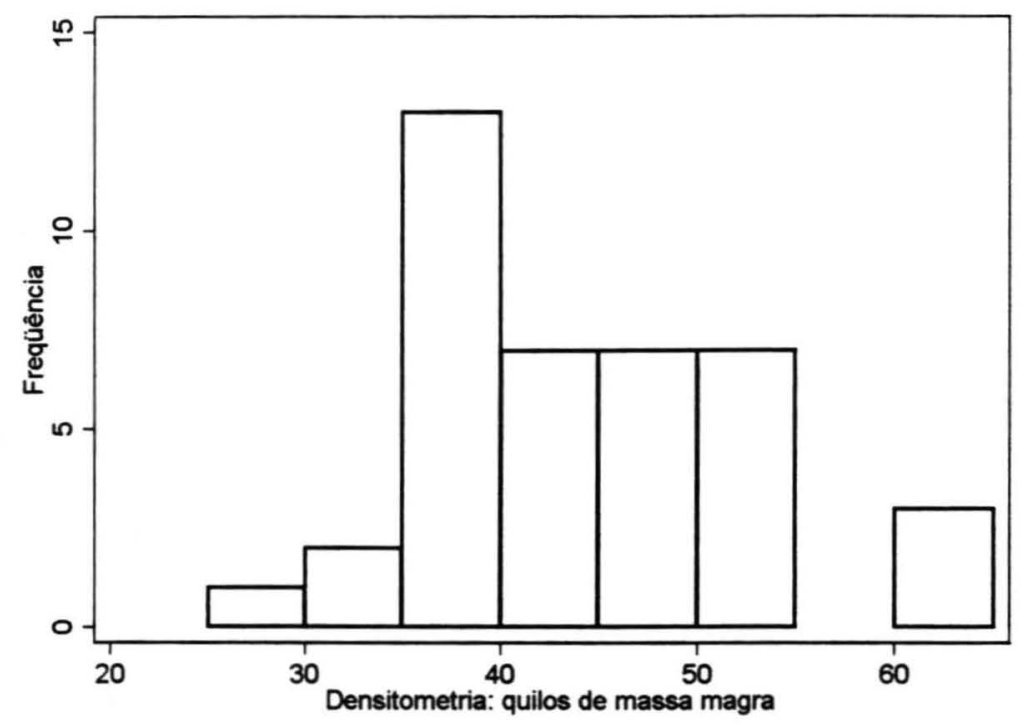

$(s w=0,96 ; p=0,03)$

Figura 5. Histograma da MM em quilos, estimada pela DEXA

As figuras 6 e 7 apresentam os histogramas dos valores de GO em quilos estimadas pela BIA e pela DEXA.

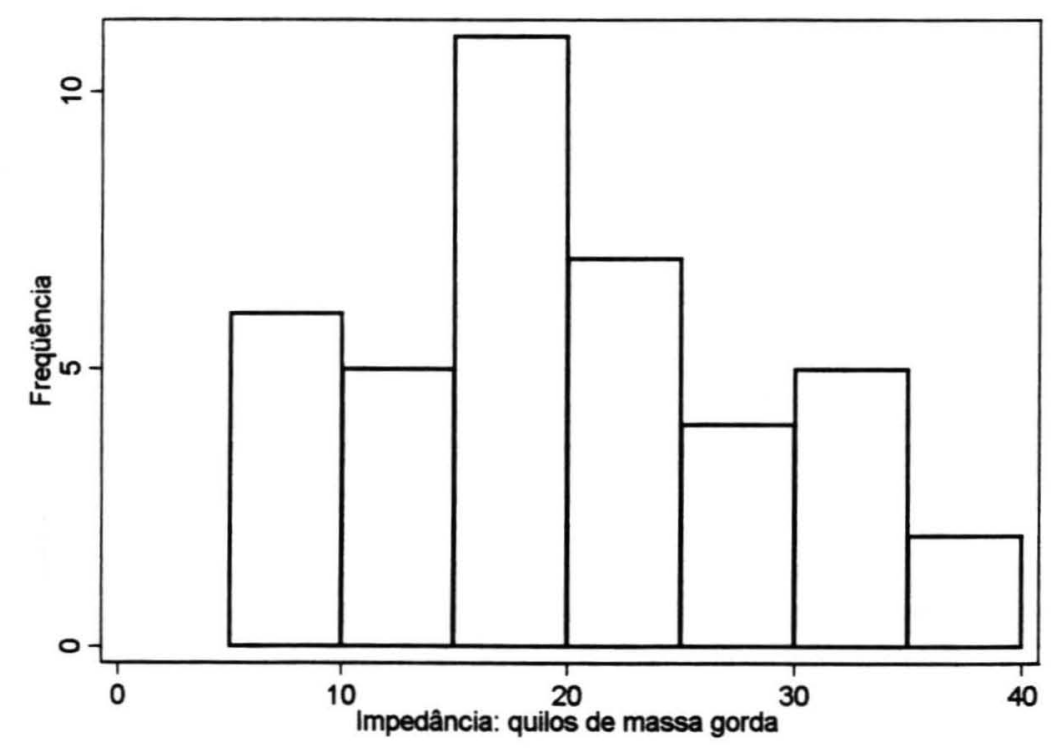

$(s w=0,96 ; p=0,02)$

Figura 6. Histograma da GO em quilos, estimada pela BIA 


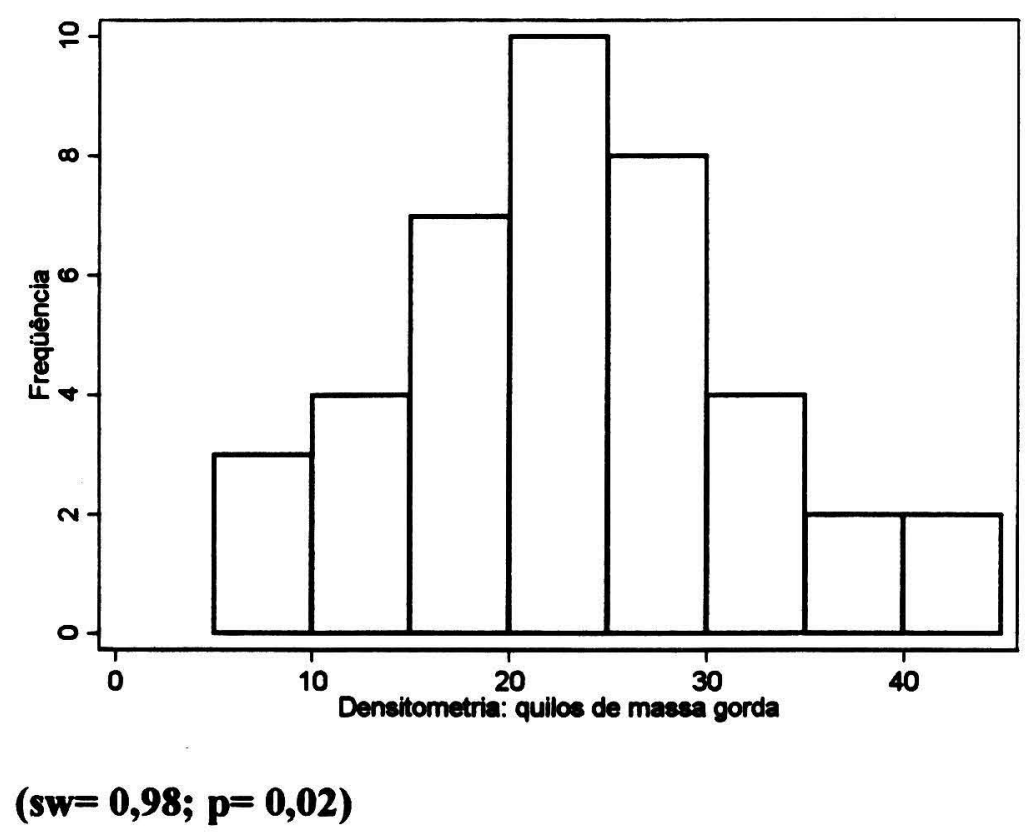

Figura 7. Histograma da GO em quilos, estimada pela DEXA.

\subsection{Descrição conjunta das variáveis estudadas}

Com o intuito de avaliar o comportamento conjunto das variáveis estudadas, foi apresentado o gráfico de dispersão com o valor do Coeficiente de Correlação de Pearson. Encontrou-se correlação positiva entre os valores de MM determinados pela BIA e os valores de MM estimadas pela DEXA. $(r=0,91 ; p<0,001)$ (Figura 8). 


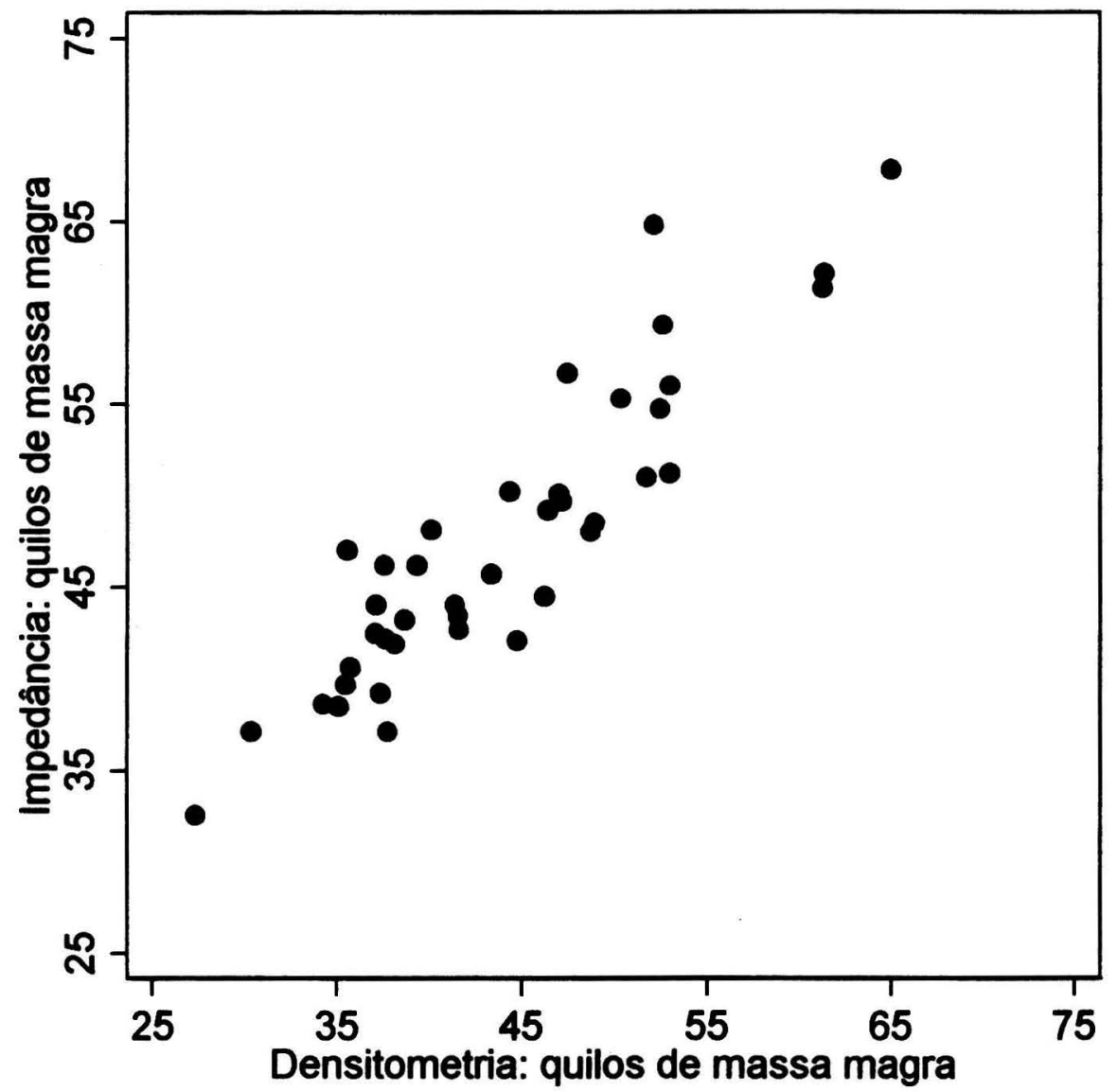

Figura 8. Gráfico de dispersão de MM estimada pela BIA e pela DEXA.

Observou-se também, que houve correlação positiva entre os valores de GO estimadas pela BIA e os valores de GO estimadas pela DEXA $(r=0,92 ; p<0,01)$ (Figura 9). 


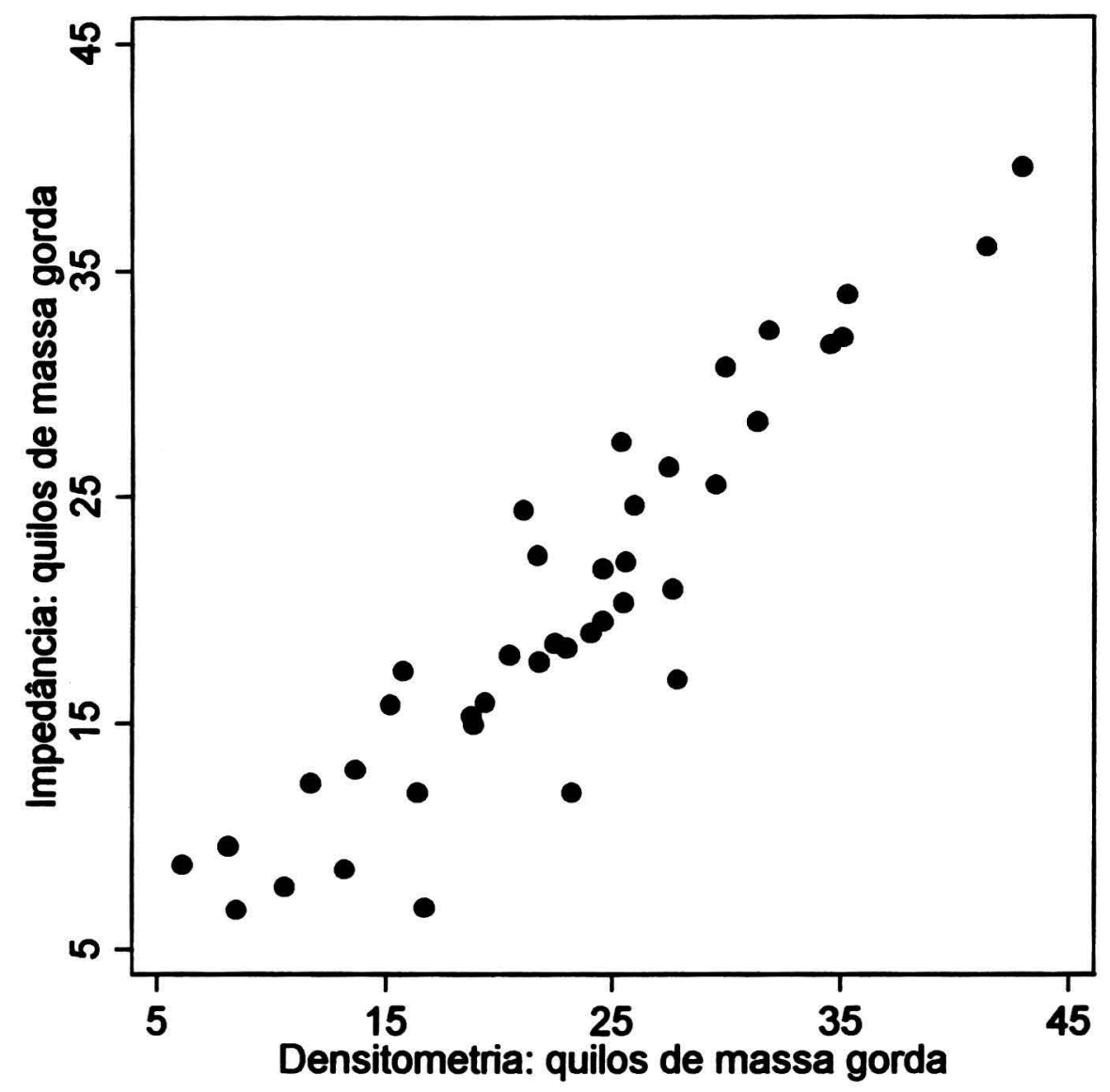

Figura 9. Gráfico de dispersão de GO estimada pela BIA e pela DEXA.

5.5 Análise de Concordância entre os métodos de BIA e DEXA

\subsubsection{Coeficiente de concordância/Correlação - CCC}

Com o objetivo de verificar a variabilidade entre os dois métodos analisados (BIA e DEXA), foi utilizado o Coeficiente de Concordância/Correlação - CCC (Lin, 1989). Estas análises foram apresentados respectivamente nos Quadro 6 e 7. 
Foi possível verificar concordância na determinação da MM (em quilos) entre BIA e DEXA $(C C C=0,83 ; p=0,001)$. A Figura 10 apresenta a demonstração gráfica desta análise, na qual é possível verificar que os pontos estão posicionados, em sua maioria, acima da linha de concordância total.

Quadro 6. Coeficiente de concordância/correlação da MM (kg) entre a BIA e a DEXA

\begin{tabular}{|c|c|c|c|c|}
\hline & & \multicolumn{2}{|c|}{ Limite de concordância 95\% } & \multirow{2}{*}{. } \\
\cline { 3 - 5 } CCC & $\mathbf{N}$ & Limite inferior & Limite superior & Valor de p \\
\hline 0,829 & 40 & 0,742 & 0,916 & 0,001 \\
\hline
\end{tabular}




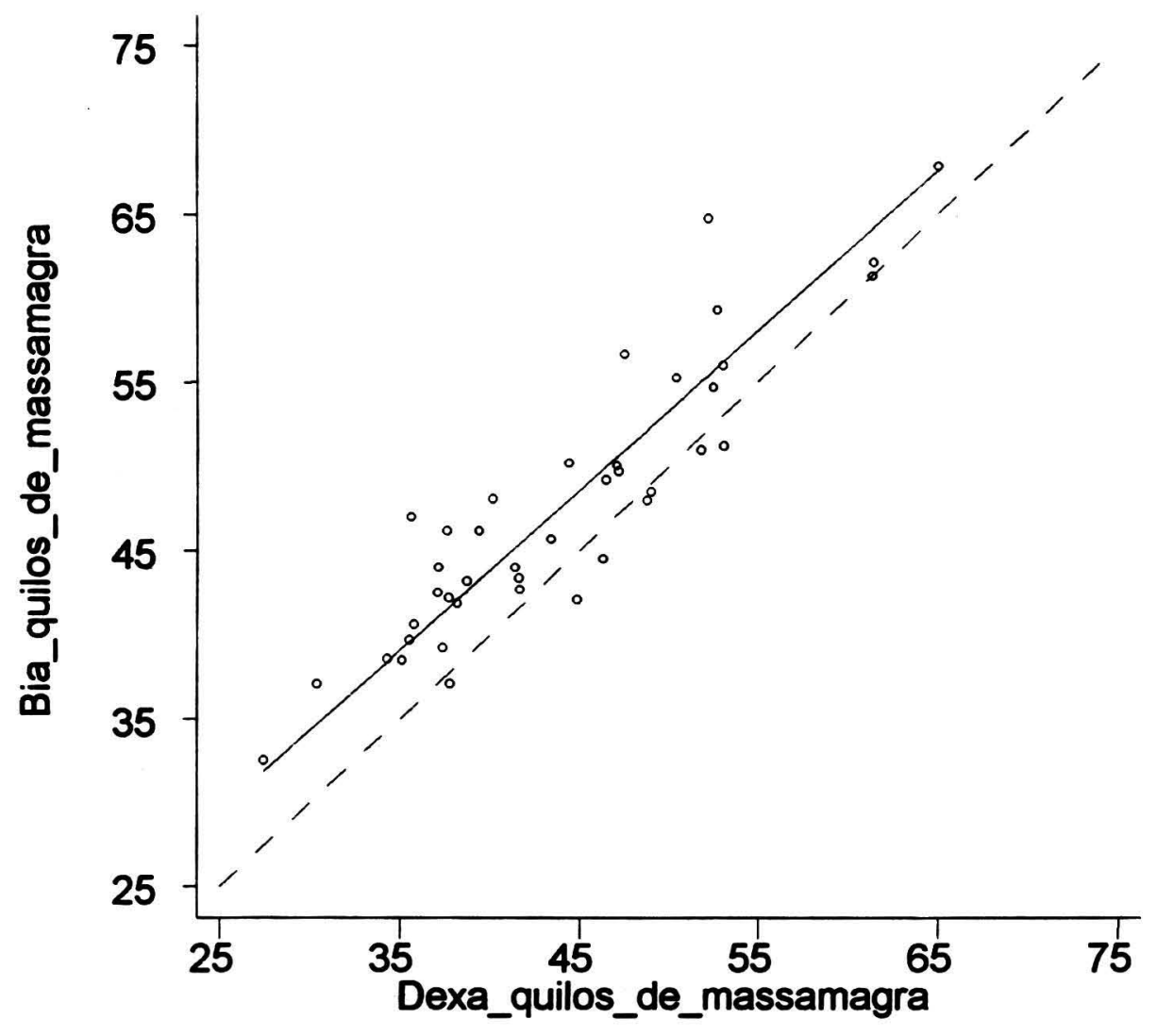

Figura 10. Coeficiente de concordância/correlação de MM (kg) estimada pela BIA e pela DEXA

Foi constatada concordância na determinação da GO (kg) entre a BIA e a DEXA $(C C C=0,88 ; p=0,001)$. A Figura 11 apresenta a demonstração gráfica desta análise, na qual é possível verificar que os pontos estão posicionados, em sua maioria, abaixo da linha de concordância total. 
Quadro 7. Coeficiente de concordância/correlação da GO em quilos entre a BIA e a DEXA

\begin{tabular}{|c|c|c|c|c|}
\hline \multirow{2}{*}{ CCC } & & \multicolumn{2}{|c|}{ Limite de concordâneia 95\% } & \multirow{2}{*}{} \\
\cline { 3 - 5 } & $\mathbf{N}$ & Limite inferior & Limite superior & Valor de p \\
\hline 0,875 & 40 & 0,806 & 0,944 & 0,001 \\
\hline
\end{tabular}

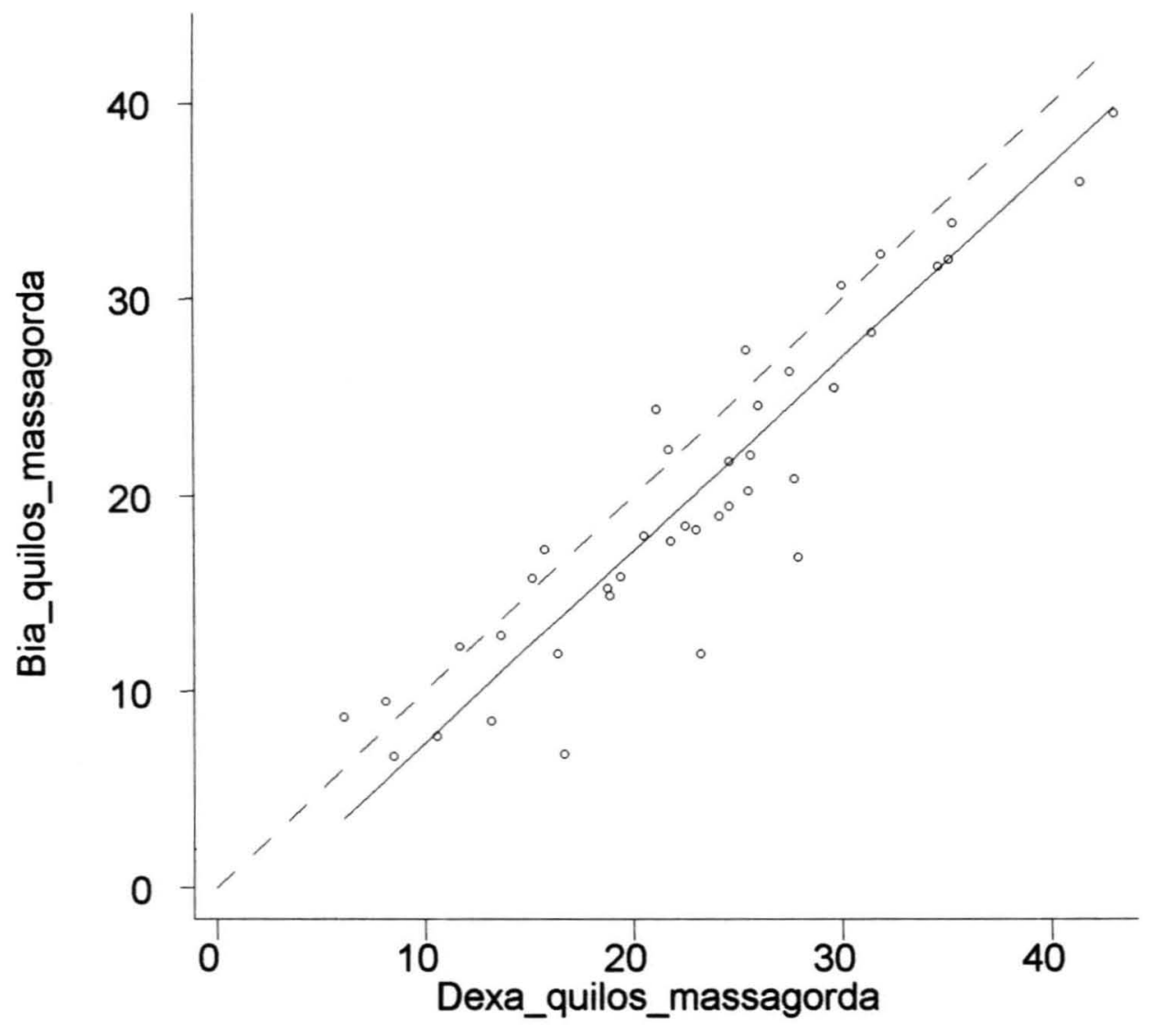

Figura 11. Coeficiente de concordância/correlação da GO (kg) estimadas pela BIA e pela DEXA. 


\subsubsection{Gráficos de Bland-Altman}

Para avaliar a concordância entre os dois métodos, foi utilizado o procedimento de Bland e Altman (1986). A análise da MM e da GO pelos 2 métodos avaliados estão apresentados, respectivamente, nos Quadros 8 e 9.

A Figura 12 apresenta a média da diferença entre os valores de MM obtidos pela DEXA e pela BIA. Encontrou-se o valor da $m=3,63$ e d.p. $=3,54$ (limite de concordância $95 \%$ foi de $-3,30 ; 10,56$ ). Pode-se observar que a BIA superestima os valores médios de MM em relação à DEXA.

$\mathrm{Na}$ figura 12, verificam-se 2 observações acima do limite de concordância superior. Os demais encontram-se entre os limites de concordância 95 \%. Nota-se também uma assimetria na distribuição das observações. 


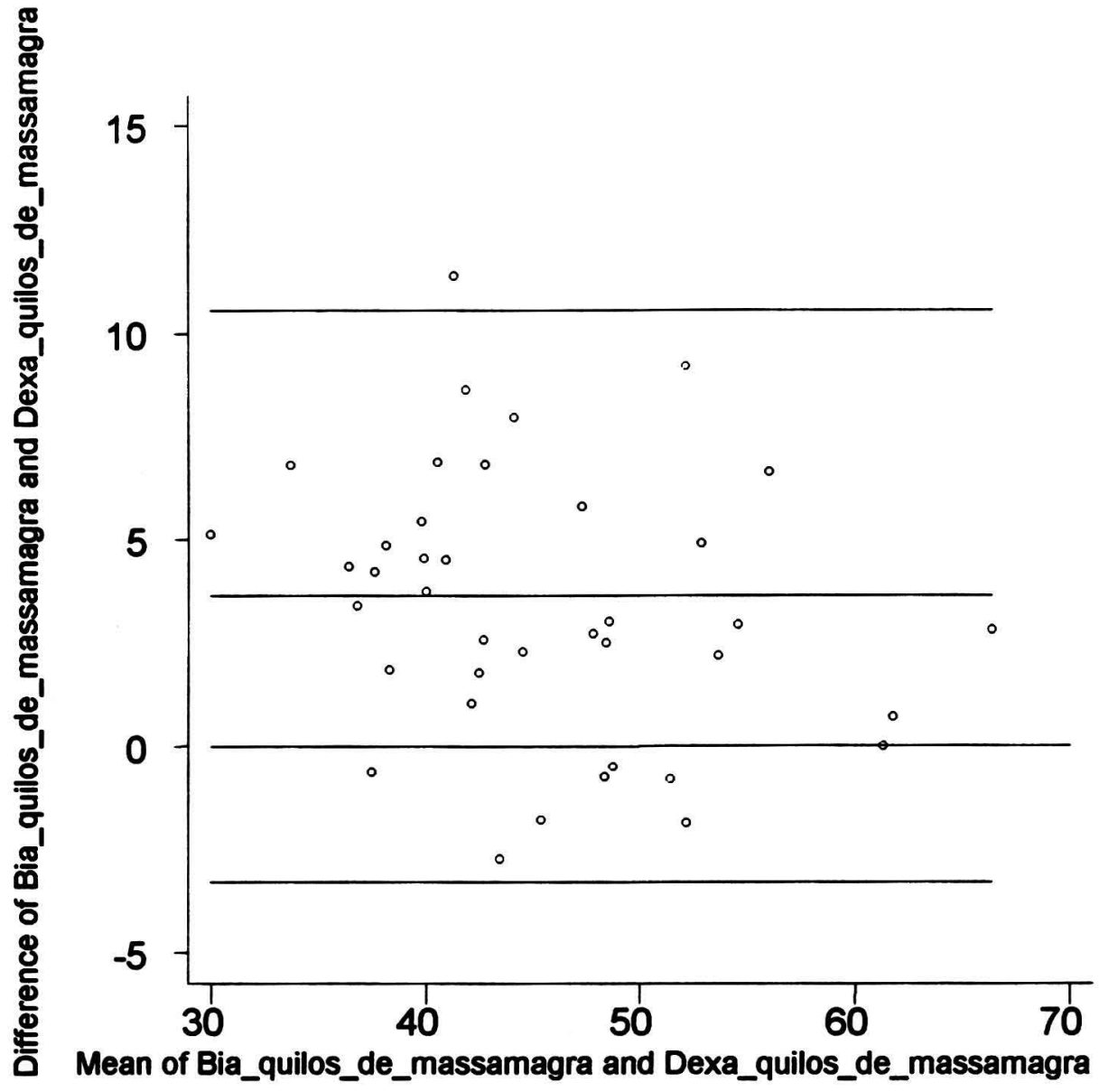

Figura 12. Concordância entre as estimativas de MM pela BIA e pela DEXA. 0 eixo horizontal (x) mostra a média de MM obtida pelos dois métodos, o eixo vertical (y) as diferenças entre os valores de MM obtidos pelos dois métodos.

A Figura 13 apresenta a média da diferença entre os valores de GO obtidas pela DEXA e BIA. Encontrou-se o valor da $m=-2,85$ e d.p.=3,37 (limites de confiança $95 \%$ : $-9,46 ; 3,76)$. Pode-se observar que a BIA subestima os valores médios de GO em relação a DEXA. 
Na figura 13, verificam-se 3 observações abaixo do limite de concordância inferior. Os demais encontram-se entre os limites de concordância de $95 \%$. Nota-se também uma assimetria na distribuição das observações.

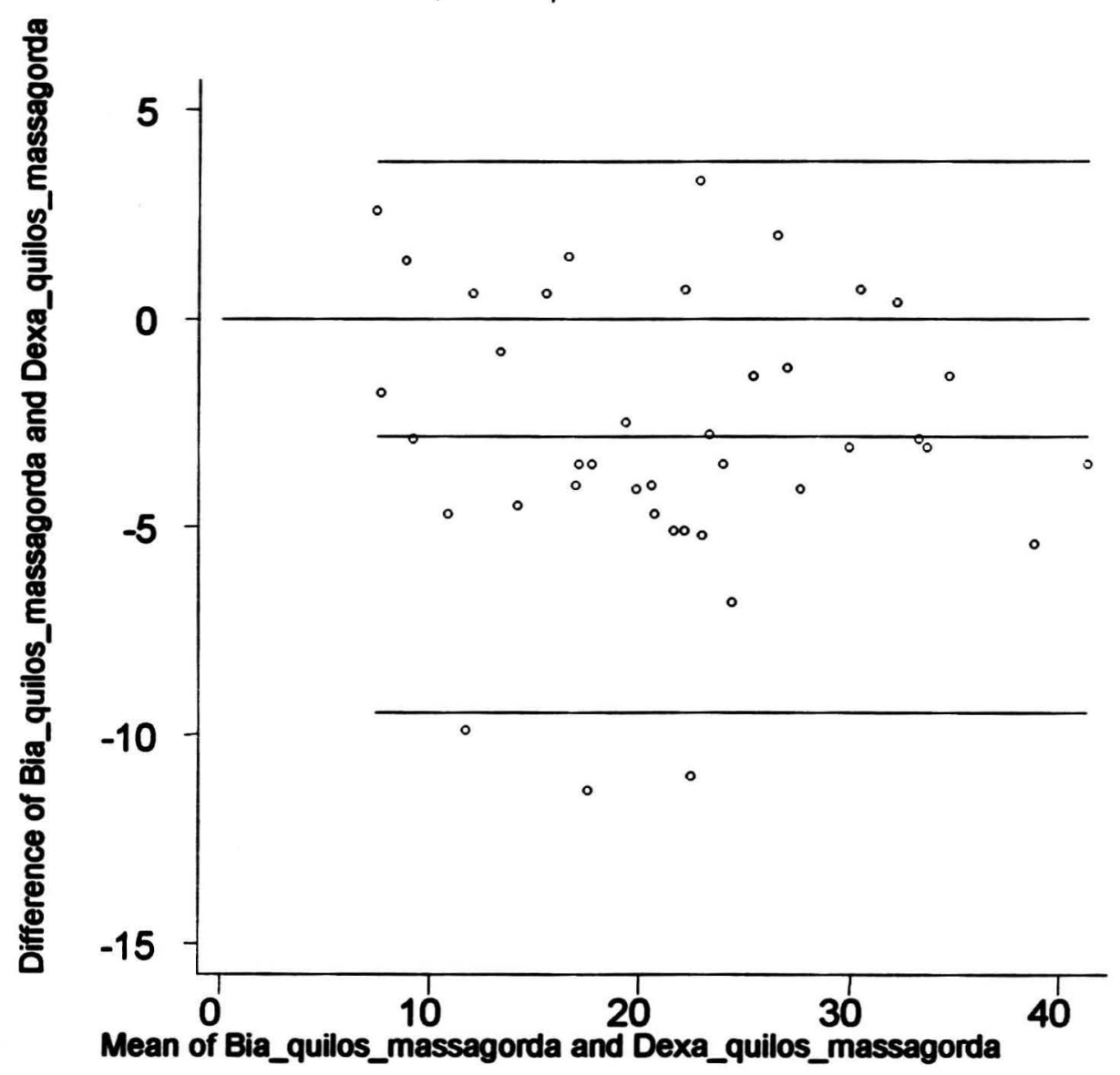

Figura 13. Concordância entre as estimativas de GO pela BIA e pela DEXA. 0 eiro horizontal (x) mostra a média de GO obtida pelos dois métodos, o eiro vertical (y) as diferenças entre os valores de MM obtidos pelos os dois métodos. 


\subsection{Teste de diferença entre as médias}

\subsubsection{Teste t pareado}

Utilizando o teste $t$ pareado $(t)$, verificou-se que houve diferença significativa entre a média da MM estimada pela BIA e pela DEXA $(t=6,49 ; p=0,001)$. Portanto, a BIA e a DEXA apresentaram valores diferentes para MM.

Constatou-se, também, que houve diferença significativa entre a média da GO estimada pela BIA e pela DEXA $(t=-5,35 ; p=0,001)$. Portanto, a BIA e a DEXA apresentaram valores diferentes para GO.

\subsubsection{Teste t pareado em relação ao sexo}

Quando foi realizado o teste t pareado em relação ao sexo, observou-se que houve diferença significativa entre a média da $\mathrm{MM}$ estimada pela $\operatorname{BIA}(t=6,46$; $p=0,001)$ e pela $\operatorname{DEXA}(t=7,11 ; p=0,001)$. Contudo não houve diferença significativa entre a média da $G 0$ estimada pela BIA $(t=-1,23 ; p=0,23)$ e pela $\operatorname{DEXA}(\mathrm{t}=-1,54 ; \mathrm{p}=0,13)$ 


\subsubsection{Teste t pareado em relação a idade}

Foi realizada também a análise em relação à idade, observando-se que não houve diferença significativa entre a média da MM estimada pela BIA $(t=0,69$; $p=0,49)$ e pela DEXA $(t=0,56 ; p=0,58)$. Verificou-se também que, não houve diferença significativa entre a média da GO estimada pela BIA $(t=-0,28 ; p=0,78)$ e pela DEXA $(t=-0,24: p=0,81)$.

\subsection{Regressão Linear}

Inicialmente, foi realizada uma análise das diferenças das médias das variáveis. Este recurso teve como objetivo verificar quais variáveis fariam parte do modelo (Quadro 8)

Em relação ao sexo, verificou-se que houve diferença estatisticamente significativa com a variável BIA MM $(\mathrm{p}<0,001)$ e com a DEXA MM $(\mathrm{p}<0,001)$. Contudo, não houve diferença estatisticamente significativa com a variável BIA GO e a variável DEXA GO.

Quando se realizou a análise em relação à idade, não houve diferença estatisticamente significativa com nenhuma variável (Quadro 8). 
Quadro 8. MM (kg) e GO (kg) estimados pela BIA e DEXA em relação ao sexo e à idade

\begin{tabular}{|l|c|}
\hline \multicolumn{1}{|c|}{ VARIÁVEIS } & Valor de $\mathrm{p}$ \\
\hline BIA MM E SEXO & 0,001 \\
\hline DEXA MM E SEXO & 0,001 \\
\hline BIA GO E SEXO & 0,225 \\
\hline BIA GO E SEXO & 0,133 \\
\hline BIA MM E IDADE & 0,150 \\
\hline DEXA MM E IDADE & 0,183 \\
\hline BIA GO E IDADE & 0,719 \\
\hline DEXA GO E IDADE & 0,728 \\
\hline
\end{tabular}

Com base no Quadro 8, optou-se por construir dois modelos: um para Massa Magra e outro para Gordura.

Primeiro, realizou-se análise do modelo de regressão para avaliar a existência de uma equação que pudesse converter um valor de BIA - quilos de MM (variável independente) em valor de DEXA - quilos de MM (variável dependente) dentro de uma margem aceitável (Quadro 9).

Quadro 9. Análise univariada de regressão linear da BIA (quilos de MM) com DEXA (quilos de MM).

\begin{tabular}{|c|c|c|c|c|c|c|}
\hline modelo & $\mathbf{R}$ & $\mathbf{R}^{2}$ & $\mathbf{P}$ (modelo) & Intercepto & Coeficiente & I,C.95\% \\
& & & & $(\boldsymbol{\beta 0})$ & $(\boldsymbol{\beta})$ & (Bi) \\
\hline BIA-MM & 0,91 & 0,83 & $<0,001$ & $-1,660$ & 0,959 & 0,$89 ; 1,03$ \\
\hline
\end{tabular}


Equação do modelo de regressão linear simples para MM

DEXA (quilos MM) $=-1,660+0,959$ BIA (quilos MM)

Para cada variação de $1 \mathrm{~kg}$ no valor de MM, estimada pela BIA, há variação de $0,959 \mathrm{~kg}$ nos valores de MM, estimados pela DEXA.

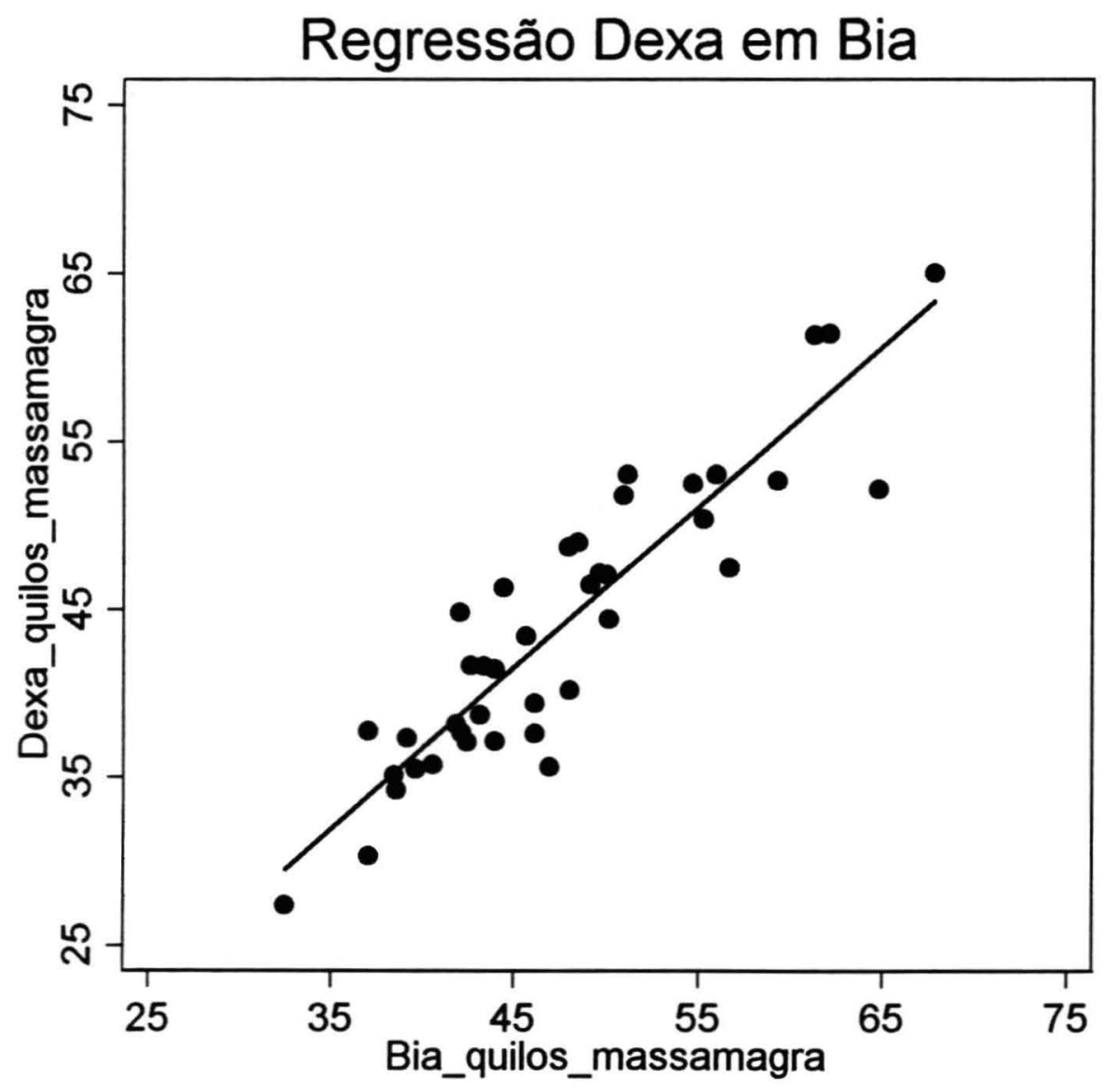

Figura 14. Gráfico de Regressão DEXA em BIA (MM) 
Foi desenvolvido um gráfico de Estimativas por Pontos (média) e intervalo de confiança (Figura 16).

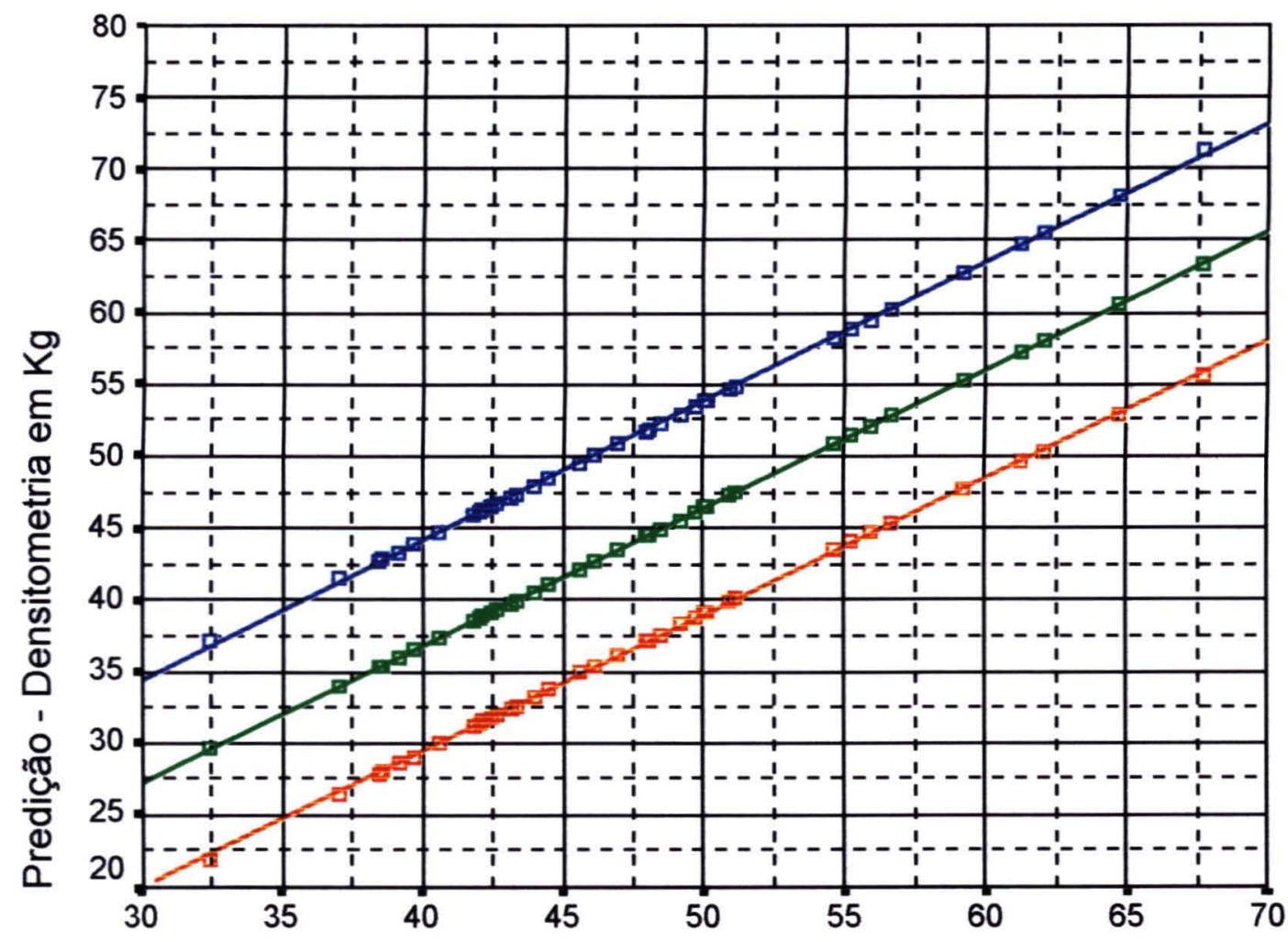

Bioimpedância em Kg

Figura 15. Predição de valor individual para quilos de MM. O eixo horizontal (x) mostra quilos de MM estimados pela BIA e o eixo vertical (y) mostra quilos de MM determinados pela DEXA

Posteriormente, desenvolveu-se análise do modelo de regressão para avaliar a existência de uma equação que pudesse converter um valor de BIA - quilos de GO (variável independente) em valor de DEXA - quilos de GO (variável dependente) dentro de uma margem aceitável (Quadro 10). 
Quadro 10. Análise univariada de regressão linear da BIA (quilos de GO) com DEXA (quilos de GO).

\begin{tabular}{|c|c|c|c|c|c|c|}
\hline modelo & $\mathbf{R}$ & $\mathbf{R}^{2}$ & $p($ modelo $)$ & $\begin{array}{l}\text { Intercepto } \\
(\boldsymbol{\beta} 0)\end{array}$ & $\begin{array}{c}\text { Coeficiente } \\
\text { (Bi) }\end{array}$ & $\begin{array}{l}\text { I.C. } 95 \% \\
\text { (Bi) }\end{array}$ \\
\hline BIA-GO & 0,92 & 0,85 & $<0,001$ & 4,063 & 0,940 & 0,$81 ; 1,07$ \\
\hline
\end{tabular}

Equação do modelo de regressão linear simples para GO

DEXA (quilos GO) $=4,063+0,940$ BIA (quilos GO)

Para cada variação de $1 \mathrm{~kg}$ no valor de GO, estimada pela BIA, há variação de $0,940 \mathrm{~kg}$ nos valores de GO, estimados pela DEXA 


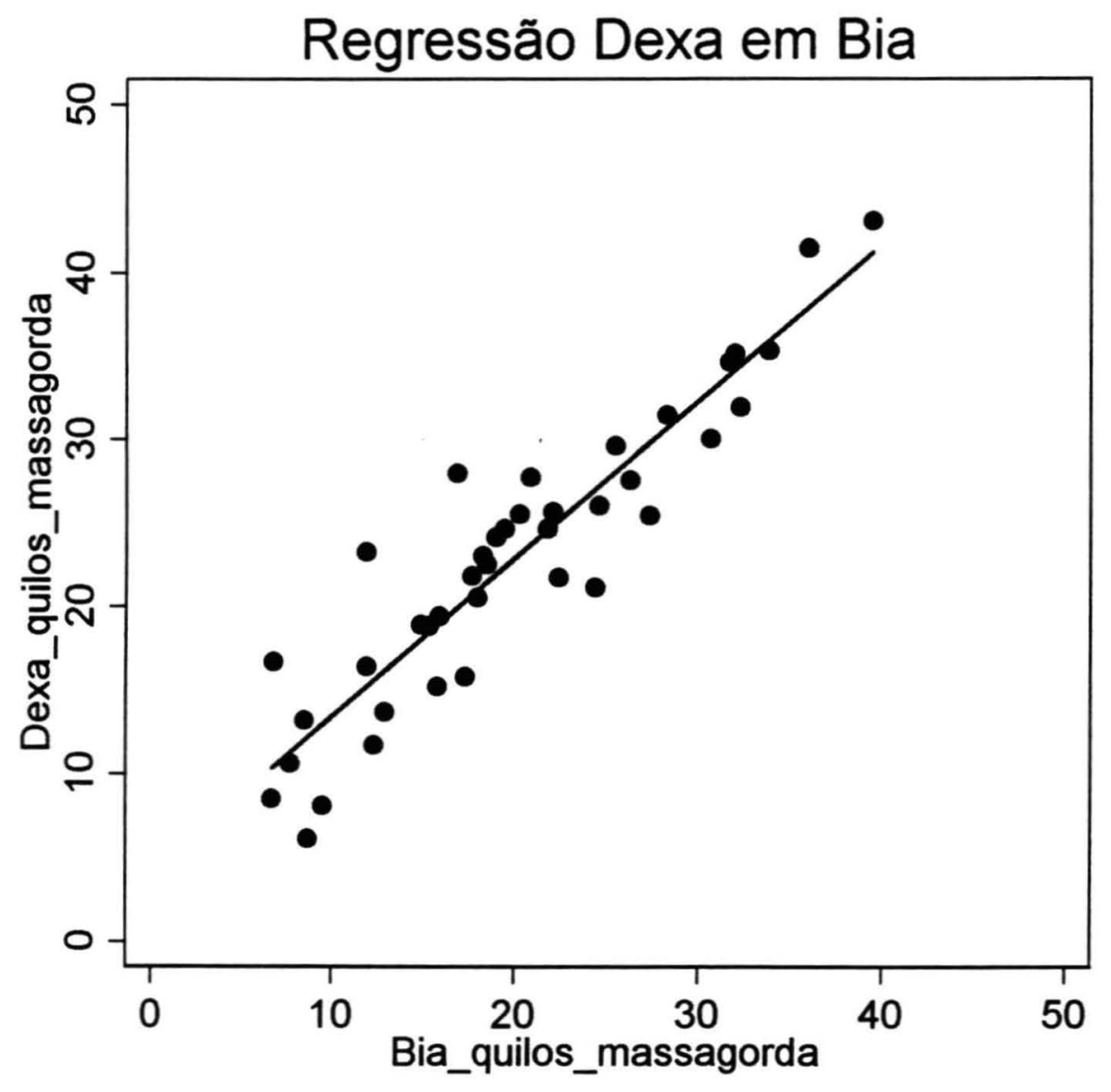

Figura 16. Gráfico de Regressão DEXA em BIA (GO)

Foi desenvolvido um gráfico de Estimativas por Pontos (média) - e intervalo de confiança (Figura 17). 


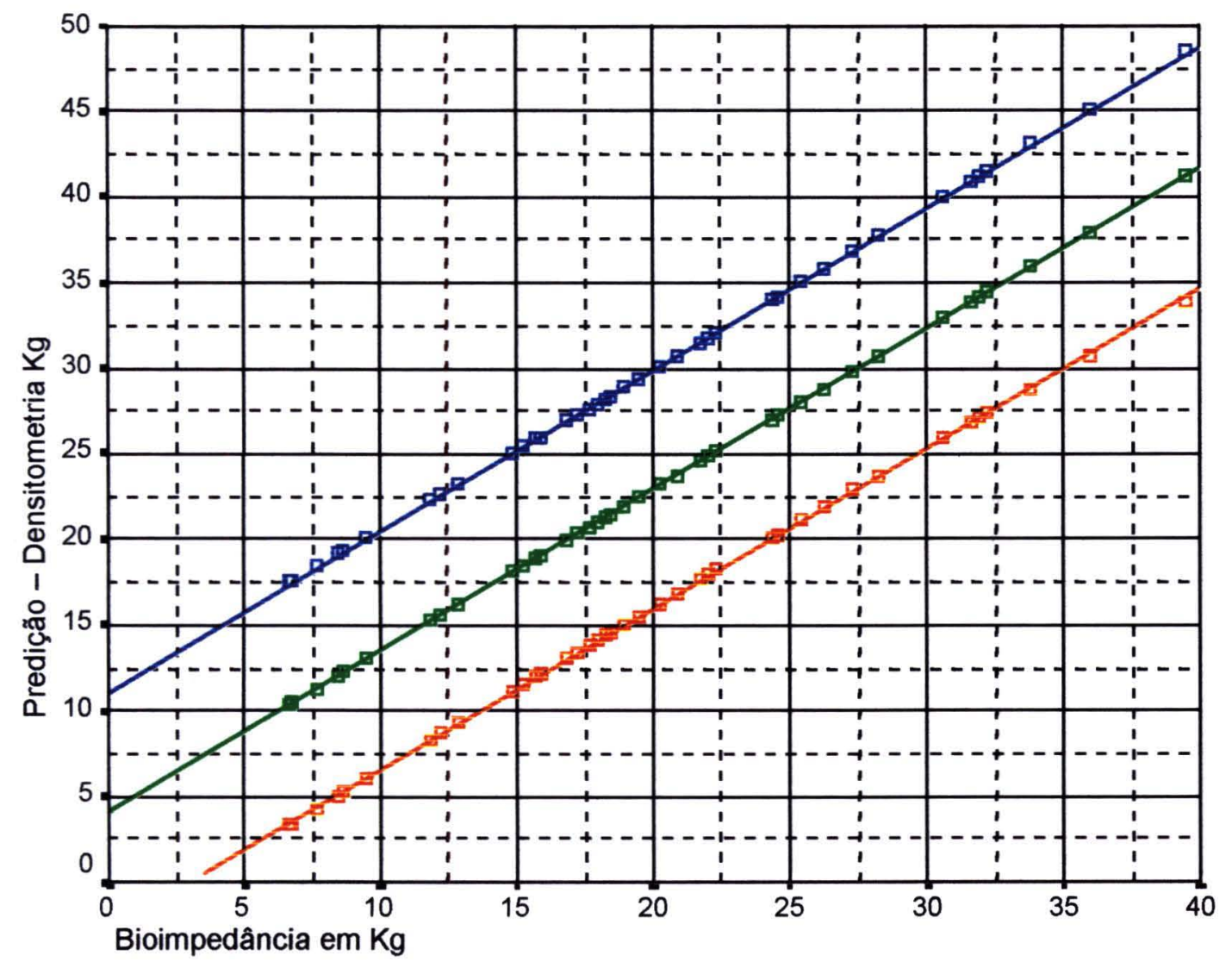

Figura 17. Predição de valor individual para quilos de GO. O eixo horizontal (x) mostra quilos de GO estimados pela BIA e o eixo vertical (y) mostra quilos de GO determinados pela DEXA 
Discussão 


\section{DISCUSSÃo}

O presente trabalho caracterizou-se por ser um estudo transversal e contribuiu para caracterizar a população estudada em relação à composição corporal e verificar a concordância entre os métodos da BIA e DEXA.

Os procedimentos para caracterizar o perfil dos indivíduos estudados foram realizados com a amostra analisada e com a amostra complementar, e foi verificado que eram semelhantes, ou seja, as diferenças entre as duas amostras não foram estatisticamente significativas.

Analisando os dados de caracterização da população estudada, observou-se que houve maior proporção de indivíduos do sexo feminino nas duas amostras estudadas (amostra analisada 65,0 \% e amostra inicial 63,3 \%) em relação ao sexo masculino.

Esta situação também foi verificada nos Relatórios Estatisticos do Ambulatório do HSPE, onde foi observado que $60 \%$ dos usuários assistidos pelo hospital são do sexo feminino (PRODESP, 1994).

Em outros estudos desenvolvidos no Serviço de Geriatria e Gerontologia, verificou-se proporção superior de mulheres $(85,50 \%)$ em relação aos homens (14,50\%) (NASCIMENTO e MARUCCI, 2004).

A maior participação de indivíduos do sexo feminino também foi verificada em outras pesquisas que envolveram indivíduos idosos (MARUCCI, 1992; NAJAS, 1995; FRANK et al., 1996).

Segundo vários autores, além das diferenças biológicas, como, por exemplo, o fator de proteção conferido pelo hormônio feminino em relação aos eventos cardiovasculares, há outras possiveis explicações que justificariam a longevidade 
feminina. Uma das principais diferenças refere-se à atitude das mulheres em relação à doença, pois fazem uso sempre mais freqüente dos serviços de saúde e sempre procuram informações sobre saúde, o que possivelmente leva a diagnósticos precoces e a tratamentos mais adequados (KATCH e MCARDLE, 1996; PASCHOAL, 1997, ACHUTTI E AZAMBUJA, 2004).

Quanto ao grupo etário, verificou-se que tanto na amostra analisada $(52,50 \%)$ como na amostra complementar $(69,20 \%)$, a maior parte dos indivíduos estudados se encontravam no grupo etário de 73 anos e mais.

$\mathrm{Na}$ pesquisa de Saúde- Bem Estar e Envelhecimento, desenvolvida no município de São Paulo, foram verificados resultados diferentes. As mulheres representaram $58,6 \%$ do universo estudado de idosos paulistanos e os homens, 41,4 \%. Isso nos dois grupos etários considerados (60-74 anos e 75 anos e mais). A estrutura etária das mulheres é mais envelhecida que a dos homens, pois, uma em cada quatro têm 75 anos ou mais, e no caso dos homens, essa proporção é de um para cada cinco (LEBRÃO, 2003a).

Analisando os demais dados de caracterização da população estudada, foi possivel observar neste trabalho a predominância de indivíduos da cor branca (amostra analisada $75,00 \%$ e amostra complementar $64,20 \%$ ) e aposentados (amostra analisada 52,50\% e amostra complementar 50,80\%).

O hospital no qual foi realizada esta pesquisa atende funcionários públicos e seus dependentes e, desde 2004, foi autorizada a assistência a agregados dos usuários assistidos. Em sua maioria estes dependentes e agregados são constituídos de familiares dos funcionários públicos aposentados e que não dispõem de assistência médica própria (PRODESP, 2004). 
Em relação à caracterização do estilo de vida, constatou-se que $57,5 \%$ dos idosos na amostra analisada e 56,70 \% na amostra complementar, afirmaram praticar algum tipo de atividade física. Foi verificado também que $90,00 \%$ dos idosos da amostra analisada e 95,00 \% na amostra complementar, não apresentavam o hábito de fumar; $80,00 \%$ dos idosos da amostra analisada e 85,80 \% na amostra complementar, não utilizavam qualquer tipo de bebida alcoólica.

Neste estudo, verificou-se, que em sua grande maioria, os idosos não apresentaram os principais fatores de risco externos que contribuem para 0 surgimento das várias enfermidades crônicas não transmissiveis.

A atividade física regular parece ter efeitos positivos em várias funções fisiológicas e vem sendo discutida em estudos e revisões como elemento fundamental na promoção da saúde dos indivíduos, proporcionando beneficios mesmo quando iniciada em idade avançada (BARBOSA et al., 2001). Desta forma a prática de atividade fisica proporciona beneficios que estão relacionados à melhora da qualidade de vida.

Essa prática ativa, inicialmente, a ação da musculatura esquelética que proporcionara adaptações secundárias nos sistemas respiratório, cardiovascular e neuro-endócrino entre outras. A sobrecarga imposta pela atividade fisica ao sistema cardiovascular permite observar os efeitos fisiológicos tanto agudos quanto crônicos (COSTA, 2004).

As mudanças no estilo de vida são fator de grande importância na promoção da saúde de idosos. Atenção tem sido dada aos fumantes passivos, uma vez que estudos têm demonstrado que eles também apresentam maior prevalência de eventos 
ateroscleróticos. Contudo, estudos observacionais indicam que a interrupção do fumo é benéfica para ambos os sexos e em todas os grupos etários (BERTOLAMI, 2002).

Em estudo realizado, com idosos, no município de São Paulo, foi possível constatar, semelhante a este trabalho, que independente da idade, $70,4 \%$ das mulheres idosas nunca fumaram e apenas $26,1 \%$ dos homens ofizeram (LEBRÃO, 2003b).

“As avaliações de saúde auto-referidas hoje não são mais consideradas meramente impressões relacionadas a condições reais de saúde. Muitos estudos recentes têm mostrado que os individuos que relatam condições de saúde escassa ou pobre têm riscos de mortalidade consistentemente mais altos que aqueles que reportam melhor estado de saúde" (IDLER e BENYAMINI, 1977).

Analisando o perfil de morbidade das duas amostras estudadas: amostra analisada e amostra complementar, constatou-se que os diagnósticos mais freqüentes foram respectivamente: HAS (67,50 \% e 70,8 \%), Obesidade (45,00 \% e 49,29 \%) e Diabete Melito (27,50 \% e 40,0 \%). Em relação à utilização de medicamentos, foi possível verificar que os idosos, nas duas amostras avaliadas, utilizavam com maior freqüência os seguintes medicamentos: anti-hipertensivos (72,50\% e 72,50 \%), hipolipemiantes ( $15,50 \%$ e $25 \%$ ) e hipoglicemiantes orais ( $10 \%$ e $20 \%$ ).

Em trabalho sobre o perfil nutricional de idosos freqüentadores de Associação Recreativa no Rio de Janeiro, foram estudados 50 idosos de ambos os sexos. Nessa pesquisa, foi possivel constatar que a hipertensão foi a enfermidade mais citada pelos idosos entrevistados, equivalendo a $36,0 \%$ do grupo, seguida da diabetes melito, relatada por $26,0 \%$ dos idosos. A hiperlipidemia, angina pectoris e isquemia foram 
citadas por $14,0 \%, 18,0 \%$ e 6,0 \% respectivamente. (MACHADO et al., 2004). Mostrando um perfil de morbidade muito semelhante a presente pesquisa.

LEBRÃO (2003b) verificou que a doença de maior prevalência foi "Pressão Alta" que atingiu 53,3 \%, sendo 56,3 \% e 49,9\%, respectivamente no sexos feminino e masculino. Trata-se de uma freqüência realmente alta e levando-se em conta o envelhecimento populacional é de se prever o aumento de recursos necessários para o tratamento e prevenção das complicações dessa doença na população.

A hipertensão arterial está normalmente associada com outros fatores de risco para doenças cardiovasculares, incluindo elevados niveis séricos de colesterol ,e é um achado prevalente entre os idosos ( $50 \%$ da mulheres acima dos 80 anos têm pressão arterial sistêmica de $160 \mathrm{mmHg}$ ). Concentrações sangüineas elevadas de colesterol são comuns entre idosos, $61 \%$ das mulheres entre 65 e 74 anos têm concentrações plasmáticas do colesterol total acima de $240 \mathrm{mg} / \mathrm{dl}$ (BECKETT et. al., 2000).

O envelhecimento pode ser acompanhado pelo aumento das concentrações plasmáticas de colesterol, o que eleva o risco de aterosclerose, doença cardiovascular e doenças endócrinas, entre elas o Diabetes (NORMANDO, 2000). Este aspecto aumenta a prescrição e a utilização de medicamentos que são indicados para controlar esses agravos (ALMEIDA, 2002).

Torna-se claro e evidente, mediante estas observações, que informações sobre os fatores de riscos oferecidos à saúde e o perfil de morbidade podem reduzir a incidência de muitas enfermidades responsáveis por transtornos irreparáveis entre os idosos. Considerando estes aspectos, informações sobre a composição corporal estão sendo considerados como parte essencial do controle de muitas patologias, 
permitindo assim intervenções nutricionais que possam amenizar ou prevenir complicações orgânicas que venham interferir na qualidade de vida dos idosos.

Os resultados de análises epidemiológicas indicam que a obesidade está associada ao aparecimento de eventos clínicos em particular a hipertensão arterial, distúrbios cardiovasculares e endócrinos. $\mathrm{O}$ ganho de peso agrava as alterações da composição corporal que ocorrem nesta fase da vida, como o declínio da massa muscular esquelética, o aumento do tecido adiposo e da gordura visceral. (GIANINNI, 1988).

Não há dúvida de que, com o avançar da idade, ocorrem alterações estruturais e funcionais. As doenças crônicas não transmissíveis, em particular as destacadas neste trabalho, podem interferir também em tais modificações. Sendo assim, torna-se tarefa fundamental dos profissionais da saúde direcionar suas ações para identificação e tratamento dos fatores de risco controláveis, incluindo a determinação das alterações na composição corporal dos indivíduos.

Avaliar o estado nutricional de idosos é uma atividade complexa, uma vez que existem dificuldades para distinguir as alterações orgânicas relacionadas ao envelhecimento daquelas decorrentes de doença, do consumo inadequado de alimentos e nutrientes, do estilo de vida sedentário, e do consumo de medicamentos que podem gerar interações indesejáveis com nutrientes (ACUNÃ e CRUZ, 2004).

- Informações sobre as modificações nos compartimentos corporais, particularmente, de massa magra e gordura, podem trazer benefícios no acompanhamento clínico, conduzindo a intervenções mais precisas (LUKASKI, 1993b). 
A avaliação nutricional pode ser realizada de várias formas. A antropometria é de relativo baixo custo e de făcil execução, podendo estimar a gordura subcutânea em determinados locais do corpo, de forma razoavelmente acurada (ACUNÃ e CRUZ, 2004). Contudo, alguns problemas como redistribuição e internalização da gordura subcutânea, espessura e elasticidade da pele, assim como atrofia dos adipócitos, podem contribuir para maior compressão entre gordura e a massa muscular, podendo afetar de forma significativa a confiabilidade das estimativas da massa magra e gordura corporal em indivíduos idosos (ALBALA et. al., 1994).

A BIA, apesar de apresentar custo mais elevado do que a antropometria, é um método de fácil aplicação, de alta reprodutibilidade e pode ser utilizado em estudos clínicos, embora fatores como posição do indivíduo, colocação dos eletrodos, temperatura ambiente, nível de hidratação e de atividade fisica, possam afetar essa medida. Todavia, alguns pesquisadores recomendam que seria fundamental estudar a utilização da BIA em individuos com idades mais avançadas (NELSON et al., 1996; DEURENBERG et al., 1989).

A DEXA é um método acurado e preciso para mensurar a massa magra e a gordura em estudos transversais e longitudinais. É também um método de alta reprodutibilidade, porém de custo elevado (SLOSMAM et al., 1992, LULASKI, 1993b).

Por todas essas razões optou-se verificar a concordância entre a BIA e a DEXA.

No presente estudo, foi possível verificar que as médias da MM estimadas pela BIA foram maiores do que as médias estimadas pela DEXA. Quando se avaliou a MM em relação ao sexo, observou-seque as médias estimadas pela BIA e DEXA 
foram maiores no sexo masculino. Essas diferenças foram estatisticamente significativas. Realizando a análise de MM em relação ao grupo etário, para os dois métodos, foi possivel constatar que as médias de MM foram maiores no grupo etário de 60 a 72 anos Estas diferenças não foram estatisticamente significativas.

As médias de GO estimadas pela DEXA foram maiores do que as médias estimadas pela BIA. Em relação ao sexo, foi possivel verificar que as médias de GO estimadas pela BIA e DEXA foram maiores no sexo feminino. Essas diferenças não foram estatisticamente significantes. $\mathrm{Na}$ análise da $\mathrm{GO}$, em relação ao grupo etário, para os dois métodos, foi possível verificar que as médias de GO foram maiores no grupo etário de 73 anos e mais. Estas diferenças não foram estatisticamente significativas.

Geneticamente, os homens apresentam proporção maior de MM e proporção menor de GO em comparação às mulheres; isto é, em condições controladas de idade, alimentação, atividade, raça, e outros fatores (MATSUDO et al. 2000).

No presente estudo, observou-se que a BIA superestima os valores de MM em relação à DEXA, provavelmente, porque a massa magra contém aproximadamente $73 \%$ de água e eletrólitos, portanto é melhor condutor de corrente elétrica do que a gordura. A gordura é anidra e má condutora de corrente elétrica. A BIA é medida em freqüência constante (de $50 \mathrm{Khz}$ ) e, portanto, reflete, principalmente, os valores de água e compartimentos musculares, ou seja a MM (KRUSHNER, 1992).

Da mesma forma, a MM é menor em grupos etários mais avançados, devido à mais baixa quantidade relativa de minerais e água. Com o envelhecimento, o conteúdo mineral relativo à $\mathrm{MM}$ diminui aproximadamente $1 \%$ ao ano entre os cinqüenta e setenta anos de idade (HEYMSFIELD et al., 1989). 
A DEXA tem alto grau de concordância com as estimativas de GO obtidas pela pesagem hidrostática. A proporção da GO é maior em idosos, pois ocorre uma redução de MM na velhice, e quando se estima a $\mathbf{G O}$ através de métodos de 2 compartimentos (tecido gorduroso e tecido livre de gordura), estes tendem a superestimar sistematicamente a gordura corporal nos dois sexos (BAUMGARTNER et. al., 1991).

Em estudo sobre avaliação da composição corporal, usando DEXA e BIA em uma amostra de 100 indivíduos adultos, assim como neste estudo foi observado que a DEXA em comparação com a BIA subestima os valores de MM e superestima os valores de GO (BOLANOWSKI, 2001).

Em outros estudos, foram encontrados resultados semelhantes a este estudo. (MAZARIEGOS et al., 1996)

ACUNÃ e CRUZ (2004) compilaram dados sobre alterações fisiológicas da composição corporal ocorridas durante o processo de envelhecimento. Os dados obtidos indicaram que, aos 60 anos, ocorre uma diminuição significativa de massa muscular seguida de um aumento gradativo no percentual de gordura corporal. Os homens perdem, aproximadamente $11 \mathrm{~kg}$ de massa muscular e as mulheres, aproximadamente $4 \mathrm{~kg}$.

Existem muitas maneiras de ilustrar as características da distribuição das frequêencias de um conjunto de dados. Neste trabalho, optou-se pelo histograma, para analisar visualmente, o comportamento das variáveis estudadas (BIA E DEXA). Verificou-se que essas variáveis apresentavam distribuição aproximadamente normal. 
Avaliando a descrição conjunta das variáveis estudadas, foi possível observar correlação entre a BIA e DEXA. Esses resultados foram estatisticamente significativos ( $p<0,001)$ e os gráficos de dispersão possibilitaram confirmar estes dados.

LERÁRIO, 2002, em estudo sobre comparação da antropometria, bioimpedância e densitometria como métodos de avaliação nutricional, analisou 61 pacientes com doença pulmonar obstrutiva crônica e verificou que os 3 métodos utilizados apresentaram alta correlação, estatisticamente significativa, na determinação da massa magra e da gordura.

A utilização do coeficiente de correlação não é apropriada para avaliar a concordância entre os dois métodos, visto que alta correlação pode não refletir alto nível de concordância. (BLAND e ALTMAN, 1986; WATTANAPENPAIBOON et al. 1998).

Para estudar a concordância, no presente estudo, foram utilizados o coeficiente de concordância/correlação de Lin (1989) e a técnica de Bland \& Altman (1986), para estimar o viés e o limite de concordância entre os dois métodos.

A partir das análises, foi verificada concordância entre os dois métodos avaliados: $\mathrm{CCC}$ da $\mathrm{MM}=0,83 ; \mathrm{p}<0,001$ e $\mathrm{CCC}$ da $\mathrm{GO}=0,88 ; \mathrm{p}<0,001$. Analisando o gráfico, foi possível observar que, em relação à $\mathrm{MM}$, os pontos estão distribuídos acima da linha de concordância total, podendo representar que BIA superestima os valores de MM estimadas pela DEXA (Figura 11). Em relação à GO, os pontos estão distribuídos abaixo da linha de concordância total, podendo representar que a BIA subestima os valores de GO estimadas pela DEXA (figura 12). 
A escolha do método de avaliação da composição corporal para pacientes idosos, não pode ser feita somente em relação à diferença das médias, mas também verificando a dispersão em que se encontram os indivíduos dentro do limite de concordância - $(95 \%)$ da análise de concordância. Neste estudo, observou-se que a BIA pode ser uma boa escolha para avaliar a MM e a GO em indivíduos idosos, considerando as suas limitações.

PICHARD (1997), BARBOSA et al. (2001) e LERÁRIO (2002), estudando grupos populacionais diferentes, verificaram resultados semelhantes com aeste trabalho em relação à concordância entre os métodos de BIA e DEXA.

Existem, na literatura, várias fórmulas para estimar os compartimentos corporais, sendo que algumas reconhecem o efeito do envelhecimento sobre a composição corporal e utilizam o sexo e a idade como variáveis na predição da MM e da GO (PICHARD et al., 1992, BAUMGARTNER et al., 1991, DEY et al., 2003).

No presente trabalho, quando se compararam as variáveis BIA e DEXA, com o sexo e a idade, não houve diferenças estatisticamente significativas. Este fato, provavelmente, está relacionado ao pequeno tamanho da amostra. Portanto, optou-se por realizar a análise de regressão sem as variáveis sexo e idade.

Foram desenvolvidos dois modelos de regressão: um para estimar a MM (kg) e outro para estimar a $\mathrm{GO}(\mathrm{kg})$.

As equações propostas possibilitam a conversão de um valor de MM ou GO estimadas pela BIA em DEXA dentro de uma margem aceitável. Portanto, mesmo se o aparelho de DEXA não estiver disponível para a realização do exame para estimar a composição corporal, esta poderá ser estimada pela BIA. 
Para BIA, foram desenvolvidas equações preditivas e validadas, baseadas em indivíduos caucasianos de países desenvolvidos. Pesquisadores têm sustentado, a necessidade de desenvolver métodos ou modelos para verificar a composição corporal, mais adaptado às diferenças no padrão de distribuição de $\mathrm{MM}$ e $\mathrm{GO}$, principalmente, em relação aos diferentes grupos etários, etnias e outras características. Existem raras referências da população brasileira para essas medidas, em indivíduos idosos (BARBOSA et al., 2002).

Portanto, as equações desenvolvidas neste trabalho permitem estimar, para populações com perfil semelhante, dois dos principais componentes corporais (MM e GO), através da BIA.

A BIA não depende de pessoal técnico especializado, é simples e não causa nenhum desconforto ao indivíduo, inclusive pelo fato de que o exame pode ser feito com o indivíduo vestido, em ambulatório, enfermaria ou outro ambiente.

A adoção dessa metodologia pode contribuir para o melhor conhecimento da composição corporal dos idosos, assim como na realização de diagnósticos mais precisos e na avaliação da conduta nutricional adotada..

É importante ressaltar que a amostra analisada nesse estudo não é populacional e, portanto não representa de forma genérica os idosos do município de São Paulo.

Esses aspectos, somados aos resultados encontrados neste estudo, poderão estimular o desenvolvimento de outros estudos para verificar as alterações na composição corporal que ocorrem durante o processo de envelhecimento. 
Conclusão 


\section{CONCLUSSÕES}

- A composição corporal (quilos de massa magra e de gordura) dos idosos, estimada pela impedância bioelétrica apresentou níveis de concordância aceitável com a densitometria.

- As equações de regressão propostas possibilitam estimar os valores de massa magra e gordura de indivíduos idosos, segundo densitometria, em função dos valores obtidos pela impedância bioelétrica:

Equação do modelo de regressão linear simples para MM

DEXA (quilos MM) $=-1,660+0,959$ BIA (quilos MM)

Para cada variação de $1 \mathrm{~kg}$ no valor de MM, estimada pela BIA, há variação de $0,959 \mathrm{~kg}$ nos valores de $M M$, estimados pela DEXA.

$>$ Equação do modelo de regressão linear simples

DEXA (quilos GO) $=4,063+0,940$ BIA (quilos GO) para GO

Para cada variação de $1 \mathrm{~kg}$ no valor de GO, estimada pela BIA, há variação de $0,940 \mathrm{~kg}$ nos valores de GO, estimados pela DEXA. 
Referências 


\title{
8. REFERÊNCIAS
}

Acunã K, Cruz T. Avaliação do estado nutricional de adultos e idosos e situação nutricional da população brasileira. Arq Bras Endocrionol Metab. 2004; 48, 3 junho.

Achutti A, Azambuja MI, Doenças crônicas não-transmissíveis no Brasil: repercussões do modelo de atenção à saúde sobre a seguridade social. Cienc Saúde Coletiva 2004; 9(4):833-840.

\begin{abstract}
Albala C, Yanes M, Salazar G, Vio F. Body composition in the elderly: total body water and anthropometry. Nutr Res 1994; 14 (12): 1789-809.
\end{abstract}

Barbosa AR, Santarém JM, Jacob Filho W, Meirelles ES, Marucci MFN. Comparação da gordura corporal de mulheres idosas segundo antropometria, bioimpedância e DEXA. Arch. Latinoam de Nutricion 2001; 41, 1.

Bland JM, Altman DG. Statistical methods for assessing agreement between two methods of clinical measurement. Lancet 1986; 1: 307-10.

Baumgartner RN, Heymsfield SB, Lichtman S, Wang J, Pierson Jr RN. Body composition in elderly people: effect of criterion estimates on predictive equations. Am J Clin Nutr 1991; 53: 1345 - 53. 
Beckett N, Junes M, Bulpitt C. Is it a advantageous to lower cholesterol in the elderly hypertensive? Cardiovascular Drugs 2000; 14(4): 397 - 405.

Bertolami MC. Fatores de risco para doença coronariana em idosos. In Borges J Manual de cardiogeriatria. Ed. Lemos, São Paulo; 45 - 55, 2002.

Cabreira M. Abordagem da obesidade em pacientes idosos. In: Jacob Filho W. Promoção da saúde do idoso. São Paulo: Lemos Editora: p 83-92, 1998.

Carpas E, Harman SM, Blackman MR. Human growth hormone and human aging. Endocrine Rev 1993; 14: 20-39.

Carvalho Filho ET. Fisiologia do envelhecimento. In: Papaléo Netto, $M$. Gerontologia. São Paulo: Editora Atheneu: p 60-76, 1997.

Carvalho JAM, Garcia RA. O envelhecimento da população brasileira: um enfoque demográfico. Cad Saúde Pública 2003; 19(3): 725-733.

Carvalho EB. Manual de Suporte Nutricional. Rio de Janeiro: Medsi, 1: 5-26, 1992.

Chaimowicz F. A saúde dos idosos brasileiros às vésperas do século $\mathrm{XXI}$ : problemas, projeções e alternativas, Rev Saúde Pública 1997; 31: 184 -200. 
Chumlea WC. Changes in anthropometric indices of body composition with age in a heath elderly population. A J Hum Biol 1989; 1:457-462.

Chumlea WC, Guo SS, Cockram DB, Siervogel RM. Mechanical and physiologic modifiers and bioelectrical impedance spectrum determinants of body composition. In: Bioelectrical Impedance Analysis. The Am J. Clin Nutr [Supplement] 1996; 64 - Number 3 (s): 413s- 422s.

Clevidence BA, Judd JT, Schatzkin A, Meusing RA, Camphekk WS, Brown CC, Taylor PR. Plasma lipid and lipoprotein concentration of men consuming a low-fat, high-fiber diet. Am J Clin Nutr1992; 55: 689 -694.

Costa ACB. Adesão de idosos coronariopatas crônicos estáveis a um programa de orientação para a prática domiciliar de atividade física. São Paulo, 2004.[Dissertação de mestrado Faculdade de Saúde Pública da USP]. 2004.

Costa MFFL, Guerra HL, Barreto SM, Guimarães RM. Diagnóstico da situação de saúde da população brasileira: um estudo da mortalidade e das internações hospitalares públicas. Informe epidemiológico SUS 20: 9(1):23-41,

Costa RF. Avaliação Física. São Paulo. Fitness Brasil Colletion, 1: 8-23,1996.

Costa RF. Avaliação da composição corporal (CD-ROM). Santos, FGA Multimidia, 1999. 
Curiati JAE, Alencar YMG. Nutrição e envelhecimento .In: Carvalho Filho ET, Papaléo Netto M. Geriatria: fundamentos, clínica e terapêutica. São Paulo: Atheneu, p.335-44, 1994.

Deurenberg P, Weststrate JA, Paymans I, Van Der Kooy K. Factors affecting bioelectrical impedance measurements in humans. Eur J Clin Nutr 1988; 42: 1017-22.

Deurenberg P, Van Der Kooy K, Evars P, Hulsof t. Is a adaptation of Siri's formula for the calculation for body fat percentage from body density in the elderly necessary ? Eur J Clin Nutr 1989; 43: 559-67.

Dey DK, Rothenberg E, Sundh V, Bosaeus I, Steen B. Height and body weight in the elderly. I. A 25-year longitudinal study of a population aged 70 to 95 years. Eur J Clin Nutr 1999; 53(12): 905-14.

Diaz RB. Adesão ao tratamento medicamentoso em pacientes idosos, In Papaléo Netto, M. Gerontologia. São Paulo: Editora Atheneu 1997; p 230-241.

Frank AA. Estudo antropométrico e dietético de idosos. Rio de Janeiro, 1996. [Dissertação de Mestrado Centro de Ciências da Saúde da UFR]]. 
Frank AA, Soares EA, Fernandes AD, Santimori E. Adequação de proteínas e lipídios na dieta de idosos. In: Frank AA, Soares EA. Nutrição no envelhecer. São Paulo Ed. Atheneu, 2:13-41,2002.

Frisancho AR, Anthropometric standards for the assessment of growth and nutrition status, $4^{\text {th }}$ ed. Michigan: ann Arbor, 1993.

Gama EV, Antalejo FR, Diaz AP, Orus PG, Martin JPM. Consumo de medicamentos en los ancianos resultados de un los ancianos resultados de un estudio problacional. Rer. Esp. Salud. Publica. 1998; 72: $209-19$.

Giannini SP. Obesidade e aterosclerose In: Aterosclerose e dislipidemia. BG Editora e produções culturais Ltda, 51-55. 1998.

Heymsfield SB, Wang J, Lichtman S, Kamen Y, Kehayias J, Pierson RN. Body composition in elderly subjects: a critical appraisal of clinical methodology. Am J Clin Nutr 1989 50: 1167-1175..

Heyward VH, Stolarazyk LM. Avaliação da composição corporal aplicada. Ed. Manole. p: 5-22, 2000.

Idler EL, Benyamini Y. "Self rated health and mortality: a review of twenty - seven community studies". J Health Soc Behav 1997; 38 (March) 21- 37. 
Jacob Filho W. Promoção da saúde do idoso: um desafio interdisciplinar. In: Jacob Filho W. Promoção da Saúde do idoso. São Paulo: Lemos Editora. p. 11 -18,1998.

Jekel JF, Elmore JG, Katz DL. Entendendo e reduzindo erros em medicina clínica. In: Epidemiologia, bioestatística e medicina preventiva, Artmed,: $100-112$, 1999.

Kasin SE. Dietary and anthropometric determinants of plasma lipoproteins during a long-term low-fat diet in healthy women. Am J Clin Nutr 199357: 146-154.

Katch FI, McArdle WD. Nutrição, exercício e saúde. $4^{\text {a }}$ ed. Rio de Janeiro. Medsi, 5:156-160, 1996.

Kleinbaum DG, Kupper LL. Applied regression analysis and other multivariable methods. North Scituate; MA Duxburry Press, 1978.

Kuczmarski MF, Kuczmarski RJ, Najjar M. Descriptive anthropometric reference data for older americans. J Am Diet Assoc 2000; 100: 59-6.

Kushner RF. Bioelectrical impedance analysis: a review of principles and applications. J Am Clin Nutr 1992;11: 199-209. 
Larsson EJ, Prado RR. Programa de avaliação corporal por bioimpedância. Manual do usuário CompCorp. CompCorp Ltda. Versão 2.4, s/d.

Lean MEJ, Han TS, Deurenberg P. Predicting body composition by densitometry from simple anthropometric measurements. Am J Clin Nutr 1997; 63: 4 -14.

Lebrão ML. $O$ projeto SABE em São Paulo. In Lebrão ML e Duarte YAO. SABE Saúde, bem estar e envelhecimento - 0 projeto SABE no municipio de São Paulo: uma abordagem inicial. Brasilia: Organização Pan- Americana da Saúde, 35 $-43 ; 2003$.

Lebrão ML b, Laurenti R. Condições de saúde. In Lebrão ML. SABE - Saúde, bem estar e envelhecimento - 0 projeto Sabe no município de São Paulo: uma abordagem inicial. Brasilia: Organização Pan- Americana da Saúde, 75 - 91;. 2003.

Lerário MC. Comparação da antropometria, bioimpedância e densitometria (DEXA) como métodos de avaliação nutricional e composição corporal em pacientes ambulatoriais portadores de doença pulmonar obstrutiva crônica DPOC. São Paulo, 2002 [Tese de Mestrado - Universidade Federal de São Paulo. Escola Paulista de Medicina Programa de Pós-Graduação em Reabilitação].

Lin LIK. A concordance correlation coefficient to evaluate reproducibility. Biometrics. 1989; 45, 255-268. March. 
Lukaski HCa, Johnson PE, Bolonchuk WW, Lyklen GI. Assessment of fat-free mass using bioelectrical impedance measurements of the human body. Am J Clin Nutr $1985 ; 41: 810-17$.

Lukaski $\mathrm{HC}_{\mathrm{b}}$. Soft tissue composition and bone mineral status. Evaluation by dualenergy X ray absorptiometry. J Nutr 1993 123: 438-443.

Machado JS, Souza VV, Vidal AT, Ramos FRM, Frank AA. Perfil nutricional de idosas freqüentadoras da associação recreativa de Copacabana, Rio de Janeiro. Nutrifĭo Brasil. 2004 -3(2): 85- 91.

Marcus R. Physical activity and regulation of bone mass. In: Favius MJ. Primer on the metabolic bone diseases and disorders of meneral metabolic. $3^{\text {rd }}$. Chicago: Lippincott-Raven 1996 p.254-256.

Marucci MFN. Aspectos nutricionais e hábitos alimentares de idosos, matriculados em ambulatório geriátrico. São Paulo, 1992 [Tese de DoutoradoFaculdade de Saúde Pública da USP].

Máttar JA. Bioimpedância, reactância e resistência: parâmetros biofísicos úteis em suporte nutricional e medicina intensiva. Medicus. Informação científica e serviços na área de saúde, 1995. 
Matsudo SM, Matsudo VKR, Barros Neto TL. Impacto do envelhecimento nas variáveis antropométricas, neuromotoras e metabólicas da aptidão fisica. Rev Bras Ciên Mov 2000; 8(4): 21-32.

Mazariegos M, Valdez C, Kraaij S, Van Setten C, Liurink C, Breuer K, Haskell M, Mendoza I, Solomons W, Deurenberg P. A comparison of body fat estimates using anthropometry and bioelectrical impedance analysiswith distinct prediction equations in elderly persons in the Republic of Guatemala. Nutr 1996; 12: 168 -175.

Mazes RB, Barden HS, Bisek JP, Hanson J, Dual-energy Xray absorptiometry totalbody and regional bone-mineral and soft-tissue composition. Am J Clin Nutr 1990 $51: 1 ; 1106-12$.

Monteiro JC. Obesidade: diagnóstico, métodos e fundamentos: In Harpern A, Matos AFG, Suplicy H, Mancini MC, Zanella MT. Obesidade; Ed. Lemos, p 31- 53, 1998.

Najas MS. Avaliação do estado nutricional de idosos a partir da utilização da medida do comprimento da perna "Knee Height"- como método preditivo da estatura. São Paulo, 1995. [Dissertação de Mestrado - Departamento de Medicina Preventiva da Universidade Federal de São Paulo].

Nascimento ML, Marucci MF. Relação cintura-quadril, niveis séricos de colesterol e fraçð̃es em adultos e idosos. Gerontologia 2004 12(1-2):22-27. 
National Institutes of Health. Technology Assessment Conference Statement. Bioelectrical Impedance Analysis In Body Composition Measurement; dec 12-14, 1994.

Nelson M, Fiatarone MA, Layne JE, Trice I, Ecônomos CD, Fielding RA, Pierson RN, Evans WJ. Analysis of body composition techniques and models for detecting change in soft tissue eigth strength training. Am J Clin Nutr. 1996; 63(5): p 678686.

Normando RM. Lipid levels. Applying the second national cholesterol education program. Report to geriatric medicine. Geriatrics 2000. 55(8): 48-53.

Papaléo Netto M, Ponte JR. Envelhecimento: desafio na transição do século In: Papaléo Netto M. Gerontologia: São Paulo. Atheneu p. 3-12, 1997.

Pascoal SMPa. Epidemiologia do envelhecimento. In: Papaléo Netto $\mathbf{M}$. Gerontologia; São Paulo. Atheneu p. 26-43, 1997.

Pascoal SMPb. Autonomia e independência. In: Papaléo Netto M. Gerontologia; São Paulo. Atheneu p. 313-323, 1997.

Pichard C. Body composition X ray absorptiometry and bioelectrical impedance in chronic respiratory insuficience. Nutr . 1997; 13: 952-958. 
[PRODESP] - Companhia de Processamentos de dados do Estado de São Paulo. Relatório sobre totalização de pacientes atendidos no ambulatório do HSPE - FMO de acordo com a especialidade sexo e faixa etária. São Paulo, 2004.

Prothro J. Protein and amino acid requirements of the elderly. Ann N Y Acad Sci 1989; 561: 143-56.

Riella MC. Suporte nutricional, parenteral e enteral. $2^{a}$ ed. Rio de Janeiro: Ed, Guanabara-Loogan, 1993.

Rousenbaum M. Obesity. N Engl J Med 1997; 337: 396-405.

Roubenoff R, Kehayias JJ, Dawson-Hughes B, Heymsfield SB. Use of dual energy X-ray absorptiometry in body composition studies: not yet a "gold standard". Am J Clin Nutr 1993; 58: 589-91..

Sampaio LR. Avaliação nutricional e envelhecimento. Rev. Nutr 2004; 17 (4): 507-514.

Schaefer EJ, Lichtenstein AH,Lamon-Fava S, Mc Namara JR, Schaefer MN, Rasmussen H, Ordorvas JM. Body weght and low-density lipoprotein of a low-fat ad libitum diet. JAMA 1995: 274: 1450 - 1455.

Schlenker ED. Nutrition in aging, 2nd ed. St. Louis: Mosby, 1993. 
Schols AMWJ, Wouters EFN, Soeters PB, Westerterp KR. Body composition by bioelectrical impedance analysis compared with deuterium dilution and skinfold anthropometry in patients with chronic obstructive pulmonary disease. Am J Clin Nutr 1991; 53: 421-4.

Slosman D, Casez JP, Pichard C, Rochat T, Fery F, Rizzoli R, Bonjour JP, Morabia A, Donath A. Assessment of whole-body composition with dual-energy X ray absorptiometry. Nutr 1992; 185:593-598.

Snyder PJ, Peachey H, Hannoush P. Effect of testosterone treatment, in body composition and muscle strength in man over 65 years of age. $\mathbf{J}$ Clin Endocrinol Metab 1999; 84: 67-73.

Steen B. Body composition and aging. Nutr Rev 1988; 46 (2).

Stuck AE, Walthert JM, Nikolaus T, Bula CJ, Hohmann C, Beck J.Risk factors for functional status decline in community-living elderly people: a systematic literature review. Soc Sci Med 1999; 48(4):445-69.

Svendesen OL, Haarbo J, Hassager C, Christiansen C. Accuracy of measurements of body composition by dual-energy X ray absorptiometry in vivo. Am J Clin 1993; 57: 605-8. 
Tagliabue A, Andreoli A, Comelli M, Bertoli S, Testollin G, Oriani G, De Lorenzo A. Prediction of lean body mass from multifrequency segmental impedance: influence of adiposity. Acta Diabetol 2001; 38 (2): 93 - 7.

Vieira S. Introdução à bioestatística. $2^{a}$ ed. Rio de Janeiro: Campus, 1991.

Wattanapenpaiboon N, Lukito W, Strauss BJG, Hsu-Hage BH-H, Wahlqvist ML, Stroud DB. Agreement of skinfold measurements and bioelectrical impedance analysis (BIA) methods with dual energy ray absorptiometry (DEXA) in estimating total fat in Anglo-Celtic Australians. Int J Obes.: 22, 854 -860, 1998.

World Health Organization Physical Status: The use and interpretation of anthropometry. Geneva; (who Tecnical Report Series, 854) 1995.

World Health Organization Introducing the WHOQOL instruments [online]. Available URL: http://www.who.int/msa/mnh/mhp/ql.htm [1999 Oct28]. 
Anexos 


\section{ANEXOS}

ANEXO 1

\section{Universidade de São Paulo}

Faculdade de Saúde Pública

COMITÊ DE ÉTICA-COEP

Av. Dr. Arnaldo, 715 - CEP 01246-904 - São Paulo - Brasil

Telefones: (55-11) 3066- 7734 - fone/fax (55-11) 3064 -7314 -e-mail: mdgracas@usp.br

\section{Of.COEP/244/02}

11 e setembro de 2002

Pelo presente, informo que o Comitê de Ética em Pesquisa da Faculdade de Saúde Pública da Universidade de São Paulo-COEP, analisou e aprovou, em sua $7^{\mathrm{a}} .02$, realizada em 10.09 .02 , de acordo com os requisitos da Resolução CNS/196/96, o Protocolo de Pesquisa n. ${ }^{\circ} 832$, intitulado: "AVALIAÇÃO DA COMPOSIÇÃO CORPORAL: DENSITOMETRIA E IMPEDÂNCIA BIOELÉTRICA EM ADULTOS E IDOSOS", apresentado pela pesquisadora Maria de Lourdes do Nascimento.

Atenciosamente,

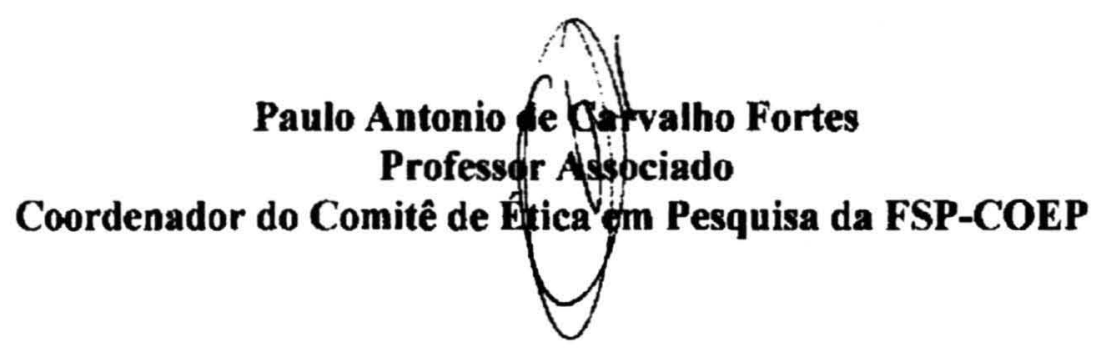




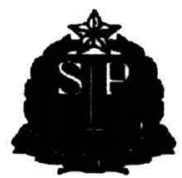

\author{
SECRETARIA DE ESTADO DA SAÚDE \\ INSTITUTO DE ASSISTÊNCIA MÉDICA AO SERVIDOR PÚBLICO ESTADUAL \\ Comitê de Ética em Pcsquisa - Av. Ihirspuera, 981 - $6^{\circ}$ andar - sL. 605 - SP \\ Fonea: 5088-8658 / 5088-8175 - FAX: 573.8854 - E-mail= ccniamsneca uol.com.hr
}

\title{
COMITÊ DE ÉTICA EM PESQUISA
}

Este Comitê de Ética em Pesquisa Aprova o Protocolo de Pesquisa registrado e arquivado junto ao CEP-HSPE sob o $\mathrm{n}^{\circ}$ 045/02.

Ref: "Avaliação da Composição Corporal: densitometria e impedância bioelétrica em adultos e idosos".

Investigador: Maria de Lourdes do Nascimento

Serviço: Geriatria

São Paulo, 18 de outubro de 2002.

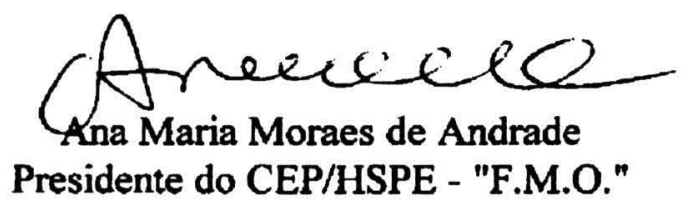


ANEXO 3

\section{HOSPITAL DO SERVIDOR PÚBLICO ESTADUAL "FRANCISCO MORATO DE OLIVEIRA" SERVIÇO DE GERIATRIA E GERONTOLOGIA}

\section{TERMO DE CONSENTIMENTO LIVRE E ESCLARECIDO}

Prezado(a) Senhor(a)

Com o objetivo de aprimorar nosso atendimento e prestar assistência de melhor qualidade aos indivíduos que são atendidos no ambulatório de Geriatria e Gerontologia deste hospital, estamos realizando um trabalho de pesquisa sob a responsabilidade da nutricionista Maria de Lourdes do Nascimento (doutoranda da Faculdade de Saúde Pública - USP) e da Profa. Dra. Maria de Fátima Nunes Marucci (Docente da Faculdade de Saúde Pública - USP)

Este estudo intitulado: "Avaliação da composição corporal: densitometria, impedância bioelétrica e antropometria em adultos e idosos", analisará as alterações que ocorrem nos compartimentos corporais devido ao processo de envelhecimento. Os três métodos que serão utilizados nesta pesquisa não causam qualquer espécie de dor ou desconforto e não acarretam nenhum prejuízo à sua saúde.

Preocupados com sua satisfação, solicitamos gentilmente seu consentimento para posteriormente publicarmos, os dados obtidos neste estudo o qual poderá contribuir para um maior conhecimento e atualização sobre o tema.

Garantimos o sigilo da identidade dos participantes deste estudo sendo que, em qualquer etapa da pesquisa, a sua participação poderá ser interrompida sem prejuízo para o seu atendimento, ou para o seu tratamento neste serviço.

São Paulo,

Assinatura do Cliente

Maria de Lourdes do Nascimento Nutricionista Responsável pelo estudo tel. para informações: 5088-8270 tel. Para reclamações: 5088-8332 
ANEXO 4

HOSPITAL DO SERVIDOR PÚBLICO ESTADUAL"FRANCISCO MORATO DE OLIVEIRA" SERVIÇO DE GERIATRIA E GERONTOLOGIA

ATENDIMENTO NUTRICIONAL

ESTUDO DA AVALIAÇÃO DA COMPOSIÇÃO CORPORAL

1- IDENTIFICAÇÃO

Nome:

Registro:

2- CARACTERIZAÇÃO

Sexo: Masculino $\square$ feminino $\square$

idade: ___ data de nascimento:

cor: branca $\square$ negra $\square$ amarela $\square$ parda $\square$ outras $\square$

Atividade ocupacional/profissão

\section{3- ESTILO DE VIDA}

\subsection{Atividade física}

Atualmente, pratica atividade física: $\square$ não $\square$ sim que tipo

Freqüência duração parcial: duração total:

3.2 Tabagismo

$\square$ não $\square$ sim quant/ freq: duração/período vida tipo:

3.3. Etilismo

$\square$ nåo $\square$ sim quant/freq: Tipo: duração/período vida 
4- PERFIL DE MORBIDADE

$\square$ HAS $\square$ Hipotiroidismo $\square$ Osteoporose $\square$ Desnutrição $\square$ Obesidade $\square$ Diabetes

Outros:

5- MEDICAMENTOS: $\square$ Diuréticos $\square$ Corticóides $\square$ Suplementos vitamínicos e minerais $\square$ Suplementos calóricos

Outros:

6- DADOS ANTROPOMÉTRICOS E DA IMPEDÂNCIA BIOELÉTRICA

Peso (kg): $1^{\circ}$ $2^{\circ}$

Estatura (cm): $1^{\circ}$ $2^{\circ}$

Res. (ohm):

Reac.(ohm): 
ANEXO 5

\section{Exame de Helena Rodrigues Ferreira}

\begin{tabular}{|lll|}
\hline Dados informados: & & \\
Data do exame: 16/02/2005 & Altura: $144,0 \mathrm{~cm}$ & Resistência: $523 \mathrm{ohm}$ \\
Sexo: Feminino & Peso: $75,0 \mathrm{Kg}$ & Reatância: $37 \mathrm{ohm}$ \\
Idade: $\pi$ anos & Nivel de Atividade Fisica: Leve & \\
\hline
\end{tabular}

\begin{tabular}{l}
\hline Dados calculados: \\
\begin{tabular}{|l|c|c|c|}
\hline & Peso atual & Percentagem atual & Percentagem ideal \\
\hline Agua corporal & $31,0 \mathrm{Kg}$ & $42 \%$ & de $50 \%$ a $60 \%$ \\
\hline Massa magra & $42,6 \mathrm{Kg}$ & $57 \%$ & de $69 \%$ a $78 \%$ \\
\hline Gordura corporal & $32,4 \mathrm{Kg}$ & $43 \%$ & de $22 \%$ a $31 \%$ \\
\hline
\end{tabular}
\end{tabular}

\begin{tabular}{|l|c|c|}
\hline & Valor atual & Valor ideal \\
\hline Peso & $75,0 \mathrm{Kg}$ & $56 \mathrm{Kg} \mathrm{a} 60 \mathrm{Kg}$ \\
Peso em gordura & $32,4 \mathrm{Kg}$ & $15 \mathrm{Kg}$ \\
Peso em massa magra & $42,6 \mathrm{Kg}$ & $43 \mathrm{Kg}$ \\
Relaçăo massa magra gordura & $1,3: 1$ & $2,2: 1$ ou maior \\
\hline
\end{tabular}

Gasto Energetico Basat: 1121 calorias

Diela Recomendada: 1200 calorias

Índice de Massa Corporal: $\quad 36,0 \mathrm{Kg} / \mathrm{m}^{2}$

Massa Celular: $\quad 14,5 \mathrm{Kg}$

\section{Conclusōes:}

Reduça de peso de $15 \mathrm{Kg}$ a $19 \mathrm{Kg}$

Taxa de perda de peso:0,15 Kg/ semana, com ingestăo de uma dieta de $1200 \mathrm{Kcal}$ e nivel de atividade atual.

O ideal seria perder $17 \mathrm{Kg}$ de gordura e manter, ou mesmo aumentar, a sua massa magra, com a realizaçāo de exercicios físicos adequados.

Recomendaços:

1.) Exercicios físicos

2 -) Dieta de 1200 calorias port 15 semanas

O peso meta é calculado baseado na sua composięăo corporal, prineipaimente massa magra. Em programaçăo de ganho ou perda de peso, periodicamente, deve-se repetir o exame para reavaliaçäo da composiçảo corporal, podendo ocorrer adequaçấo do peso meta. 


\section{ANEXO 6}

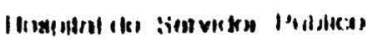

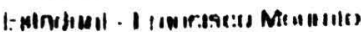
di) Givente

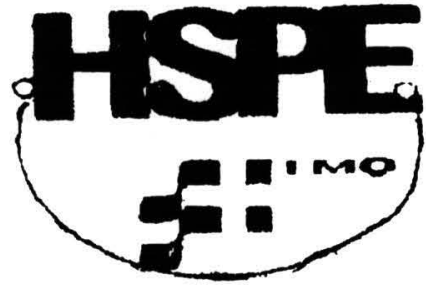

\section{OUESTIONARIO-DENGITOMETRIA OSSEA}

NOME:

PESO:

ALTURA:

1) It fez densitometria dasea anteriormente? Quantas? a) Sim,

b) Nlo

2) Tem diagnóstico de osteoporose confirmado?
a) Sim
b) Nllo

3) (Se d Mulher) Jit estid na menopausa? Hid quanto tempo?
a) Sim,
b) Nlo

4) Tem hipertireoidismo ou doença renal?
a) Sim
b) Nio

5) Que outras doencas tem?
a) Nenhuma b) Hipertens alo
c) Diabetes
d) Artrite
e) Artrose i) Outra,

6) Tome ou ja tomou cortisone ou anticonvulsivante? Hil quanto tempo?
a) Sim,
b) Nlo

7) Faz uso de callcio a pedido médico? Ha quanto tempo?
a) Sim,
b) NEo

8) Faz tratamento com hormónio? Ha quanto tempo?
a) Sim,
b) NRo

9) Que outros medicamentos toma reguiarmente?

10) Faz exercicios? Com que frequencia?
a) Sim,
b) Nào

11) It softeu aiguma fratura? Onde?
a) Sim.
b) Na

12) Toma cafe? Quantas xicaras por dia?
a) Sim.
b) Nao

13) Fuma? Quantos cigarro\& por dia?
a) $\mathrm{Sim}$
b) Nto

14) Toma bebids alcoólica? Com que frequencia?
a) Sim.
b) Nao

tinderç̧o:

islefone 

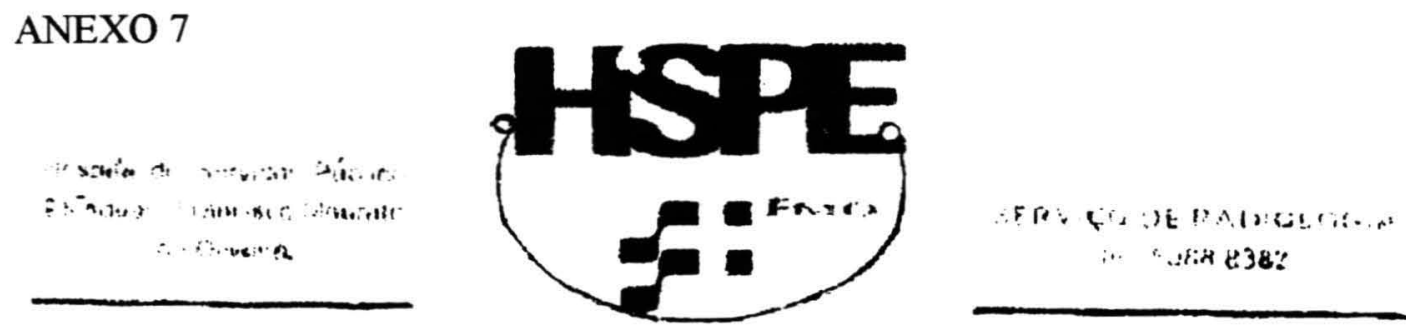

\section{Laudo - Densitometria Óssea}

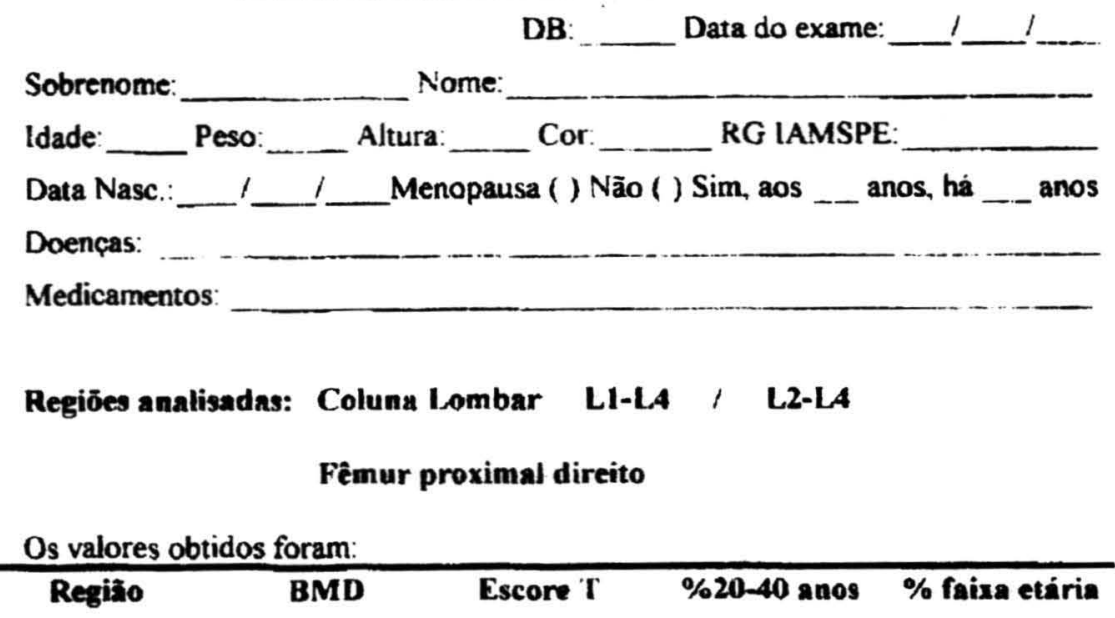

Coluna Lombar

Colo Femoral

Trocànter

\section{Conclusões:}

Coluna Lombar:

Fèmur proximal:

\begin{tabular}{|l|l|l|l|l|}
\hline & 1 & 1 & 1 & 1 \\
\hline L1-L4 & & & & \\
\hline Colo femoral & & & & \\
\hline Trocânter & & & & \\
\hline
\end{tabular}


ANEXO $8^{\text {A }}$

IAMSPE

DENSITOMETRIA OSSEA

RUA PEDRO DE TOLEDO, 1800 - RADIOLOGIA - TEL : 5088-8382

\begin{tabular}{lllll}
\hline PATIBNT ID: ALMB1401.B50 & SCAN: & 3.65 & 19.02 .2005 \\
NAME: AIMEIDA, LOURDES BUENO NOVABS & ANALYSIS: & 3.65 & 25.02 .2005
\end{tabular}

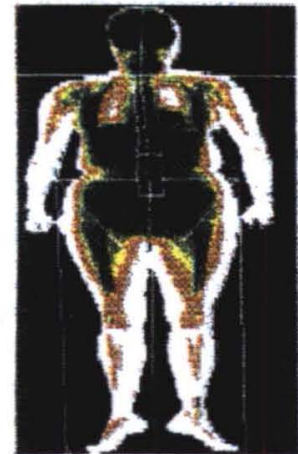

LUNAR

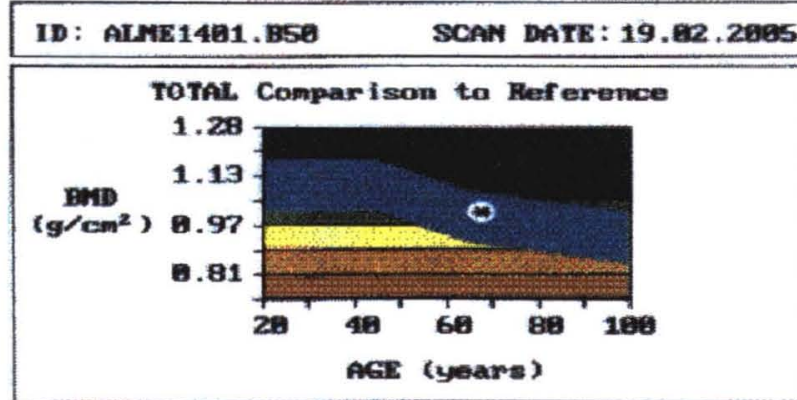

TOTAL. BND $\left(\mathrm{g} / \mathrm{cm}^{2}\right) 1$

TOTAL $x$ Young Adult 2

Total. $\%$ Age Matehed 3
$1.699+0.61$

$90 \div 3$

$162 \pm 3$

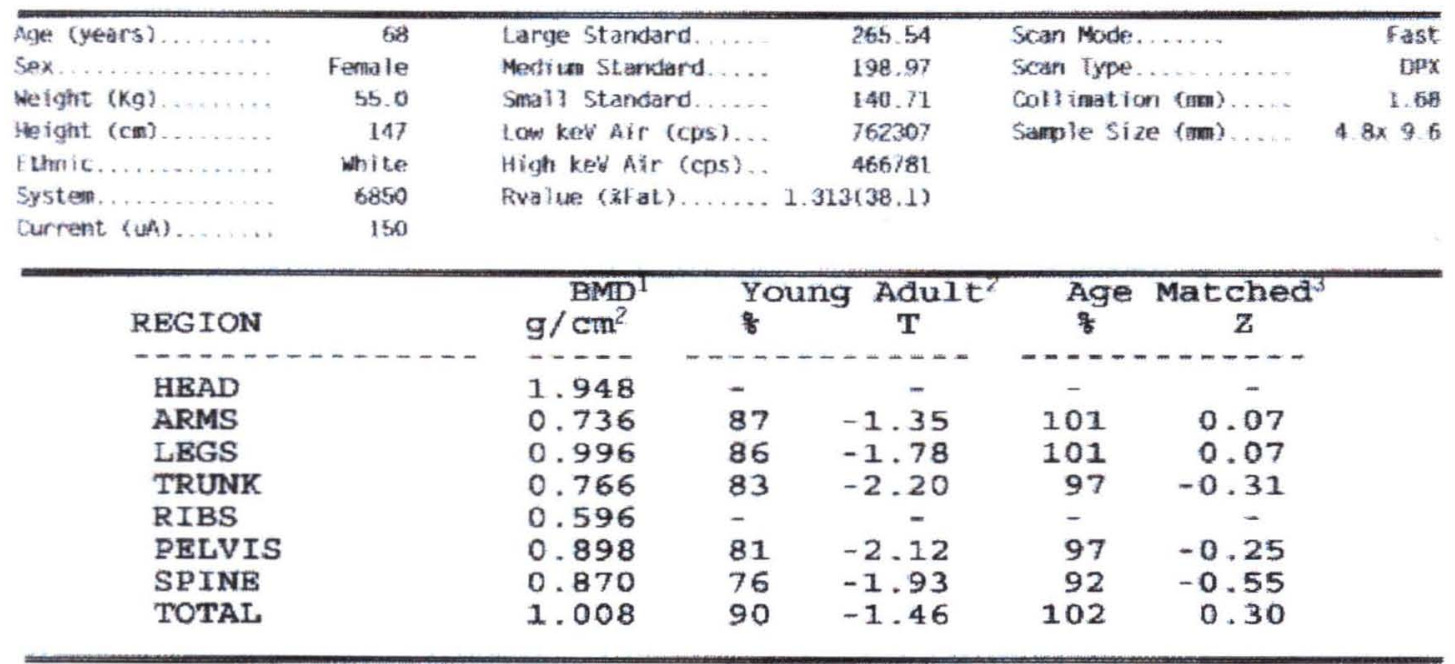

- See appendix $F$ on precisiun and accuracy. Statistically 68 \% of repeat scans will fall within 1 Sh

2 - Brazil Total Body Reference Population. Ages 20-45. See Appendices.

3 - Matched for Age. Weight imales 25-100kg; temales 25-100kgl. Lthnic

Extented Research Analys is 
ANEXO 8B

IAMSPB

DENSITOMETRIA OSSEA

RUA PEDRO DE TOLEDO, 1800 - RADIOLOGIA - TEL: 5088-8382

\begin{tabular}{|c|c|c|c|c|c|c|c|}
\hline \multicolumn{4}{|c|}{ PATIENT ID: ALME1401.B50 } & \multicolumn{2}{|c|}{$\begin{array}{ll}\text { SCAN: } & 3.65 \\
\text { ANALYSIS: } & 3.65\end{array}$} & \multicolumn{2}{|c|}{$\begin{array}{l}19.02 .2005 \\
25.02 .2005\end{array}$} \\
\hline \multicolumn{8}{|c|}{ BODY COMPOSITION" } \\
\hline $\begin{array}{l}\text { Region of } \\
\text { Interest }\end{array}$ & $\stackrel{\mathrm{R}}{\text { value }}$ & $\begin{array}{l}\text { Tissue } \\
\text { \% Fat }\end{array}$ & $\begin{array}{l}\text { Region } \\
\text { \% Fat }\end{array}$ & $\begin{array}{c}\text { Tissue } \\
\text { (g) }\end{array}$ & $\begin{array}{l}\text { Fat } \\
\langle g\rangle\end{array}$ & $\begin{array}{l}\text { Lean } \\
(g)\end{array}$ & $\begin{array}{l}\text { BMC } \\
(g)\end{array}$ \\
\hline $\begin{array}{ll}\text { LEFT } & \text { ARM } \\
\text { LEFT } & \text { LEG } \\
\text { LEFT } & \text { TRUNK } \\
\text { LEFT } & \text { TOTAL }\end{array}$ & $\begin{array}{l}1.312 \\
1.309 \\
1.312 \\
1.313\end{array}$ & $\begin{array}{l}38.9 \\
40.2 \\
38.6 \\
38.0\end{array}$ & $\begin{array}{l}37.6 \\
38.9 \\
38.0 \\
36.9\end{array}$ & $\begin{array}{r}2863 \\
8160 \\
14302 \\
27743\end{array}$ & $\begin{array}{r}1115 \\
3279 \\
5521 \\
10555\end{array}$ & $\begin{array}{r}1748 \\
4882 \\
8781 \\
17188\end{array}$ & $\begin{array}{l}105 \\
278 \\
214 \\
846\end{array}$ \\
\hline $\begin{array}{ll}\text { RIGHT } & \text { ARM } \\
\text { RIGHT LEG } \\
\text { RIGHT TRUNK } \\
\text { RIGHT TOTAL }\end{array}$ & $\begin{array}{l}1.317 \\
1.308 \\
1.312 \\
1.313\end{array}$ & $\begin{array}{l}36.2 \\
40.7 \\
38.6 \\
38.1\end{array}$ & $\begin{array}{l}34.7 \\
39.2 \\
38.0 \\
36.9\end{array}$ & $\begin{array}{r}2333 \\
7498 \\
13569 \\
25266\end{array}$ & $\begin{array}{r}844 \\
3049 \\
5237 \\
9618\end{array}$ & $\begin{array}{r}1489 \\
4449 \\
8331 \\
15647\end{array}$ & $\begin{array}{l}101 \\
288 \\
223 \\
822\end{array}$ \\
\hline $\begin{array}{l}\text { ARMS } \\
\text { LBGS } \\
\text { TRUNK } \\
\text { TOTAL }\end{array}$ & $\begin{array}{l}1.314 \\
1.309 \\
1.312 \\
1.313\end{array}$ & $\begin{array}{l}37.7 \\
40.4 \\
38.6 \\
38.1\end{array}$ & $\begin{array}{l}36.3 \\
39.0 \\
38.0 \\
36.9\end{array}$ & $\begin{array}{r}5196 \\
15659 \\
27871 \\
53009\end{array}$ & $\begin{array}{r}1959 \\
6328 \\
10759 \\
20174\end{array}$ & $\begin{array}{r}3237 \\
9331 \\
17112 \\
32835\end{array}$ & $\begin{array}{r}206 \\
567 \\
436 \\
1668\end{array}$ \\
\hline
\end{tabular}

ANCILIARY TOTAL BODY RESULTS* *

\begin{tabular}{|c|c|c|c|c|}
\hline \multirow{9}{*}{ 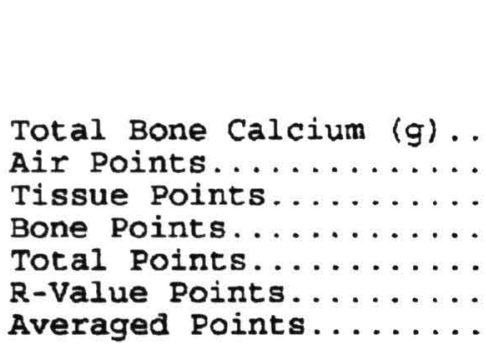 } & & \multicolumn{3}{|c|}{ Cut Locations } \\
\hline & & Name & Actual & Relative \\
\hline & 634 & Neck & 33 & 33 \\
\hline & 11907 & Left Arm & - & - \\
\hline & 9079 & Left Rib & - & - \\
\hline & 3591 & Right Rib & - & - \\
\hline & 21000 & Right Arm & - & - \\
\hline & 3475 & Spine & 61 & 61 \\
\hline & 77 & Pelvis & 70 & 70 \\
\hline & & $\begin{array}{l}\text { Top of Head } \\
\text { Center }\end{array}$ & $\begin{array}{l}0 \\
-\end{array}$ & \\
\hline
\end{tabular}

* Ancillary resull.s for rescarch purposes, not clinical use

Extended Research Nolysis. 